Illinois State University

ISU ReD: Research and eData

Theses and Dissertations

$5-14-2018$

\title{
The Effects of Technical Language and Individual Differences on Evaluating Interventions for Autism Spectrum Disorders
}

Jillian R. Reiher

Illinois State University, jillianrreher@gmail.com

Follow this and additional works at: https://ir.library.illinoisstate.edu/etd

Part of the Psychology Commons

\section{Recommended Citation}

Reiher, Jillian R., "The Effects of Technical Language and Individual Differences on Evaluating Interventions for Autism Spectrum Disorders" (2018). Theses and Dissertations. 1101.

https://ir.library.illinoisstate.edu/etd/1101

This Dissertation is brought to you for free and open access by ISU ReD: Research and eData. It has been accepted for inclusion in Theses and Dissertations by an authorized administrator of ISU ReD: Research and eData. For more information, please contact ISUReD@ilstu.edu. 
THE EFFECTS OF TECHNICAL LANGUAGE AND INDIVIDUAL DIFFERENCES ON EVALUATING INTERVENTIONS FOR AUTISM SPECTRUM DISORDERS

\author{
Jillian R. Reiher
}

106 Pages

Previous research has identified many interventions for Autism Spectrum Disorders (ASD). Some of these interventions are evidence-based; others are not. However, previous research has also found that people select interventions for their children with ASD based on several factors other than the evidence base. Other research has found that the language used when describing interventions also influences people's perceptions of them. The current study examined several factors that may influence how people evaluate two widely used ASD interventions: Applied Behavior Analysis (ABA) and Sensory Integration (SI). ABA is an evidence-based intervention, but SI does not have any empirical support. The type of language (i.e., jargon) used to describe these two interventions was experimentally manipulated using a vignette paradigm. Based on the results of a pilot study, order of presentation was also examined as a manipulated factor that influences evaluations of interventions. Participants rated the interventions described in the vignettes with respect to (a) effectiveness, (b) credibility (c) likelihood of implementation, (d) perceived ease of implementation, and (e) likelihood of recommending in the future. Additionally, I examined whether experience with ASD and perceptions of ASD influenced ratings about these two interventions. Participants read a vignette endorsing ABA or SI described with or without technical language, answered questions about the vignette and intervention, then did the same for the second intervention. They also completed 
measures of their experience with ASD and their perceptions of ASD as a disorder. Although participants rated interventions described without jargon more favorably, particularly when ABA was used describing jargon and SI was described without jargon, experience did not affect participants' ratings of the interventions. The order in which participants read about the interventions was important. Participants rated the interventions they read about first more favorably and were more likely to select them when presented with a forced-choice question regarding which intervention they would pick if their child or a close friend's child had ASD. Participants' perceptions of ASD as a disorder did not affect their ratings of the interventions. In general, participants favored interventions described without jargon. Additionally, they preferred the intervention they read about first. As such, practitioners might be able to improve perceptions of evidence-based ASD interventions by ensuring people learn about them first and describing them in non-technical language.

KEYWORDS: Autism Spectrum Disorders, Interventions, Jargon, Technical Language, Applied Behavior Analysis, Sensory Integration, Efficacy 
THE EFFECTS OF TECHNICAL LANGUAGE AND INDIVIDUAL DIFFERENCES ON EVALUATING INTERVENTIONS FOR AUTISM SPECTRUM DISORDERS

\author{
JILLIAN R. REIHER
}

A Dissertation Submitted in Partial

Fulfillment of the Requirements

for the Degree of

DOCTOR OF PHILOSOPHY

Department of Psychology

ILLINOIS STATE UNIVERSITY 
(C) 2019 Jillian R. Reiher 
THE EFFECTS OF TECHNICAL LANGUAGE AND INDIVIDUAL DIFFERENCES ON EVALUATING INTERVENTIONS FOR AUTISM SPECTRUM DISORDERS

JILLIAN R. REIHER

COMMITTEE MEMBERS:

Corinne Zimmerman, Chair

Thomas Critchfield

J. Cooper Cutting

Christina Borders 


\section{ACKNOWLEDGMENTS}

I would like my committee members Tom Critchfield, J. Cooper Cutting, Cristina Borders for their feedback and assistance on this project. I would also especially like to thank my Chair, Corinne Zimmerman for reading through this document approximately a million times and providing more support than I could have ever expected. I could not have done this without you.

I would also like to thank Steve Croker for his feedback on drafts of the document and materials for this project, as well as his assistance in interpreting the results. I also thank Emilio Lobato for answering my many questions about Qualtrics and rescuing my survey flow from disaster.

Finally, I would like to thank my wonderfully supportive family, friends, and cohort members. I cannot image completing this project without all of you to vent to, bounce ideas off of, or take a break with. I was able to accomplish this project because of all of you. 


\section{CONTENTS}

Page

ACKNOWLEDGMENTS

$\begin{array}{ll}\text { CONTENTS } & \text { ii }\end{array}$

FIGURES

CHAPTER I: THE PROBLEM AND ITS BACKGROUND 1

CHAPTER II: REVIEW OF THE LITERATURE

Autism Spectrum Disorder 3

Evidence-Based Reasoning About Health Issues $\quad 5$

Decision-Making About ASD Interventions 9

Effect of Source of Information on Decision Making $\quad 19$

Effects of Jargon on Decision Making $\quad 23$

$\begin{array}{ll}\text { Therapeutic Approaches to ASD } & 27\end{array}$

$\begin{array}{ll}\text { Applied Behavioral Analysis (ABA) } & 27\end{array}$

Sensory Integration (SI) 28

$\begin{array}{ll}\text { Current Research } & 29\end{array}$

CHAPTER III: PILOT STUDY: DEVELOPMENT OF MATERIAL 30

Creation of Vignettes $\quad 30$

Creation of the ASD Experiences Questionnaire $\quad 31$

Method 31

$\begin{array}{ll}\text { Participants } & 31\end{array}$

Measures $\quad 33$

$\begin{array}{ll}\text { Procedure } & 34\end{array}$

$\begin{array}{ll}\text { Results } & 35\end{array}$

ASD Experiences Questionnaire $\quad 35$

Testing the Jargon Manipulation $\quad 35$

$\begin{array}{ll}\text { Order Effects } & 37\end{array}$

$\begin{array}{ll}\text { Discussion } & 40\end{array}$

Research Questions and Hypotheses $\quad 41$

Jargon and ASD Experiences Hypotheses $\quad 42$ 
$\begin{array}{ll}\text { Order Effects } & 48\end{array}$

Illness Perception Hypotheses $\quad 50$

CHAPTER IV: METHOD $\quad 51$

Participants $\quad 51$

$\begin{array}{ll}\text { Measures } & 52\end{array}$

Illness Perception Questionnaire-Revised for Autism,

English Version (IPQ-RAE) 52

Vignettes $\quad 53$

Intervention Perceptions Rating Scale $\quad 54$

ASD Experiences Questionnaire $\quad 55$

$\begin{array}{ll}\text { Procedure } & 55\end{array}$

CHAPTER V: RESULTS

$\begin{array}{ll}\text { Descriptive Statistics } & 57\end{array}$

Intervention Perceptions Rating Scale $\quad 57$

ASD Experiences Questionnaire $\quad 58$

Hypothesis Testing: Jargon and ASD Experience $\quad 59$

Hypothesis Testing: Order Effects $\quad 64$

Hypothesis Testing: Correlations with External Cause 71

$\begin{array}{ll}\text { Exploratory Analyses } & 72\end{array}$

$\begin{array}{ll} & 77\end{array}$

General Discussion $\quad 77$

Strengths and Limitations of the Current Study $\quad 81$

Directions for Future Research $\quad 85$

$\begin{array}{ll}\text { Conclusions } & 87\end{array}$

$\begin{array}{lc}\text { REFERENCES } & 88\end{array}$

APPENDIX A: VIGNETTES

APPENDIX B: EXPERIENCES WITH AUTISM SPECTRUM DISORDER (ASD) 97

APPENDIX C: INTERVENTION PERCEPTIONS RATING SCALES 99

APPENDIX D: DEMOGRAPHICS 104

$\begin{array}{ll}\text { APPENDIX E: TABLES } & 105\end{array}$ 


\section{FIGURES}

Figure

Page

1. Mean Ratings of an Intervention's Effectiveness as a Function of Order and Intervention Type in the Pilot Study

2. Mean Ratings of Whether an Intervention Was Perceived as Credible as a Function of Order and Intervention Type in the Pilot Study

3. Mean Ratings of Whether an Intervention Would Be Recommended as a Function of Order, Jargon, and Condition in the Pilot Study

4. Predicted Effectiveness Ratings from Participants with ASD Experience (Top Panel) and Without ASD Experiences (Bottom Panel) for ABA and SI in the No Jargon and Jargon Conditions

5. Predicted Credibility Ratings from Participants with ASD Experience (Top Panel) and Without ASD Experiences (Bottom Panel) for ABA and $\mathrm{SI}$ in the No Jargon and Jargon Conditions

6. Predicted Likelihood of Implementation Ratings from Participants with ASD Experience (Top Panel) and Without ASD Experiences (Bottom Panel) for ABA and SI in the No Jargon and Jargon Conditions

7. Predicted Ease of Implementation Ratings from Participants with ASD Experience (Top Panel) and Without ASD Experiences (Bottom Panel) for ABA and SI in the No Jargon and Jargon Conditions

8. Predicted Likelihood of Implementation Ratings from Participants with ASD Experience (Top Panel) and Without ASD Experiences (Bottom Panel) for $\mathrm{ABA}$ and $\mathrm{SI}$ in the No Jargon and Jargon Conditions

9. Predicted Interaction for Ratings of Effectiveness, Credibility, and Likelihood of Recommendation as a Function of Order, Intervention, and Survey Version

10. Participant Ratings of the Effectiveness of Interventions

11. Participant Ratings of the Credibility of Interventions

12. Participant Ratings of Their Likelihood of Implementing the Interventions

13. Participant Ratings of the Ease of Implementing the Interventions 
15. Mean Ratings of Whether an Intervention Would be Perceived as Effective as a Function of Order, Intervention, and Survey Version

16. Mean Ratings of Whether an Intervention Would be Perceived as Credible as a Function of Order, Intervention, and Survey Version

17. Mean Ratings of Whether an Intervention Would be Recommended as a Function of Order, Intervention, and Survey Version

18. Difference Scores Indicating Higher Effectiveness Rating for ABA (Positive Numbers) and SI (Negative Numbers) Based on Survey Version Received and Participants' Previous ASD Experience

19. Difference Scores Indicating Higher Credibility Rating for ABA (Positive Numbers) and SI (Negative Numbers) Based on Survey Version Received and Participants' Previous ASD Experience

20. Difference Scores Indicating Higher Likelihood of Implementation Rating for ABA (Positive Numbers) and SI (Negative Numbers) Based on Survey Version Received and Participants' Previous ASD Experience

21. Difference Scores Indicating Higher Ease of Implementation Rating for ABA (Positive Numbers) and SI (Negative Numbers) Based on Survey Version Received and Participants' Previous ASD Experience

22. Difference Scores Indicating Higher Likelihood of Recommendation Rating for ABA (Positive Numbers) and SI (Negative Numbers) Based on Survey Version Received and Participants' Previous ASD Experience 


\section{CHAPTER I: THE PROBLEM AND ITS BACKGROUND}

Those working with children with Autism Spectrum Disorder (ASD) are faced with a wide variety of interventions when selecting appropriate treatments for children. The evidence base for these interventions ranges from strong to nonexistent (Green et al., 2006). Although effective communication of the evidence base for interventions might help parents make decisions, many other factors have been shown play a role in the decision-making process (Bruine de Bruin \& Bostrom, 2013; Fischhoff \& Davis, 2014). The decisions parents make about their children's interventions could be influenced by their perceptions of ASD and its causes. Parents' ratings of the seriousness, timeline, and cause of ASD have all been found to be related to interventions selected, as has parental affect toward ASD (Al Anbar, Dardennes, Prado-Netto, Kaye, \& Contejean, 2010). Additionally, since many people have some type of experience with ASD, that experience could also influence their decision-making regarding ASD interventions (Reiher, 2016).

Along with individual factors, previous research has shown that the language used to describe interventions has an influence on decision-making. Tversky and Kahneman (1981) demonstrated that framing the outcome of a decision as either a gain or a loss affected people's decisions. In one example, participants rated meat labeled $75 \%$ lean as better tasting than meat that was 25\% fat (Levin \& Gaeth, 1988). Weisberg, Keil, Goodstein, Rawson, and Gray (2008) found that language affects participant decision-making through what they called "the seductive allure of neuroscience," or the tendency for people to rate explanations of phenomena as more satisfying when neuroscientific terms were used even when those terms did not add information to the explanation. Other research has demonstrated that jargon associated with Applied 
Behavior Analysis (ABA), a common evidence-based intervention for ASD, evokes unpleasant and unmotivated responses in participants (Becirevic, Critchfield, \& Reed, 2016; Critchfield et al., 2017). Given these findings, it is evident that the language used to describe interventions is an important factor that may influence evaluations and decisions.

In the current study, I examine how the presence or absence of jargon used to describe interventions affects people's evaluations of the efficacy, credibility, and ease of implementing two commonly used interventions for ASD. As noted, ABA is an evidence-based intervention; Sensory Integration (SI) is commonly used but has no empirical support for its use (Green, 2006; Jacobsen, Mulick, Foxx, \& Kryszake, 2016). I also examine the effects of jargon on participants' ratings of likelihood of implementing and recommending those interventions. I assessed participants' previous experiences with ASD and their perceptions of ASD as a disorder to determine if these individual difference factors influenced their evaluations of the ASD interventions. In my review of the literature, I first describe ASD, including its defining features, prognosis, and prevalence. I then discuss factors related to decision-making about health issues, including ASD. Next, I review the research on the effects of source and jargon on decisionmaking. Finally, I describe and review the evidence base for ABA and SI as ASD interventions. 


\section{CHAPTER II: REVIEW OF THE LITERATURE}

\section{Autism Spectrum Disorder}

Autism Spectrum Disorder (ASD) includes diagnoses previously labeled as autism, Asperger's, childhood disintegrative disorder, Rhett's, and pervasive developmental disorder not otherwise specified (PDD-NOS). ASD is associated with social communication and interaction difficulties and restricted or repetitive patterns of behavior or interest. Additionally, these difficulties must have been present since early childhood and must cause a clinically significant disturbance in the child's life. Intellectual disability can co-occur with ASD, but it is not a diagnostic feature. Delays in learning language are also common. Additionally, many other conditions such as Down Syndrome, epilepsy, and attention-deficit/hyperactivity disorder can co-occur with ASD (American Psychiatric Association, 2013).

The severity of ASD varies widely across diagnosed individuals. Some individuals can function in their day-to-day lives with minimal support, while others require life-long intensive care. According to the Diagnostic and Statistical Manual of Mental Disorders ( $5^{\text {th }}$ ed.; DSM-5; American Psychiatric Association, 2013), there are three levels of severity ranging from Level 1 (least severe) to Level 3 (most severe). The DSM-5 provides examples of social communication deficits experienced by people whose ASD severity is classified as Level 1 including difficulties initiating social interactions and a lack of interest in social interactions. Level 1 restricted, repetitive behaviors include difficulty switching between activities and organizing one's time. People whose ASD severity is classified as Level 2 often only speak in short, simple sentences and have noticeable difficulties understanding and using nonverbal behaviors. They also engage in restricted or repetitive behaviors often enough to be noticed by casual observers. Individuals 
whose ASD severity is rated as Level 3 may not exhibit any verbal communication. They engage in repetitive or restricted behaviors to an extent that interferes with all aspects of their lives. Additionally, people whose ASD severity is rated as Level 3 often demonstrate major distress when directed to change their actions (American Psychiatric Association, 2013).

Symptoms of ASD generally emerge when children are between 12 and 24 months old. Some children may experience a regression in skills around that time, especially in the area of communication. Most individuals with ASD improve their functioning through adolescence, although some deteriorate during adolescence. Although symptoms generally emerge during early childhood, they are not always recognized until later in life. This is especially likely to be the case if symptoms are mild (American Psychiatric Association, 2013).

Adults with ASD often struggle to function independently and have difficulty finding work. Generally, every day activities are difficult for people with ASD due to their rigidity and difficulty with social communication. The prognosis for individuals with ASD is better if they do not have an intellectual disability, and if they exhibit functional language by around age five. ASD occurs across cultures, although age of diagnosis may be affected by socioeconomic or cultural factors (American Psychiatric Association, 2013).

ASD currently affects approximately one in 68 children. It affects boys (one in 42) more often than girls (one in 189). Additionally, reported incidences of ASD have increased to their current rate from one in 150 since 2000 (CDC, 2014). However, as Taylor (2006) reports, it is unlikely that actual incidences of ASD have increased as dramatically. Instead, it is likely that the increase in the reported incidences of ASD is mainly due to other factors such as the underdiagnosis of ASD in the past. Taylor specifically mentions the addition of ASD to the list of disability categories federally mandated to receive special education services as one reason why 
there might be an increase in reported incidences of autism. Additionally, ASD awareness has increased in both professionals and laypeople, leading to increases in parents seeking diagnoses and professionals making diagnoses. In seeking such information and diagnoses, parents are also encountering competing and conflicting sources of information.

Given the importance of early intervention for ASD, parents and caregivers are required to make decisions about interventions shortly after diagnosis. To understand how people make these decisions, it is necessary to review the literature on scientific reasoning about health issues and factors that affect peoples' decision-making about ASD specifically. The scientific evidence base might play a role in the process, but other factors can also influence decision-making and how that evidence is perceived. These include the source of the information and language used to describe interventions. Because the current research is focused on decision-making about ASD treatments, some of these treatments and their evidence base will be described in more detail below.

\section{Evidence-Based Reasoning About Health Issues}

When selecting interventions, people who work with children with ASD have to process quite a bit of scientific information. As Fischhoff and Davis (2014) discuss, communicating scientific information to the public requires both the simplification of some scientific concepts, and the explanation of assumptions that scientists take for granted. This exacerbates the existing gap between research and clinical practice (Guldberg, 2017). For example, professionals who work with children with ASD from an Applied Behavior Analysis (ABA) perspective frequently use the terms "reinforcement" and "prompting." Although such terms are derived from fairly complex behavioral principles, they are in common use by ABA practitioners and are well defined. When teaching ABA interventions to parents, professionals need to be able to define 
these terms without using complicated scientific language. The use of scientific terminology is an important issue that will be described in more detail below. Additionally, Fischhoff and Davis point out that scientific communication is driven by what laypeople need to know, rather than what scientists want to communicate.

Effective communication of scientific information is an important component of influencing behavioral change (Bruine de Bruin \& Bostrom, 2013). Like Fischhoff and Davis (2014), Bruine de Bruin and Bostrom stress that scientists should keep in mind the public's needs when communicating scientific information. They state that experts often forget what it is like to be a novice, so they do not communicate the appropriate information. That is, experts do not always communicate information necessary for a novice to understand what they are describing. Additionally, experts might use technical language that is understood differently by those unfamiliar with the area of expertise. That is, experts use specialized terminology as a type of shorthand to convey a lot of information with a single word or phrase. In the case of communicating information about ASD interventions, a trained psychologist will use the term "punishment" to refer to any situation in which the repeated use of some consequence results in the voluntary decrease of a particular behavior. However, for most people, the term punishment has very different connotations.

Klahr and Li (2005) highlighted the hazards of using technical language with multiple meanings. In a series of studies, they compared what they referred to as "discovery learning," which involved allowing children to perform experiments with no guidance or instruction, to what they labeled as "direct instruction," which involved letting children interact with materials while receiving instruction from an adult. The authors reported that using this terminology allowed their research, which supported the use of "direct instruction," to be described in the 
mainstream media as supporting "passive instruction" in science rather than engaging with materials. They note that their choice of technical language led to the misinterpretation of their work and to their findings being overgeneralized and misrepresented in the popular press. Klahr and Li's experience serves as a reminder that language choice has meaningful effects on science communication and decision-making.

Fischhoff and Davis (2014) also note that scientific decision-making involves values as well as facts. Von Winterfeldt (2013) supports a mathematical decision-making strategy that takes into account scientific facts and people's values. He gives an example of using this strategy with a power company and a group of homeowners. Some research had indicated that people living near power lines were at increased risk of health problems, including childhood leukemia. Homeowners wanted the power company to solve the problem by installing the power lines underground, but the power company did not believe it was necessary. Another solution was proposed that involved mitigating the risk of the above ground power lines. After much analysis of the costs and benefits of all solutions, mitigating the risk of the current power lines was found to be the lowest-cost, highest-benefit solution. Although the plan was never carried out because of a state energy crisis, von Winterfeldt mentions that neither group was happy with the solution determined to be the best by the analysis. They felt the analysis was accurate, but the solution proposed by it conflicted with their values. The costs, risks, and benefits of the situation von Winterfeldt describes were fairly straightforward. This is not always true of the evidence base for health-related interventions.

Because determining the evidence base for health-related interventions is difficult, some research has indicated a need for actively debunking information about interventions that are not evidence-based in addition to providing information about those that are evidence-based. When 
studying a group of college students enrolled in a child psychology course, Hupp, Stary, Bradshaw, and Owens (2012) found that although students' endorsements of evidence-based interventions increased after taking the class, so did their endorsements of alternative interventions. The researchers created the Specific Therapeutic Approaches Rating Scale-Child Form (STARS-CF), which measured their participants' opinions of the effectiveness of interventions for autism, oppositional defiant disorder (ODD), attention deficit/hyperactivity disorder (ADHD), and depression. The measure includes 13 evidence-based treatments and 23 alternative treatments. Students were given the measure at the beginning and end of the semester. Hupp et al. concluded that simply teaching students which interventions are evidence-based did not limit students' perceptions of the efficacy of alternative treatments. Instead, students' perceptions of the efficacy of facilitated communication, a non-empirically supported intervention for ASD, actually increased when measured at the end of the semester. Hupp et al. speculated that this might have occurred because teaching individuals with ASD to communicate was emphasized as an important intervention. Without specific knowledge about facilitated communication, students assumed that an intervention that focused on communication would be beneficial for children with ASD.

Another study by Hupp, McKenney, Schmittel, McCobin, and Owens (2013) replicated and extended the study by Hupp et al. (2012). The same rating scale procedure was used, but the class size was larger and students received explicit instruction on the lack of evidence base for eight of the 23 alternative treatments listed. As in the previous study, researchers found that participants perceived evidence-based interventions to be more effective after taking the class. During this study, they did find a significant decrease in participant's perceptions of the efficacy of the eight alternative treatments discussed in class. However, this decrease in perceived 
efficacy did not generalize to the 15 remaining treatments. From these findings, the researchers concluded that in addition to explicit teaching on types of treatments, students should receive training on evaluating the evidence base of interventions.

\section{Decision-Making About ASD Interventions}

The student participants in the Hupp et al. (2012) study only had to rate whether 33 interventions were effective in treating children's mental and developmental disorders. Those who work with children with ASD actually have a much wider array of interventions to choose from. Additionally, students in the Hupp et al. (2013) study received direct instruction on the evidence base, or lack thereof, for 21 of the interventions (13 evidence-based and eight alternative). The information parents and caregivers receive about the evidence base for interventions is rarely so straightforward. Parents and caregivers have to choose from many interventions, and although some of the interventions they encounter are scientifically supported, others are not. When evaluating the evidence base for an intervention, those who work with children with ASD have to evaluate both its source and its content. Furthermore, unlike the Hupp et al. $(2012,2013)$ studies, parents and caregivers of children with ASD may not receive direct instruction about interventions, and they actually have to choose interventions for their children rather than simply rate the intervention's efficacy in the abstract.

In an Internet survey, parents of children with ASD reported the interventions they were currently using, or had used in the past, for their children with ASD (Green et al., 2006). Green et al. compiled a list of 111 treatments used for autism. Of those interventions, 108 were endorsed by at least one parent who took the survey, and parents reported using a few additional interventions that were not on the original list. Broad categories of interventions were 
medications, special diets, vitamin supplements, medical procedures, educational or therapeutic approaches, alternative therapies, and combined programs.

Speech therapy was the most used intervention with $93 \%$ of the 552 respondents reporting that their children either were currently receiving or had previously received speech therapy. Sensory integration (71\%), visual schedules (62\%), ABA (59\%), and social stories (54\%) rounded out the top five most utilized interventions. The mean number of interventions used per child at the time of the survey was seven. The authors noted that both the most and least commonly used interventions were a mix of empirically supported interventions and those without empirical support (Green et al., 2006). Interestingly, the severity of ASD symptoms was related to the number and type of interventions used. Children whose parents reported that they had more severe symptoms received more interventions. Additionally, parents whose children had autism were more likely than parents of children with Asperger's Syndrome to report that their child received skills training interventions based on the principles of applied behavior analysis. Regardless of symptom severity, the mean number of interventions used decreased as children aged (Green et al., 2006).

Green (2007) interviewed 19 parents of children with ASD regarding whether they used ABA, sensory integration, or Vitamin B6 with their children. All participants reported using at least one of the three types of therapy, and most used some combination of the three. Most parents found out about these interventions from other parents, the internet, or books. The time required to implement the interventions ranged from 4 to 40 hours per week for ABA and 4 to 15 hours per week for sensory integration. Most parents also reported that sensory integration was fairly easy to implement. ABA, in contrast, was reported to be difficult to implement by most parents. Most parents reported positive gains from sensory integration and ABA, while slightly 
fewer than half reported positive outcomes from Vitamin B6. Green (2007) notes that it is it unclear from the interview data whether parents attempted to evaluate scientific information received from fellow parents or the Internet. She also mentions that there is no way of knowing if parents assumed interventions were valid when recommended by professionals rather than peers.

Hebert (2014) conducted a qualitative study of how parents select interventions for their children with ASD or PDD-NOS. Across two interviews per parent participant, Hebert found that factors influencing parent intervention choice could be combined into three general categories: parental attributes, child's attributes, and program/treatment attributes. Parental attributes included personal experiences, perceptions of autism, parenting style, perspectives on how children learn, and inner sense. For example, some parents whose parenting style was more authoritative did not like the structure of ABA, so they chose child-led approaches. Two parents who talked about a relationship between medical issues and autism sought out biomedical interventions.

Child attributes related to parental choice of interventions included age, developmental level, and child's needs. Some parents reported that they felt that the ABA approach was too strict and intense for their young children, so they chose child-directed interventions instead. Conversely, other parents said that they did not think their child had enough skills to derive benefit from child-directed therapy, and instead needed the structure of ABA. Some parents reported selecting therapies to address specific issues, such as sensory integration (Hebert, 2014).

Program or treatment attributes related to parent choice included parent's perspective on therapeutic approaches, intensity, physical environment, social environment, teachers, and cost. Parents reported wanting their children's school or therapeutic environment to mirror that of typical children to the greatest extent possible. Parental acceptance of higher intensity and cost of 
interventions seemed to vary based on the severity of the child's symptoms, as well as their perceptions of the intervention's effectiveness (Hebert, 2014). Herbert also noted that parents of older children who had already tried traditional interventions were more likely to try alternative treatments. Although some parents who endorsed using alternative interventions were looking for a cure for autism, most just wanted to ensure their children reached their full potential.

McDonald, Pace, Blue, and Schwartz (2012) note that parents of children with ASD are often drawn to alternative therapies that offer "cures," regardless of the lack of scientific information supporting them. Information about alternative ASD interventions is easily accessible through the media, and the beliefs of celebrities are often given more credibility than they should. Additionally, professionals sometimes use interventions that are not empirically supported or tolerate their use by other professionals in their practice. McDonald et al. also noted that parents who believe that ASD has physiological causes are more likely to use biomedical interventions. Parents are attracted to this approach partially because of the success of dietary interventions in treating other concerns, such as diabetes and phenylketonuria (McDonald et al., 2012).

McDonald et al. (2012) argue that the antidote to parents' use of non-empirically supported treatments is more information. They encourage the production of parent-friendly resources. Additionally, the authors support teaching parents to use scientific reasoning to select interventions for their children with autism. Although these recommendations may be helpful for some parents, they may not be enough to prevent parents from selecting interventions without empirical support, or interventions that have be shown to be ineffective or harmful. This advice is also difficult to implement given the 2006 list of 111 treatment options (Green et al., 2006); other potentially dangerous non-empirically supported remedies have since emerged. For 
example, in 2016, a "miracle cure" for ASD was found to essentially be bleach (Galli, Kreider, \& Ross 2016). Although the substance was quickly identified as dangerous and ineffective, thousands of parents of children with ASD purchased and gave the chemical to their children.

A study by Berquist and Charlop (2014) provides some support for the idea that parents can be taught to evaluate interventions using scientific principles. Parents in their study received several weeks of training via a step-by-step manual and direct instruction from a trainer. Parents' evaluation skills were measured both pre-and post-intervention by having them write out their process for evaluating their children's interventions. Researchers then assessed the extent to which parents' evaluation process aligned with the process they had been taught. After instruction, all parents who received the intervention demonstrated better use of scientific reasoning skills to determine the effectiveness of interventions. However, those gains did not maintain or generalize for two of the six participants. Additionally, the researchers did not collect data about which interventions parents actually went on to use with their children.

It is also important to note that parents may not have the time to participate in training that lasts for several weeks. As with decisions that need to be made about medical treatment and care, there may be many treatment options to choose from, as well as conflicting sources about the efficacy of each of the options. Additionally, since there is so much emphasis on the importance of early intervention for ASD, some parents might feel they have a limited amount of time in which to make intervention decisions. Because of these factors, parents might make intervention decisions based on the recommendations of others rather than scientific research.

Information about empirical support may contribute to parents' selection of interventions for their children with ASD. However, research has also linked perceptions about ASD to the types of interventions parents select. In particular, perceptions about an illness or disorder can 
have an influence on interventions people select. For example, in the health psychology literature Leventhal et al. (1997) proposed the Self-Regulatory Model of Illness Perceptions. Using this model, they examined the relationships between people's perceptions of the identity (symptoms), consequences, timeline, controllability and curability (personal or treatment control), causes, and emotional representations of various illnesses and the treatments they selected to address those illnesses. Moss-Morris et al. (2002) extended this research by studying the illness perceptions of the significant others of those with serious illnesses. With respect to ASD, identity refers to the behaviors people view as being symptomatic of ASD. Consequences refers to the seriousness of the illness/disorder (i.e., how likely it is to have lasting effects on a person's life). Timeline refers to the extent to which ASD is believed to be either acute or chronic and the extent to which ASD symptoms are cyclical or consistent. Control refers to the extent to which an individual has control over his or her own illness or a loved one's. Perceptions about cause relate to whether the disorder is due to external factors such as pollution, poor diet, or past poor medical care, or other factors such as genetics or a bad luck. Emotional representations refer to the amount of negative emotion people associate with the disorder.

Al Anbar et al. (2010) demonstrated a relationship between parents' perceptions of ASD as a disorder and the interventions they selected for their children. Parents who viewed ASD as more serious were more likely to use educational or behavioral interventions such as social skills training, Training and Education of Autistic and Related Communication Handicapped Children (TEAACH) approaches, or the Picture Exchange Communication System (PECS). Those who believed ASD followed a cyclical timeline were more likely to endorse medication use. Stronger beliefs in personal control over ASD predicted a decrease in use of treatments such as special diets and vitamins, as well as medication use. Parents who had more negative emotions related to 
ASD were less likely to use educational interventions. Parents who attributed their child's ASD to an external cause were more likely to use special diets and vitamins, as were those who believed ASD is hereditary. Al Anbar et al. also found that the older parents were, the less likely they were to solicit information from educators and other professionals.

Reiher (2016) also examined parents' perceptions of ASD as a disorder in general and of their child's ASD specifically. Parents of children with ASD viewed their child's ASD being less severe than ASD in general but had more negative emotional representations of their child's ASD as compared to ASD in general. Additionally, parents of children with ASD had more negative emotional representations of ASD and viewed ASD as having more severe consequences and a more cyclical timeline when compared to the views of parents of children without ASD.

Although there has been research on how parents make decisions about their children's ASD interventions, there is a dearth of information about how others who work with children with ASD make intervention decisions and recommendations. The school consultation literature provides information about how teachers make decisions about interventions in general, but not for children with ASD specifically. Elliot (1988) described a working model of consultation that focused on four interrelated factors: treatment acceptability, treatment use, treatment integrity, and treatment effectiveness. He also discussed factors that influence teachers' intervention acceptability. Teachers preferred interventions that took less time to implement, were positive in nature, and were effective. However, Elliot also outlined other factors that contribute to decisionmaking. He noted that in one study, teachers with more knowledge of behavioral principles rated all interventions as more favorable than did teachers with less knowledge. Elliot also reported that generally, the more severe or challenging the behavior a child demonstrates, the more 
favorably any intervention is viewed. Additionally, more restrictive interventions, such as seclusion, were viewed as more acceptable for children engaging in severe behavior. This finding could partially explain why parents and teachers might use non-evidenced-based interventions for children with ASD. If they view the child's behavior as severe, parents and teachers might be willing to try any intervention that could decrease the behavior.

Elliot (1988) also mentioned that the jargon used by professionals when describing the interventions to teachers influenced teachers' ratings of interventions. He reviewed one study in which an intervention was described in either humanistic, behavioral, or pragmatic terms. Teachers preferred the intervention when it was described using pragmatic language.

To determine how student variables affect teachers' recommendations of interventions, Wood et al. (2009) asked elementary and middle school special and general education teachers how strongly they would recommend each of four common interventions for a student with Attention Deficit-Hyperactive Disorder (ADHD). Participants were presented with a scenario that described a child with ADHD who was either a male or female Caucasian, African American, or Hispanic student. Wood et al. found that all teachers were more likely to recommend interventions that required less parent involvement for African American students, and that elementary and special education teachers were more likely to recommend interventions with more empirical support as compared to regular education and middle school teachers. This pattern indicates that there might be differences between how special education and elementary school teachers compared to regular education and middle school teachers make intervention decisions.

Another study by Fairbanks and Stinnett (1997) examined teachers', school psychologists', and school social workers' perceptions of two behaviorally based interventions. 
Although the vignette describing the child's challenging behavior was held constant, teachers were told the child had either a learning disability, a behavior disorder, or ADHD. The behavioral intervention was either a token reinforcement system and verbal praise or a time-out from preferred activities and verbal praise. Although no differences were found based on the child's diagnostic label, they found that teachers rated the time-out intervention as more acceptable than did school social workers and school psychologists. Fairbanks and Stinnett hypothesized that this effect might have occurred because students' externalizing behaviors upset the classroom ecology and are often not tolerated by teachers. Their findings support the idea that teachers might find interventions more acceptable if they focus on a reduction of challenging externalizing behaviors rather than increasing prosocial behavior. By contrast, school social workers and school psychologists might prefer the opposite. This difference in intervention acceptability could lead to difficulty when professionals collaborate as they do frequently.

Very little research has been done on how professionals working with children with ASD make decisions about which interventions to use and recommend. It might be assumed that professionals select interventions based on their empirical support, but some research indicates that this might not always be the case. For example, Gee, Devine, Werth, and Phan (2013) examined occupational therapists' use of sound-based interventions for children with a variety of medical and developmental disorders, including ASD. Sound-based interventions include musical and other interventions that required children to listen to something. They are based on the idea that certain auditory input can lead to the brain to "retrain itself" and create new and "more functional" neural pathways. These interventions do not have empirical support, but Gee et al. found that most occupational therapists viewed them as effective and used them with children with a variety of disorders in conjunction with other interventions. They found that 
occupational therapists most often relied on observations of their clients when deciding to use sound-based interventions rather than peer reviewed journals or manufacturer's claims about the intervention. Additionally, Gee et al. noted that occupational therapists used subjective parent reports to determine intervention effectiveness rather than more objective measures.

A survey conducted by Kadar, McDonald, and Lentin (2012) supports Gee et al.'s (2013) finding that occupational therapists used non-evidenced-based interventions with children with ASD. They found that most occupational therapists use Sensory Integration (SI), a non-evidencebased intervention, with children with ASD. Additionally, participants reported that most of their ASD-related professional development was in SI and that they preferred face-to-face and handson training. Kadar et al. found that occupational therapists surveyed focused on sensory goals instead of occupational goals when working with children with ASD. They noted that both the focus of occupational therapy and the extensive use of SI were of potential concern.

Various forms of media can also influence the decisions people make regarding interventions. Riggot (2005) noted that non-evidence-based interventions often get a lot of attention from magazines, newspapers, and TV news programs because they are easy to explain to consumers and often have a strong emotional appeal. Riggot specifically mentioned the example of a documentary about a woman with ASD who received facilitated communication, an intervention that has been thoroughly demonstrated to be ineffective. This information was not presented by any of the major news outlets that discussed the documentary.

In addition to more traditional media outlets, people are increasingly turning to the internet for information about interventions. Many parents of children with ASD search the internet for information about ASD as a disorder and ASD interventions. Grant, Rodger, and Hoffmann (2015) compiled a list of the websites that most frequently came up first when 
searching for terms such as "autism" and "autism interventions." They evaluated the extent to which each site was reliable, dependable, and trustworthy, as well as the quality of information on treatment choices. The researchers also evaluated the overall quality of the website. They found that most of the 20 websites identified were rated as fair overall, but that most did not adequately address the risks of interventions presented, what would happen if no intervention was given, how each intervention worked, and what changes to overall quality of life could be expected from the intervention. In sum, although many parents might use the internet as a source of information about ASD interventions, the quality of the information they receive is dubious.

\section{Effect of Source of Information on Decision Making}

Al Anbar et al. (2010) also noted that where parents of children with ASD sought information about interventions was related to their perceptions of their child's disorder. This finding is important because other research from the medical field indicates that people make intervention decisions based on those sources without necessarily analyzing the evidence base of the interventions. Frawley et al. (2014) asked women who were pregnant or who had recently given birth about their use of complementary or alternative medicine (CAM) during their pregnancies and where they heard about the treatments. They found that nearly half of women consulted a CAM practitioner during their pregnancies. Most women were influenced primarily by their own experiences and the recommendations of family and friends, with general practitioners, the media, and obstetricians also playing a role.

Criss et al. (2015) examined which sources influenced Hispanic mothers' health-related decisions for their children from conception to age 24 months. The researchers conducted focus groups with women who were pregnant or had infants or young children. Although most participants reported using healthcare providers as a primary source of information about their 
children's health, many noted that they sometimes needed information when these sources were not available. At these times, participants reported that they turned to other immediately available sources, such as the internet and family members. In support of Grant et al.'s (2015) findings that parents used the internet to gather health information, parents in Criss et al.'s study reported using a variety of websites to make decisions about their children's health. One woman reported that as a recent immigrant, she did not know many people she could ask for health information, so she used internet sources. Participants also identified television as a source of information. Another parent reported that after watching a pediatrician on television speak against the use of iPads with young children, she stopped putting an iPad in her child's crib.

Criss et al. (2015) also found that their participants recognized and attempted to reconcile discrepancies in information between sources. Participants reported looking for a consensus across sources and looking for validation from their pediatrician. However, for some participants, the type of decision being made determined which source was more influential. One mother reported that she listened to her mother more when it came to activities and television for her child, but listened to the doctor more when making decisions about nutrition. Overall, Criss et al.'s findings indicate that some parents prefer to use health care professionals as primary sources, but may use other sources when they are not available and when parents view the decision being made as one outside the medical domain. These findings indicate the need to determine how people perceive ASD, as in Al Anbar et al.'s (2010) study. People who view ASD as a medical disorder might be more apt to consider interventions that purport to cure ASD as being most effective, whereas people who view ASD as a behavioral disorder that cannot be cured might view interventions aimed at controlling symptoms as most effective. 
As Criss et al. (2015) demonstrated, parents of typically developing children must evaluate an abundance of sources to make health decisions for their children. Parents of children with medical conditions need to do the same, often with the knowledge that their decisions could have major consequences for their children. Lipstein et al. (2016) surveyed parents of children with juvenile idiopathic arthritis or inflammatory bowel disease who received treatment with TFN- $\alpha$ inhibitors. The authors described TFN- $\alpha$ inhibitors as an effective treatment for both conditions, but one with potentially serious side effects. In their study, participants rated specialists, nurses from the specialists' offices, and the internet as the most commonly used and important sources of information. Most participants reported that after receiving information from the specialists and nurses at the specialists' offices, they understood the information provided. However, they then used the internet and other sources to validate the information they had received from medical professionals and to learn about other people's experiences with the treatment.

Criss et al.’s (2015) findings highlight the fact that parents look for consensus when gathering health information for their children. Bohner, Dykema-Engblade, Tindale, and Meiser (2008) studied how consensus information is processed. In their study of undergraduate participants, Bohner et al. manipulated the extent to which a source was presented as either knowledgeable or similar to participants. The source provided either weak, ambiguous, or strong arguments about the construction of a traffic tunnel in Rotterdam. Participants were either told that the source represented the minority or the majority of people in favor of the proposal. When the knowledge of the source was emphasized, people were more likely to agree with the majority if the argument was strong or ambiguous, and more likely to agree with the minority argument only when it was strong. This finding is important because it indicates that people making 
intervention decisions for children with ASD, like the mothers of young children in Criss et al.'s study, may be influenced by people presented as experts. If those experts are supporting evidence-based interventions, this could be beneficial. Otherwise, decision-makers could be swayed by consensus especially when the information presented is ambiguous.

Another important finding from Bohner et al.'s (2008) study was that when student participants were told that the source was similar to them, they were more likely to agree with the proposal regardless of the strength of the argument. Participants were told that the proposal was being presented by students from a university in Rotterdam who had similar values to students at their university. If people who make decisions about interventions for children with ASD perceive consensus sources as being like them, they might be more likely to use interventions suggested by those sources. For example, although sensory integration is not considered to be evidence-based, occupational therapists might continue to use it because other occupational therapists do so (Kadar et al., 2012; NAC, 2015).

The importance of source similarity in decision-making is underscored by the findings of Hartman and Weber (2009). They asked liberal and conservative participants about their attitudes toward a proposed Ku Klux Klan rally. Participants read a fictitious newspaper article about the issue that presented it as either a free speech or public safety concern. They were told the author of the article was either liberal or conservative. Then, in a second experiment, participants were exposed to both liberal and conservative arguments for or against the rally. Researchers found that when there was a match between the ideologies of the source and the participants, how the issue was framed affected whether participants thought the rally should be allowed. However, when there was a mismatch in between the source and the participants, the framing did not affect participants' attitudes. Participants who received information from a like- 
minded source supported whichever position was framed as supported by that source.

Participants who received information from someone with different political values disagreed with the proposal even if the source used the same language to describe the proposal as did the like-minded source. In other words, framing only mattered if the source of the information matched participants' political beliefs.

Taken together, previous research indicates that people use a variety of sources when making decisions, ranging from popular media to experts in their fields. Additionally, although perceived knowledgeability of the source can be important, people also treat source information differently based on consensus and similarity of the source to themselves.

\section{Effects of Jargon on Decision Making}

Frawley et al.'s (2014) study on CAM use in expectant mothers demonstrates that people make health-related decisions using sources without scientific support. However, the language used in describing interventions is also important when determining why people select certain interventions, as described by Elliot (1988). Jargon includes terms that serve as shorthand for members of a particular group of experts. These terms might have additional meanings known to laypeople and are rarely clear to those outside the field (Hallenstein, 1978). Classic decisionmaking research by Tversky and Kahneman (1981) demonstrated the idea that the way a decision is framed can affect the choices people make. They noted that people's decisions were dependent on how certain the outcome of the decision seemed to be and whether the description of the outcome focused on gain or loss. For example, researchers found that participants reported ground beef as tasting different depending on whether it was labeled as $75 \%$ lean or as $25 \%$ fat. Participants rated the meat labeled $75 \%$ lean as less greasy and better tasting (Levin \& Gaeth, 1988). 
Yamagishi (2002) also studied the role of gain and loss decision-making, but also examined how the presented likelihood of an outcome affected people's decisions. Participants were presented with a scenario in which they were going to be a part-time cab driver for two weeks. Participants were told that they could choose between two zones, one that offered a guaranteed gain or loss (depending on the condition) and one that presented a possible gain or loss. After choosing an option, participants were asked to rate how much better the option they chose was than the one they did not choose and how much worse they option they did not choose was than the one they did. Researchers found that when presented with certain options, participants preferred those presented with a positive valence, whereas uncertain options were preferred when presented with a negative valence.

Van 't Riet et al. (2010) examined the contribution of gains and losses in relation to health-related behavior. In one experiment, researchers presented participants with a series of health behavior statements presented in terms of gain or loss. For example, participants in the gain condition read "If I am sufficiently active, my muscles will stay strong." Participants in the loss condition read "If I am insufficiently active, my muscles will become weak." They found that participants who received the gain-framed messages reported being more accepting of the statements and having more positive affect toward the messages. The opposite was true for participants in the loss-framed condition. Van 't Riet et al. suggested that based on their results, positive affect might have an important role in persuasion.

In a meta-analysis of the literature on the role of framing on health-related decisionmaking, Gong et al. (2013) outlined a key effect. In general, people preferred invasive treatments when presented in a positive frame and new drugs when presented in a negative frame. However, Gong et al.'s main finding was that the effects of framing were dependent on a 
multitude of factors, including culture, method of data presentation, peripheral threat cues, and visual aids. The way a treatment was presented almost always affected people's decisions, but the effects were not always consistent across medical conditions and treatments. Based on this finding, the authors suggested that research is needed to determine which factors are important in any given specific situation or for any given illness or disorder.

Research from the framing literature demonstrates the effects of language describing gain versus loss and positive and negative affect on health decision-making, but other research suggests that the language used can influence people's decisions in other ways as well. Weisberg et al. (2008) examined the idea that people might find explanations using neuroscience more satisfying, even if the neuroscience was logically irrelevant to the explanation presented. They presented neuroscience experts and non-experts who were learning about neuroscience with either a good or bad explanation of 18 psychological phenomena. Half the participants in each group received explanations without neuroscience, and the other half received explanations with neuroscientific information. Neuroscience experts had previously judged the neuroscience information to be irrelevant to the explanations. Although all participants judged good arguments as more satisfying than bad arguments regardless of neuroscience content, participants who were neuroscience novices also judged bad arguments with neuroscience as more satisfying than those without. Weisberg et al. speculated that bad explanations using neuroscience might have appealed to participants because participants assumed the neuroscientific explanation connected the psychological phenomenon to a more basic physical process.

Although previous research suggests that language use is an important component of decision making, there is a dearth of research on how language affects people's decisions about interventions for children with ASD. Recognizing that the language used in applied behavior 
analysis is confusing and varies across practitioners, Peterson, Larrson, and Reidesel (2003) sought to compile a list of key terms to be used when working with teachers and families of children with ASD. They proposed that these terms be used consistently throughout the field and across settings with the goal of improving the implementation of early behavioral interventions for young children with ASD. Peterson et al.'s key terms included (a) expressive versus receptive language, (b) successive versus simultaneous responses, (c) simple versus conditional discrimination, (d) conditional cue, (e) target versus distractor item, (f) N-term conditional discrimination, (g) training and generalization mode, and (h) the language matrix.

Peterson et al. (2003) had good intentions in proposing a comprehensive and consistent set of terms to be used by ABA practitioners. However, subsequent research indicates that the terms they selected might not have the intended effect on family and teacher acceptance and implementation. Critchfield et al. (2017) analyzed the emotional responses to behavioral analysis terms often used by ABA practitioners, general science terms, behavioral assessment terms, and general clinical terms. They found that the categories of general science terms, behavior assessment terms, and general clinical terms all contained more words that evoked a pleasant response than a negative response. However, the opposite was true for behavioral analysis terms. Of the terms suggested by Peterson et al., "response" was rated as somewhat pleasant but not motivating and "discrimination" was listed as unpleasant but motivating. "Conditional" was not listed, but "conditioning" was rated as somewhat unpleasant and neutral in terms of motivation. This pattern of findings is especially problematic in light of Van 't Riet et al.'s (2010) findings regarding the role of positive affect in acceptance of health-related information.

Becirevic, Critchfield, and Reed (2016) further underscored the obstacle jargon can present to people's acceptance of evidence-based interventions. In their study, the researchers 
presented adult participants, most of whom were not familiar with behavior analysis, with six word/phrase pairs. One of the words was a behavioral term, and the other had the same meaning but was a term used in everyday language. For example, "reinforcement" was paired with "incentivizing." Participants were asked to rate the acceptability of each term for use with various populations including young children, athletes, and people with special needs. In general, people rated the behavioral terms as less acceptable to be used with all populations. This finding further supports the idea that language used to describe an intervention can affect how people perceive that intervention. In the current study, the use of technical jargon was examined directly by having participants rate two ASD interventions aimed at addressing challenging behavior and increasing communication, each of which was described either with or without jargon.

\section{Therapeutic Approaches to ASD}

In the current study, people were asked to rate the effectiveness and credibility of two ASD interventions, as well as their likelihood of recommending and implementing those interventions in the future. To contextualize people's ratings of ASD interventions, in this section I outline the current evidence base for both interventions.

\section{Applied Behavioral Analysis (ABA)}

ABA encompasses many interventions, including antecedent modifications, task analyses, reinforcement procedures, and token economies. The National Standards Project, a subsidiary of the National Autism Center (NAC), considers these primary intervention strategies to be evidence-based (NAC, 2015). However, some behaviorally based interventions, such as the Picture Exchange Communication System and social communication interventions, are listed as emerging treatments by the NAC. An "emerging" designation indicates that an intervention has some empirical support, but not enough to meet the criteria to be evidence-based. Overall, the 
NAC considers ABA to be an evidence-based intervention. Additionally, it is used with many children with ASD. In Green's (2006) study, ABA was the most used evidence-based intervention, and one of the three most used interventions used overall. The goals of ABA are to increase adaptive behaviors such as communication, self-care skills, and social skills and decrease maladaptive behaviors such as verbal and physical aggression. Generally speaking, the focus of $\mathrm{ABA}$ is on reducing symptoms rather than curing ASD.

\section{Sensory Integration (SI)}

SI involves moving a child's body to provide vestibular, proprioceptive, and tactile stimulation with the goal of changing how the central nervous system receives input. Various tools including swings, scooters, and bounce pads are used to provide children with this input (Jacobsen et al., 2016). The goals of SI are to "retrain" the brain's neural pathways by providing the child with sensory input in a variety of forms such as rolling, swinging, bouncing, or brushing. Its proponents claim that SI leads to a reduction in challenging behavior and an increase in communication skills in children with ASD. However, as Jacobsen et al. reported, there is no evidence to support these claims. The NAC (2015) lists SI as an empirically unsupported intervention. However, In Green's (2006) study, it was one of the three most commonly used interventions.

As can be seen from the previously described research, people who need to make decisions about interventions for ASD have many options available and such decisions can be influenced by a variety of factors, including perceptions of ASD as a disorder, the way the intervention is described, and who is presenting the information about the intervention. Although interventions differ with respect to their level of empirical support, this information is not always most salient when people make decisions about ASD interventions. 


\section{Current Research}

The goal of the current research was to examine the relationships among various factors that could influence people's perceptions about two ASD interventions: ABA and SI. ASD and SI were chosen because they were two of the three interventions parents of children with ASD most frequently reported using with their children in Green et al.'s (2006) survey (the third was a combination of Vitamin B6 and Magnesium). ABA was selected because it is the only evidencebased intervention in the top three most frequently used. SI was selected because, in addition to being used frequently, it is often recommended by occupational therapists and other members of school teams, including general and special education teachers, school psychologists, social workers, and speech therapists (Jacobsen et al., 2016).

The current research employed the use of vignettes describing ABA and SI, both with and without jargon, which were created for this study. I conducted a pilot study to ensure the differences in jargon were salient in the vignettes and to ensure the levels of jargon were perceived to be similar for each intervention. I also created an Autism Experiences Questionnaire and pilot tested whether it was an acceptable measure of people's experience with ASD. As some of the hypotheses were developed based on the results of the pilot study, the specific research questions and hypothesis for the main study will be outlined after the description of the pilot study results presented in Chapter III. 


\section{CHAPTER III: PILOT STUDY: DEVELOPMENT OF MATERIAL}

A pilot study was conducted to (1) determine the efficacy and ease of use of the $A S D$ Experiences Questionnaire designed for this study to quantify participants' experiences with ASD; and (2) to determine whether the manipulated features of the vignettes describing the Applied Behavior Analysis (ABA) and Sensory Integration (SI) interventions were salient to participants and equivalent in terms of comprehensibility and reading level across both jargon and non-jargon versions. The goals of the pilot study with respect to the vignettes were:

a. to determine if the $\mathrm{ABA}$ and $\mathrm{SI}$ vignettes were perceived to be of equal reading difficulty and comprehensibility;

b. to determine if the two jargon versions of the vignettes were perceived to be more difficult to read and/or comprehend than the two non-jargon versions;

c. to determine if the order in which the vignettes were presented had an influence on ratings such as effectiveness, credibility, and likelihood of recommendation;

d. to determine if a preliminary sample of participants rated the interventions differently regarding effectiveness, credibility, and likelihood of recommending the intervention.

\section{Creation of Vignettes}

In all vignettes, a therapist is describing and advocating an intervention for clients with ASD (see Appendix A). The vignettes were created based on personal experience as an ASD practitioner and in consultation with other experts in ABA and ASD. Because SI is not evidencebased, language used to describe it came from Jacobsen et al.'s (2016) chapter. Additionally, Fairbanks and Stinnett (1997) found some support for the idea that different groups of people might favor interventions that reduce a challenging behavior or increase a prosocial behavior. 
The vignettes describe the intervention as both decreasing tantrums (challenging behavior) and increasing communication (prosocial behavior).

Informal focus groups were used to verify whether the jargon terms selected were perceived to be jargon by those who work with individuals with ASD. Focus group members were asked to circle the jargon words in the first draft of the vignettes. Interestingly, these participants circled more jargon words in the SI vignette. Although this pattern may seem counterintuitive, it is consistent with the idea that with developing expertise in ABA, words that once would have been considered jargon are now familiar and routine.

\section{Creation of the ASD Experiences Questionnaire}

The ASD Experiences Questionnaire was developed based on Reiher (2016) but expanded to include (a) training experiences related to ASD, (b) number of friends, classmates, coworkers, and neighbors with ASD the participant knows, and (c) the number of clients, students, mentees, and children who have ASD the participant has worked with in formal work or training settings. Based on informal focus group input, various example categories were added, such as research on individuals with ASD and tutoring children with ASD. The instrument was then revised based on this input and used in the pilot study (see Appendix B).

\section{Method}

\section{Participants}

In the pilot study, 37 participants were recruited through Illinois State University's SONA system, and an additional 168 were recruited via Amazon's Mechanical Turk (MTURK) for a total of 205 participants. I decided to recruit participants from the general population as well as parents with children with ASD because, as previously mentioned, not much information is available about how others who work with children with ASD make decisions regarding 
interventions. Findings from Reiher (2016) support the idea that many people who do not have a child with ASD have some experience with people with ASD. According to that study, 37\% of parents of children with ASD reported having additional unpaid experience with ASD, with an average of 9.8 years of experience. Interestingly, $35 \%$ of parents of children with ASD reported having paid experience with ASD, with an average of 8.4 years of experience. For parents of children without ASD, 36\% reported having unpaid experience with ASD, with an average of 6.5 years of experience. Unexpectedly, $49 \%$ of parents of children without ASD reported having paid experience with ASD, with an average of 7.7 years of experience. This high percentage is unlikely to be representative of all parents of children without ASD, but instead may reflect a volunteer bias in which people who had experience with ASD were more likely to participate in the study. Additionally, the community in which the survey was initially circulated has strong ties to ASD organizations.

To participate in the study, MTURK respondents were required to have a HIT Approval Rate of at least $80 \%$, as well as at least 100 approved HITS. HITS, or "Human Intelligence Tasks," are discrete tasks a person can work on, submit, and collect a reward for completing. Additionally, all participants were required to be a resident of the United States and had to complete the assignment within 30 minutes. MTURK respondents were included in the sample if they answered two attention check questions correctly. At two points during the study, participants were asked to select a certain response to indicate they had read the question. Participants recruited through MTURK were paid $\$ 0.20$ for their participation. The majority of participants were female $(n=134,65.4 \%)$. The average age of participants was 34.27 years $(S D$ $=13.26)$. Most participants were married $(n=65,31.7 \%)$ or single $(n=56,27.3 \%)$ and white $(n$ 
$=153,77.1 \%)$. Forty-two percent of participants had at least one child $(n=86)$, and approximately $10 \%$ of participants had a child with ASD $(N=21)$.

\section{Measures}

The following measures were used in the Pilot Study:

Vignettes. Four vignettes were created, two endorsing ABA and two endorsing SI (see Appendix A). ABA- and SI-endorsing vignettes were created with and without jargon. Each participant saw one vignette endorsing $\mathrm{ABA}$ and one endorsing SI. There were four conditions: (a) both $\mathrm{ABA}$ and SI described without jargon, (b) ABA described with jargon and SI described without, (c) ABA described without jargon and SI described with jargon, and (d) both interventions described with jargon. Additionally, the presentation of the vignettes was counterbalanced to test for order effects (see Table E-1 for a summary of conditions and orders). The Flesch-Kincaid Grade Level readability for each vignette was determined using Microsoft Word. The vignettes without jargon had a ninth-grade (ABA) and an eighth-grade reading level (SI). The ABA and SI vignettes with jargon both had college reading levels.

Intervention perceptions rating scale. Participants were asked to rate their perceptions of the interventions' credibility, effectiveness, and ease of implementation, as well as their likelihood of implementing and recommending the intervention on a seven-point Likert scale, with one being unlikely to recommend, implement, etc. and seven being very likely to recommend, implement, etc. They were also asked about how familiar they had been with each intervention before reading the vignette and asked to rate the reading level and comprehensibility of each vignette. Additionally, participants were asked to describe the differences between the interventions and then choose which intervention they would use or recommend if they or a close friend or family member had a child with ASD (see Appendix C). Participants were asked to 
describe differences to ensure they had read the vignettes. I also included ratings of the reading level of the vignette and its comprehensibility (Kienhues, Bromme, \& Stahl, 2008).

ASD experiences questionnaire. Participants were asked how many friends, direct and extended family members, and clients with ASD they had. They were also asked about their training, paid, and unpaid experiences related to ASD and how much time per week they spend with people with ASD (see Appendix B).

\section{Procedure}

Data from Illinois State University students were collected in person using paper and pencil materials. Participants provided informed consent, and then were given a booklet with instructions, including a statement telling participants that they would be asked to answer questions about ASD, read about ASD interventions, and answer questions about ASD interventions. Participants also were informed that they could leave the study at any time with no risk of repercussions. They were asked to verify they are at least 18 years old.

After verifying their age and consenting to participate, participants were presented with two vignettes endorsing ABA or SI with or without jargon. The order of presentation of ABA and SI vignettes was counterbalanced. Therefore, participants were randomly assigned to one of eight different versions of the survey (Table E-1). Next, participants were asked to complete the Intervention Perceptions Rating Scale, followed by the Experiences with ASD scale. Finally, participants answered demographic questions including age, race/ethnicity, and whether they had children with or without ASD. Upon completion of the demographics, they were thanked for their time and provided with more information about the rationale of the study, including a debriefing statement informing them that $\mathrm{ABA}$ is an evidence-based intervention for $\mathrm{ASD}$, but $\mathrm{SI}$ 
is not. MTURK participants followed the same procedure, but all materials were presented in an online Qualtrics survey.

\section{Results}

\section{ASD Experiences Questionnaire}

The first goal of the pilot study was to determine if the revised version of Reiher's (2016) Experience with ASD Questionnaire could be used to more precisely quantify people's experiences with ASD. All parents of a child with ASD were automatically coded as having an unpaid experience with ASD. Most participants reported knowing at least one person with ASD ( $n=162,79 \%$ ), but $66 \%$ reported not having any training, paid, or unpaid experiences related to $\operatorname{ASD}(N=137)$. Approximately $40 \%$ of participants reported spending some time with a person with ASD in the last three months $(N=86)$, approximately $50 \%$ within the past year $(n=106)$, and approximately $60 \%$ prior to the past year $(n=118)$.

Based on the data collected with the ASD Experiences Questionnaire in this pilot study, two key changes were made. First, a question was added to determine if participants have been diagnosed with ASD and, if so, how long ago was the diagnosis. Second, a question was added that asks participants whether they have a child with ASD (along with information such as time since diagnosis and the child's age). That is, having a child with ASD will not be included in the "unpaid experience" category. This decision was made to better differentiate between different types of ASD experience.

\section{Testing the Jargon Manipulation}

The second goal of the pilot study was to assess whether the four vignettes were equivalent or varied with respect to the jargon manipulation. Participants in each condition (see Table E-1 for the different conditions) were asked to rate two vignettes with respect to reading 
level (i.e., where larger numbers mean the text is more difficult to read) and comprehensibility (i.e., where larger numbers mean the text is more comprehensible). This procedure has been used in previous research to measure the comparability of texts (Kienhues et al., 2008). The goal was to create vignettes where the ABA and SI jargon versions did not differ from one another with respect to ratings of comprehensibility and reading difficulty, and neither did the no-jargon vignettes. However, it was also necessary that the no jargon vignettes differed from the jargon vignettes on ratings of comprehensibility and reading difficulty.

Equivalence of ABA and SI vignettes. There was no significant difference between the overall ratings for the reading level of the $\mathrm{ABA}(M=3.63$; no jargon $M=2.88$, jargon $M=4.39)$ and SI vignettes $(M=3.59$; no jargon $M=2.88$, jargon $M=4.30)$, with an average difference of $.00(S D=1.88), t(204)=.000, p=1.00$. Participant ratings of the comprehensibility of the ABA $(M=5.47$; no jargon $M=5.66$, jargon $M=5.28)$ and SI vignettes $(M=5.45 ;$ no jargon $M=5.63$, jargon $M=5.23)$ were not significantly different, with an average difference of .06 $(S D=1.77)$, $t(204)=.51, p=.61$.

Differences between the jargon and no-jargon versions. Participants rated the ABA vignette without jargon as having an average readability score of $2.88(S D=1.56)$ and the ABA vignette with jargon as having an average readability score of $4.39(S D=1.68)$. This difference was significant, $t(203)=-6.67, p \leq .001$. Participants rated the SI vignette without jargon as having an average readability score of $2.88(S D=1.50)$ and the SI vignette with jargon as having an average readability score of $4.31(S D=1.60), t(203)=-6.61, p \leq .001$. In terms of comprehensibility, participants rated the $\mathrm{ABA}$ vignette without jargon as having an average comprehensibility score of $5.67(S D=1.33)$ and the ABA vignette with jargon had an average comprehensibility score of $5.27(S D=1.32)$. These ratings were significantly different, $t(203)=$ 
$2.15, p=.03$. The SI vignette without jargon had an average comprehensibility score of 5.63 (SD $=1.21)$ and the SI vignette with jargon had an average comprehensibility score of $5.20(S D=$ $1.40), t(203)=2.39, p=.02$.

\section{Order Effects}

It is important to determine if there are order effects with respect to the ABA and SI vignettes for both methodological and pragmatic reasons. When asked a forced-choice question about which intervention they would choose if they or a close friend had a child with ASD, participants were significantly more likely to choose the intervention they read about first, $X^{2}(1$, $N=202)=17.55, p \leq .001$.

Intervention effectiveness. A 2 (Jargon: no jargon vs. jargon) x 2 (Intervention: ABA vs. SI) x 2 (Order: ABA first, SI first) ANOVA was conducted on ratings of effectiveness. There was only one significant effect, the interaction between Order and Intervention type. As can be seen in Figure 1, ABA was rated as more effective when it was presented first, and SI was rated as more effective when it was presented first. Significant order effects were found such that participants rated the first intervention they read about as more effective $F(1,197)=21.82, p$ $<.001$. All other main effects and interactions were nonsignificant (all $F \mathrm{~s} \cong 1$ ). 


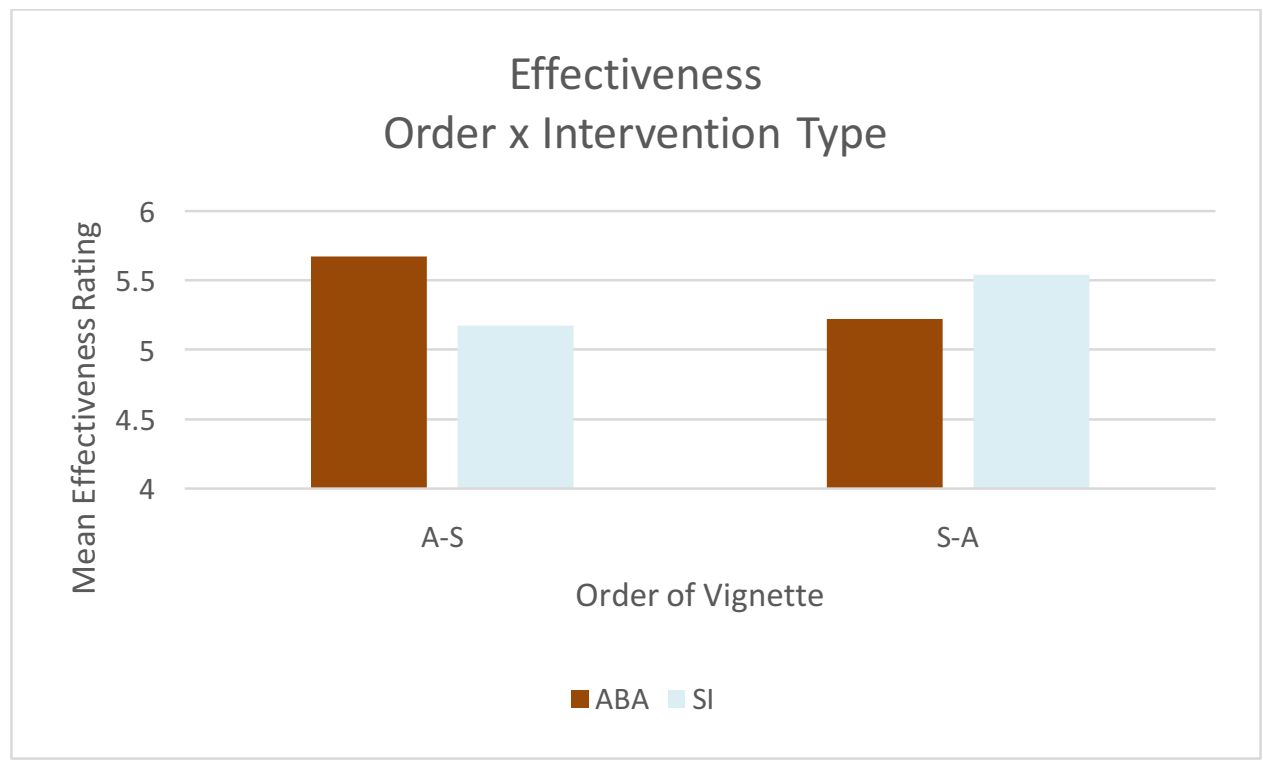

Figure 1. Mean ratings of an intervention's effectiveness as a function of Order and Intervention Type in the pilot study. Note that "A-S" refers to ABA followed by SI; "S-A" refers to SI followed by ABA.

Intervention credibility. To examine the effects of jargon, intervention type, and order on ratings of intervention credibility, a 2 (Jargon: no jargon vs. jargon) x 2 (Intervention: ABA vs. SI) x 2 (Order: ABA first, SI first) ANOVA was conducted. As can be seen in Figure 2, participants rated SI as more credible when it was presented first. Significant order effects were found, $F(1,197)=15.67, p<.001$. All other main effects and interactions were nonsignificant (all $F \mathrm{~s} \cong 1)$. 


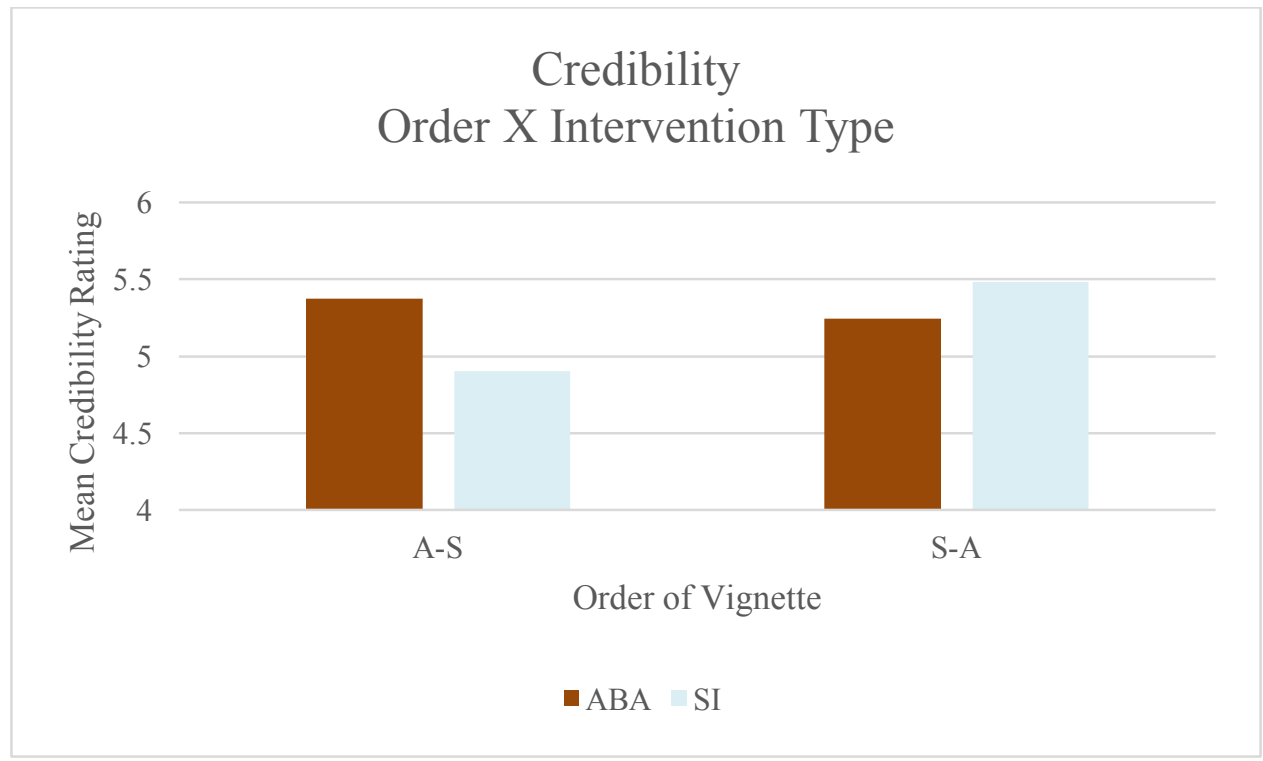

Figure 2. Mean ratings of whether an intervention was perceived as credible as a function of Order and Intervention Type in the pilot study. Note that "A-S" refers to ABA followed by SI; "S-A" refers to SI followed by ABA.

Intervention recommendation. To examine the effects of jargon, intervention type, and order on ratings of whether the intervention would be recommended, a 2 (Jargon: no jargon vs. jargon) x 2 (Intervention: ABA vs. SI) x 2 (Order: ABA first, SI first) ANOVA was conducted. As can be seen in Figure 3, although participants were more likely to recommend the first intervention that they read about, this effect was exaggerated for participants who read about ABA first without jargon followed by SI with jargon and for participants who read about ABA first when both vignettes used jargon. Similarly, participants who read about SI first without jargon followed by ABA with jargon were more likely to recommend SI. Significant order effects were found such that participants rated themselves as more likely to recommend the first intervention they read about, $F(1,197)=20.57, p<.001$. Additionally, participants rated themselves as significantly more likely to recommend the first intervention if it was described without jargon and the second intervention was described using jargon, $F(3,197)=2.68, p=$ .048. All other main effects and interactions were nonsignificant (all $F \mathrm{~s} \cong 1$ ). 

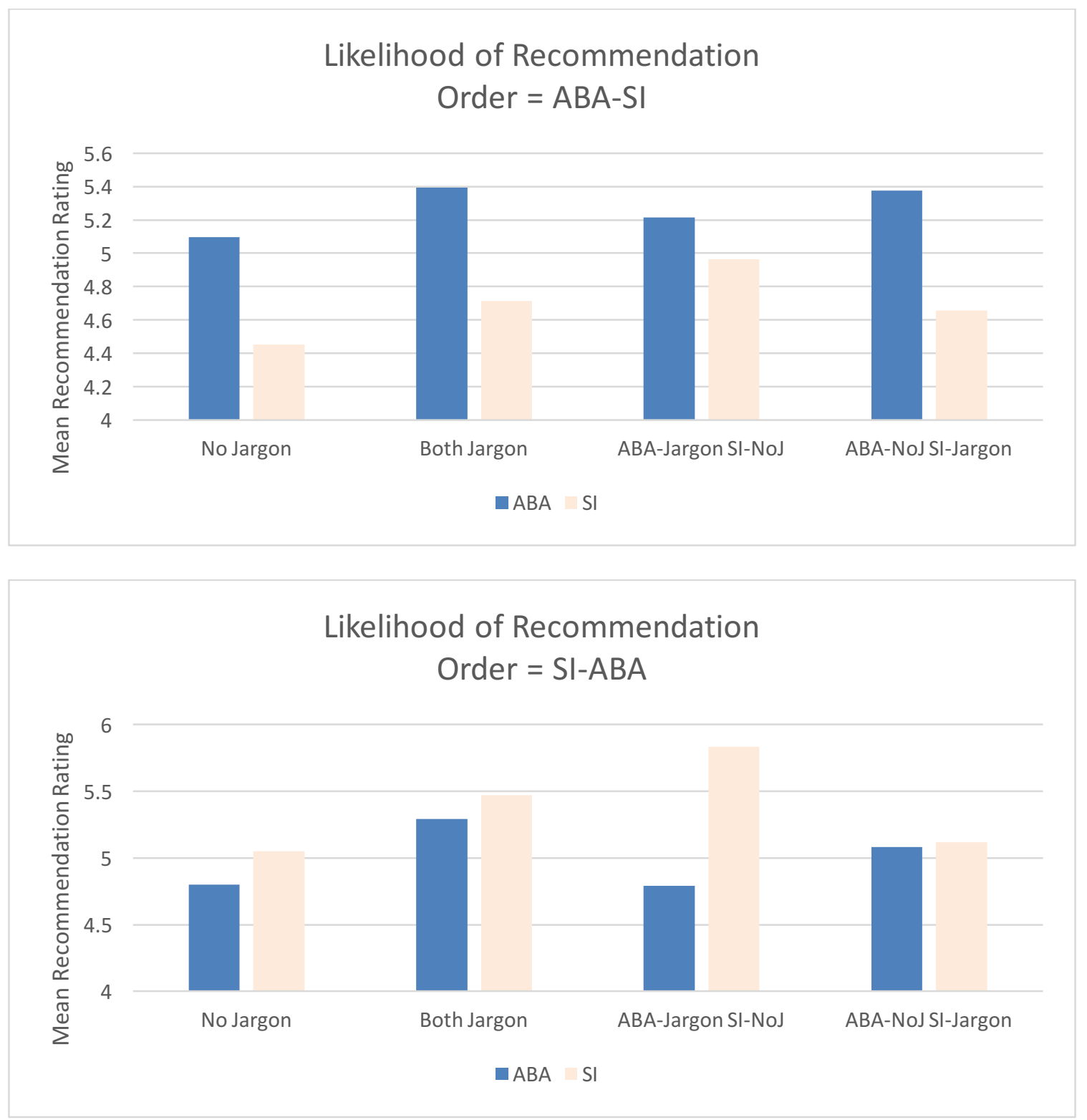

Figure 3. Mean ratings of whether an intervention would be recommended as a function of Order, Jargon, and Condition in the pilot study. The top panel shows the mean ratings for whether an intervention would be recommended when ABA was presented first; the bottom panel shows the means when SI was presented first.

\section{Discussion}

The results from the Experience with ASD Questionnaire indicate that many participants had some level of experience with ASD. Based on participant responses, questions regarding 
whether the participant has ASD or has a child with ASD, as well as length of time since diagnosis and child age were added to a revised version of the questionnaire.

Participants did perceive the jargon versions of the vignettes as being more difficult to read and lower in comprehensibility. These characteristics are in line with the goals of creating different versions of the same intervention vignette that varied with respect to the amount of jargon and creating versions of different intervention vignettes that were similar with respect to the amount of jargon. The Flesch-Kincaid grade levels were also similar for the two jargon versions and the two versions without jargon (but, importantly, different between the jargon and no jargon vignettes).

Significant order effects were found such that both ABA and SI were rated as more effective when they were read about first. Additionally, participants rated SI as more credible and that they would be more likely to recommend it if they read about SI first. Although order effects are generally problematic in experimental design, in this case they are pragmatically important. The order of intervention presentation has implications for practitioners who consult with families, schools, and other professionals. As such, the order effects will be studied further in the main study.

Based on the overall goal of determining the factors that influence various evaluations of ASD interventions, along with the review of the literature and the results of the pilot study, the following set of research questions and hypotheses were developed.

\section{Research Questions and Hypotheses}

The goal of the current study is to examine several factors that may influence people's perceptions of the effectiveness, credibility, likelihood of implementation, ease of implementation, and likelihood of recommendation of an evidence-based versus a non-evidence- 
based intervention for ASD. I focused on three manipulated variables and one individual difference variable: (a) the language used to describe interventions (i.e., jargon vs. no jargon), (b) type of intervention (evidence-based ABA vs. non-evidence-based SI), (c) the order in which participants are exposed to the interventions, and (d) level of experience with ASD. Additionally, I assessed participants' perceptions of ASD as a disorder to examine the relationship between particular illness perceptions and ratings of these ASD interventions.

\section{Jargon and ASD Experience Hypotheses}

I hypothesized that the use of jargon (jargon or no jargon) would affect participants' ratings of the efficacy and credibility of ABA and SI, as well as their likelihood and perceived ease of implementing and recommending those interventions. I also hypothesized effects would be different depending on whether participants have previous experience with ASD.

Effectiveness. I hypothesized that because participants with previous experience with ASD are more likely to know the evidence base for interventions and have interacted with more

professionals who use jargon, these participants would rate ABA as highly effective regardless of whether jargon is used to describe the intervention. Participants with experience with ASD would rate SI as ineffective, but slightly more effective when endorsed by a therapist using jargon (see top panel of Figure 4). For people without previous experience with ASD, I hypothesized both interventions would be perceived as equally effective, but interventions would be rated as more effective when the interventions are endorsed by a therapist using jargon (see bottom panel of Figure 4) based on research showing that technical jargon can lead to people evaluate explanations as better even when that language adds nothing meaningful to the description (Weisberg et al., 2008). 

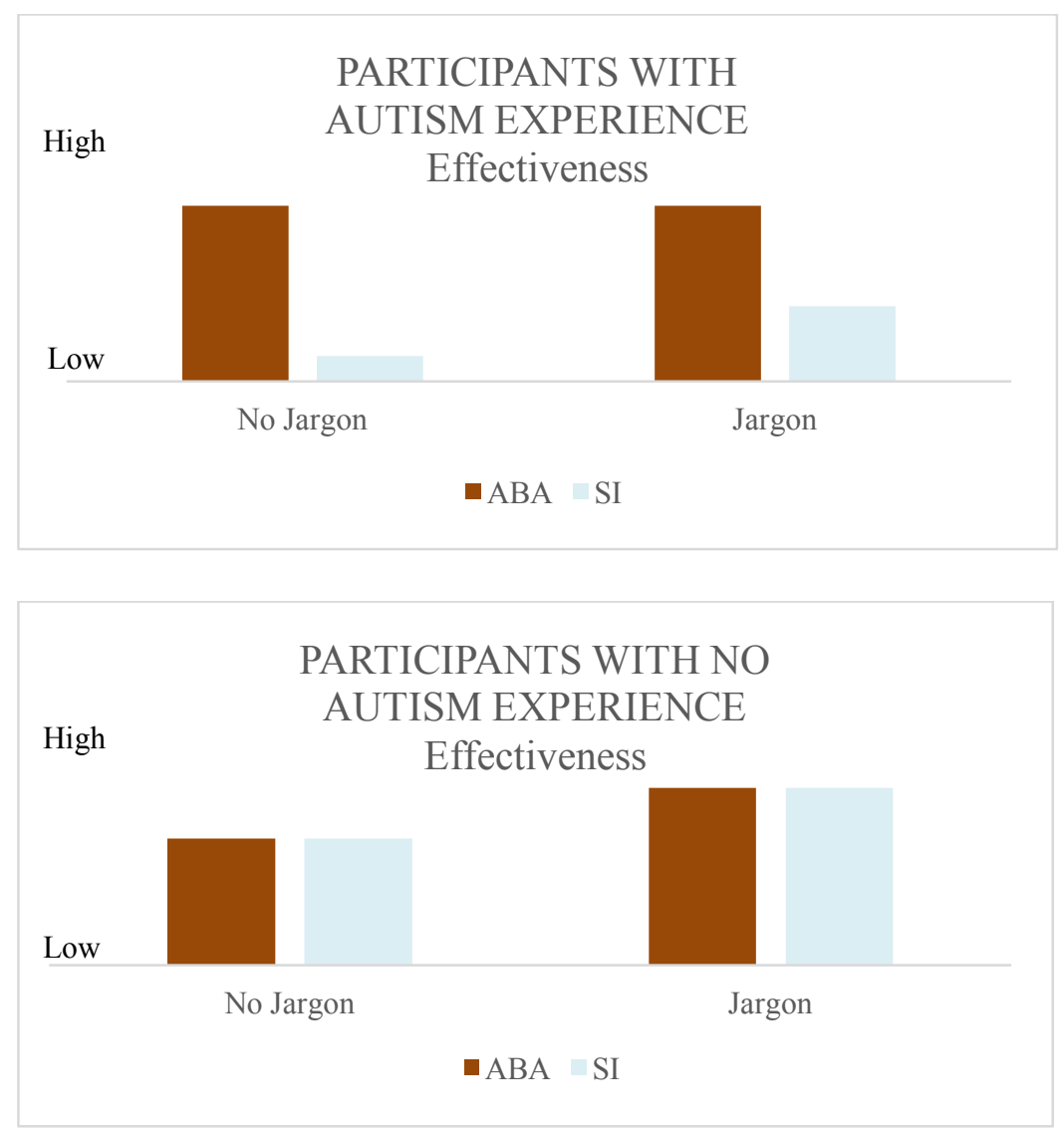

Figure 4. Predicted effectiveness ratings from participants with ASD experience (top panel) and without ASD experiences (bottom panel) for ABA and SI in the No Jargon and Jargon conditions.

Credibility. I hypothesized participants with previous ASD experience would rate ABA as highly credible when described using either jargon or no jargon. For these participants, SI would be rated as somewhat credible when endorsed by a therapist using either jargon or no jargon (see top panel of Figure 5). Further, I hypothesized that participants who do not have previous experience with ASD would perceive the credibility of the interventions similarly, except they would perceive both ABA and SI to be highly credible when presented using jargon based on Weisberg et al.'s (2008) research (see bottom panel of Figure 5). 

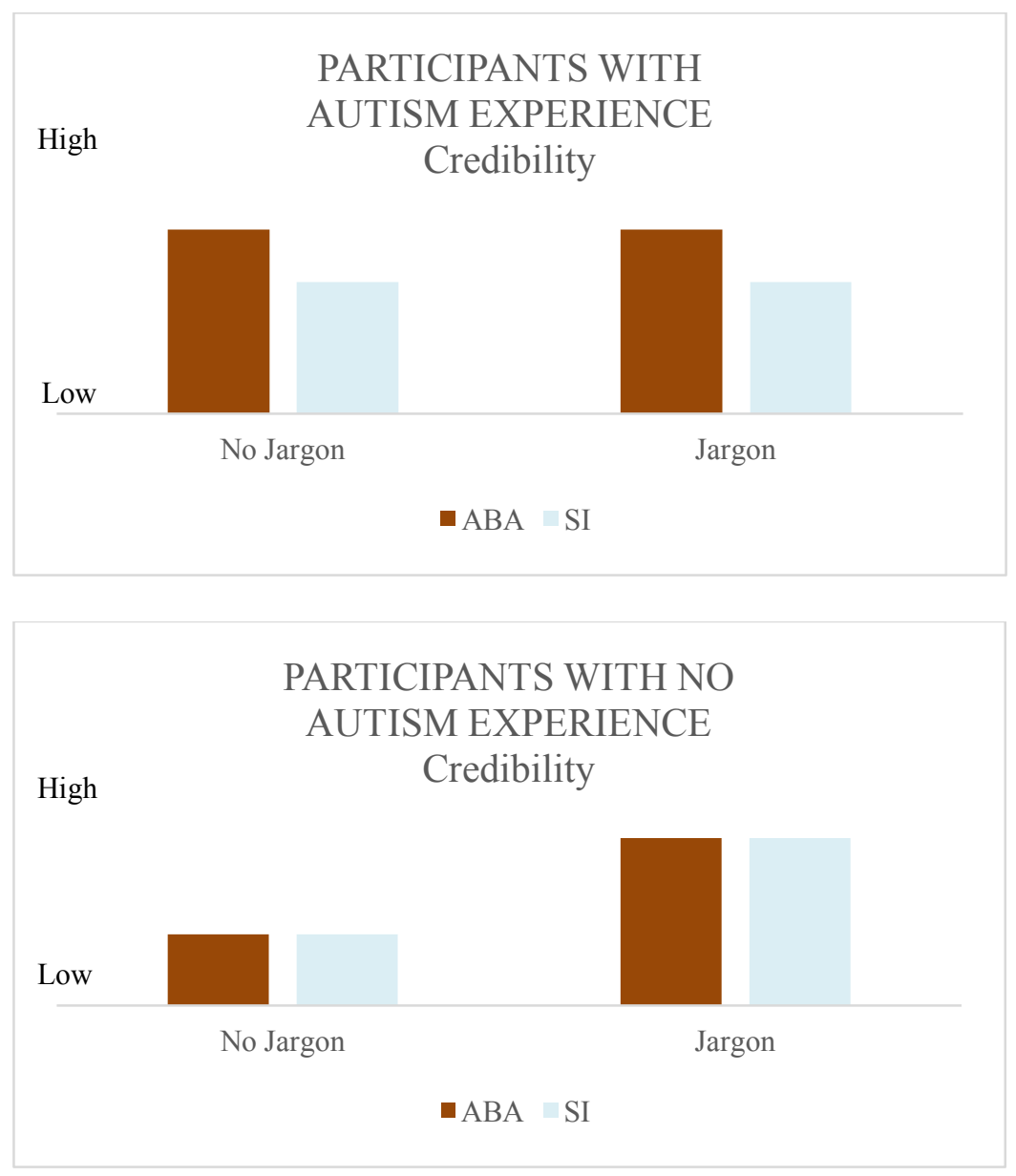

Figure 5. Predicted credibility ratings from participants with ASD experience (top panel) and without ASD experiences (bottom panel) for ABA and SI in the No Jargon and Jargon conditions.

Likelihood of implementation. I hypothesized that participants with ASD experience would rate their future likelihood of implementing ABA with children with ASD as high regardless of presence of jargon. These participants would rate their likelihood of implementing SI in the future as low regardless of the use of jargon (see top panel of Figure 6). For participants without ASD experience, I hypothesized they would report being highly likely to implement either ABA or SI when it is presented without the use of jargon, but they would rate themselves as being unlikely to implement either intervention when the interventions are described using 
jargon (see bottom panel of Figure 6). I predicted that people without ASD experience would perceive interventions described with jargon as requiring more expertise than they possessed.
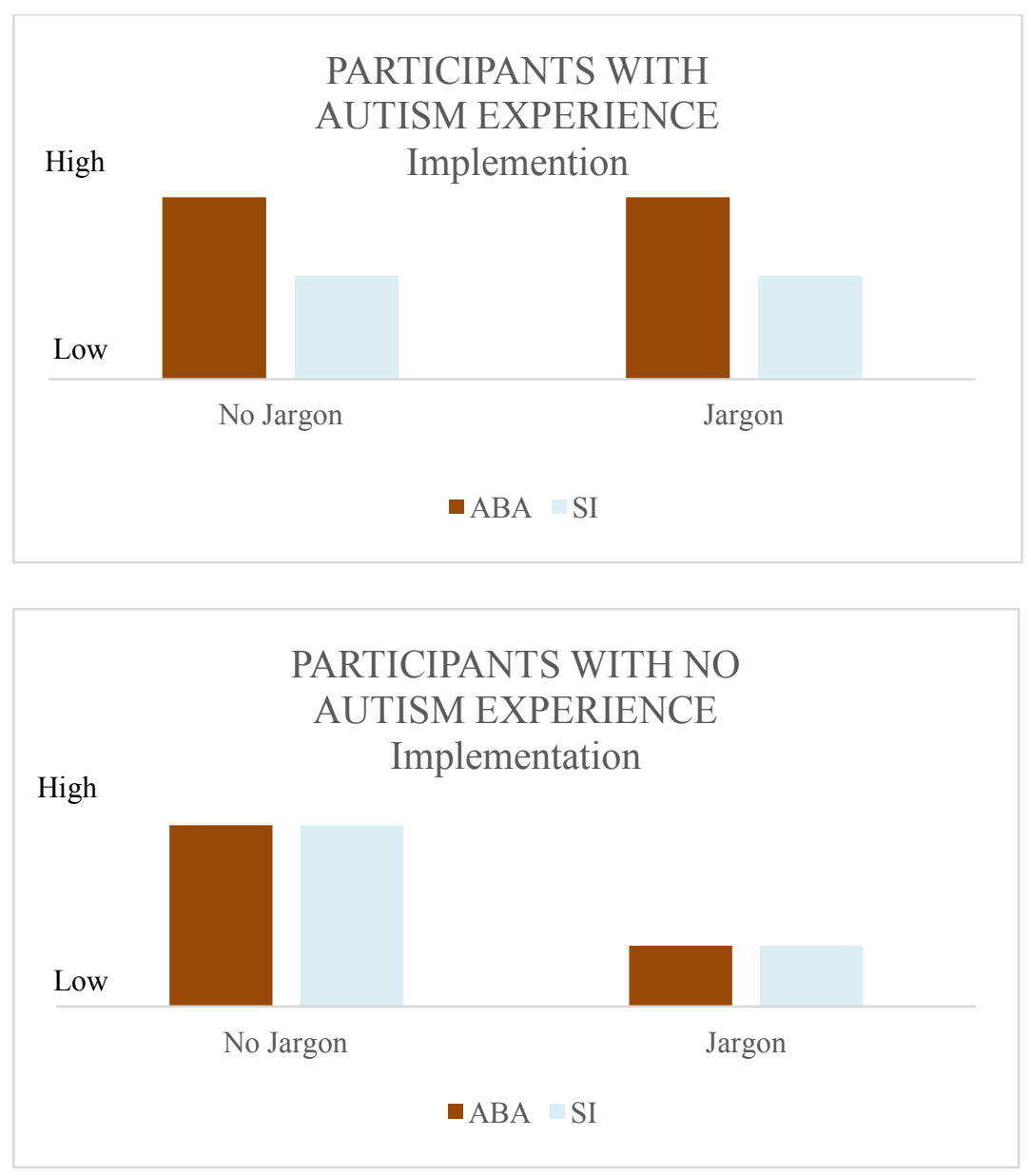

Figure 6. Predicted likelihood of implementation ratings from participants with ASD experience (top panel) and without ASD experiences (bottom panel) for ABA and SI in the No Jargon and Jargon conditions.

Ease of implementation. I hypothesized participants with experience with ASD would rate $\mathrm{ABA}$ as being easier to implement when it is described without jargon and more difficult to implement when described using jargon. These participants would rate SI as being easier to implement regardless of jargon level (see top panel of Figure 7). Participants who have experience with ASD would be more likely to know that ABA can be difficult to implement, whereas SI interventions might seem easier to implement regardless of how they are described. 
For participants without ASD experience, I hypothesized ABA and SI both would be perceived as easy to implement when described without jargon and difficult to implement when described using jargon (see bottom panel of Figure 7).
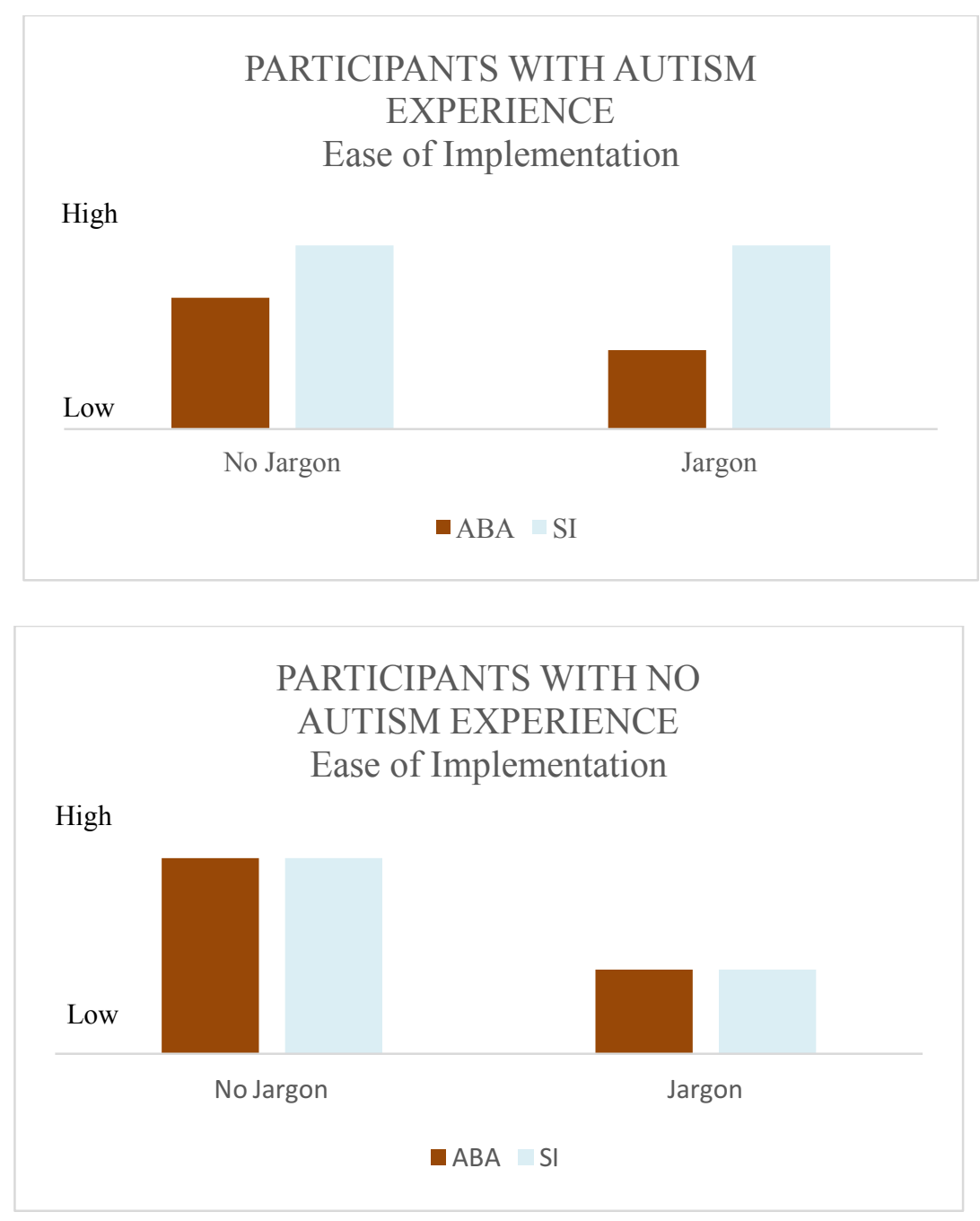

Figure 7. Predicted ease of implementation ratings from participants with ASD experience (top panel) and without ASD experiences (bottom panel) for ABA and SI in the No Jargon and Jargon conditions.

Likelihood of recommendation. I hypothesized participants with experience with ASD would rate themselves as being likely to recommend the use of $\mathrm{ABA}$ in the no jargon condition and they would rate themselves as being highly likely to recommend its use in the jargon condition. These participants would rate themselves as unlikely to recommend the use of SI 
regardless of use of jargon (see top panel of Figure 8). Additionally, I hypothesized participants without ASD experience would rate themselves as highly likely to recommend both interventions when presented without the use of jargon, but rate themselves as unlikely to recommend the use of either intervention when described using jargon, but with a decrease in likelihood of recommendation of ABA when it is described using jargon (see bottom panel of Figure 8).
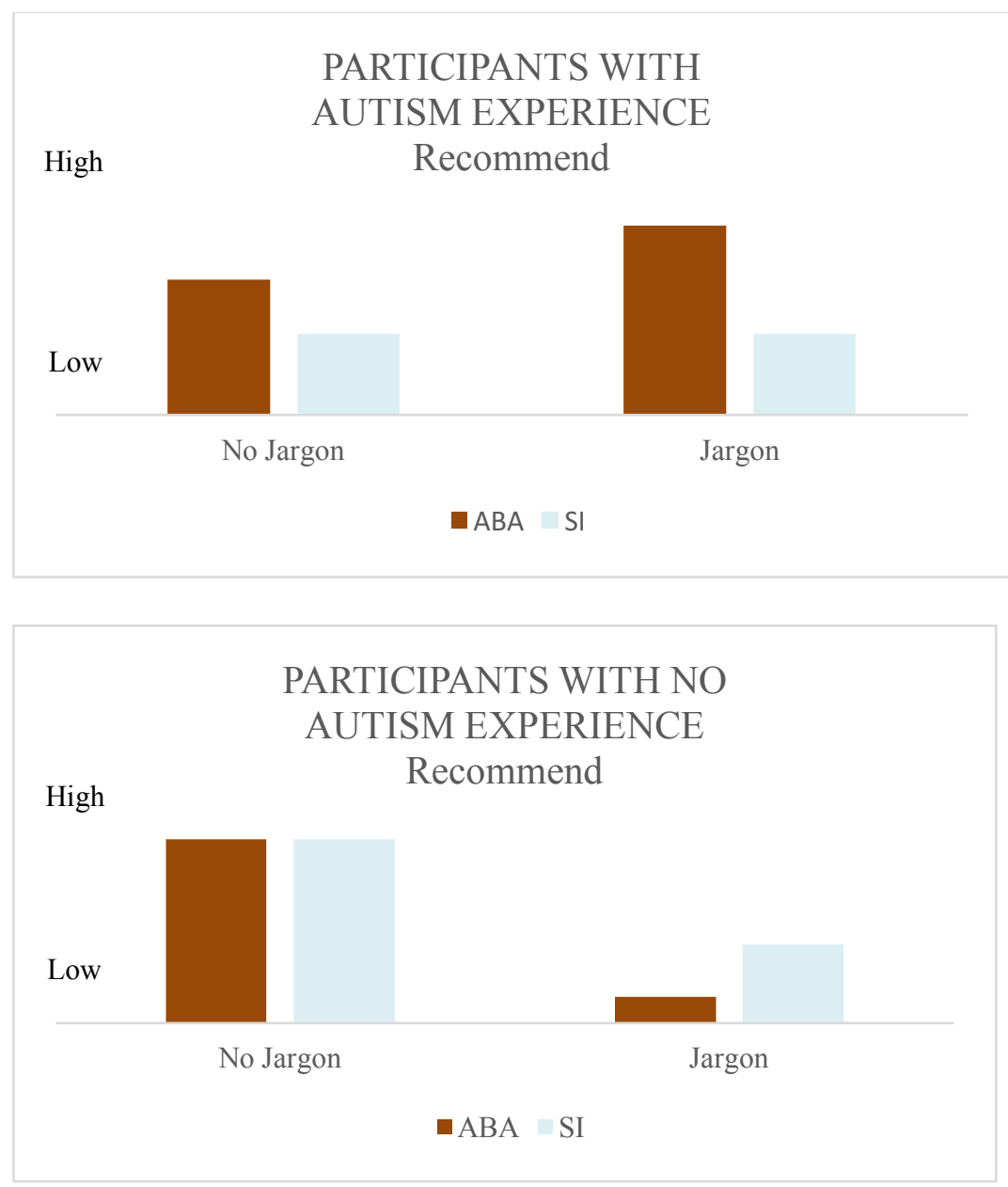

Figure 8. Predicted likelihood of implementation ratings from participants with ASD experience (top panel) and without ASD experiences (bottom panel) for ABA and SI in the No Jargon and Jargon conditions. 


\section{Order Effects}

Based on the results of the pilot study, I hypothesized that all else being equal, participants would rate the first intervention they read about in a more favorable way, regardless of the type of rating (i.e., effectiveness, credibility, and likelihood of recommendation). I also hypothesized that this effect would be exaggerated for participants who read a non-jargon vignette followed by a jargon vignette. More specifically, I predicted that the size of the Order effect will be greatest for those in the ABA-without-jargon followed by SI-with Jargon group, and those in the SI-without-jargon followed by ABA-with jargon group). 

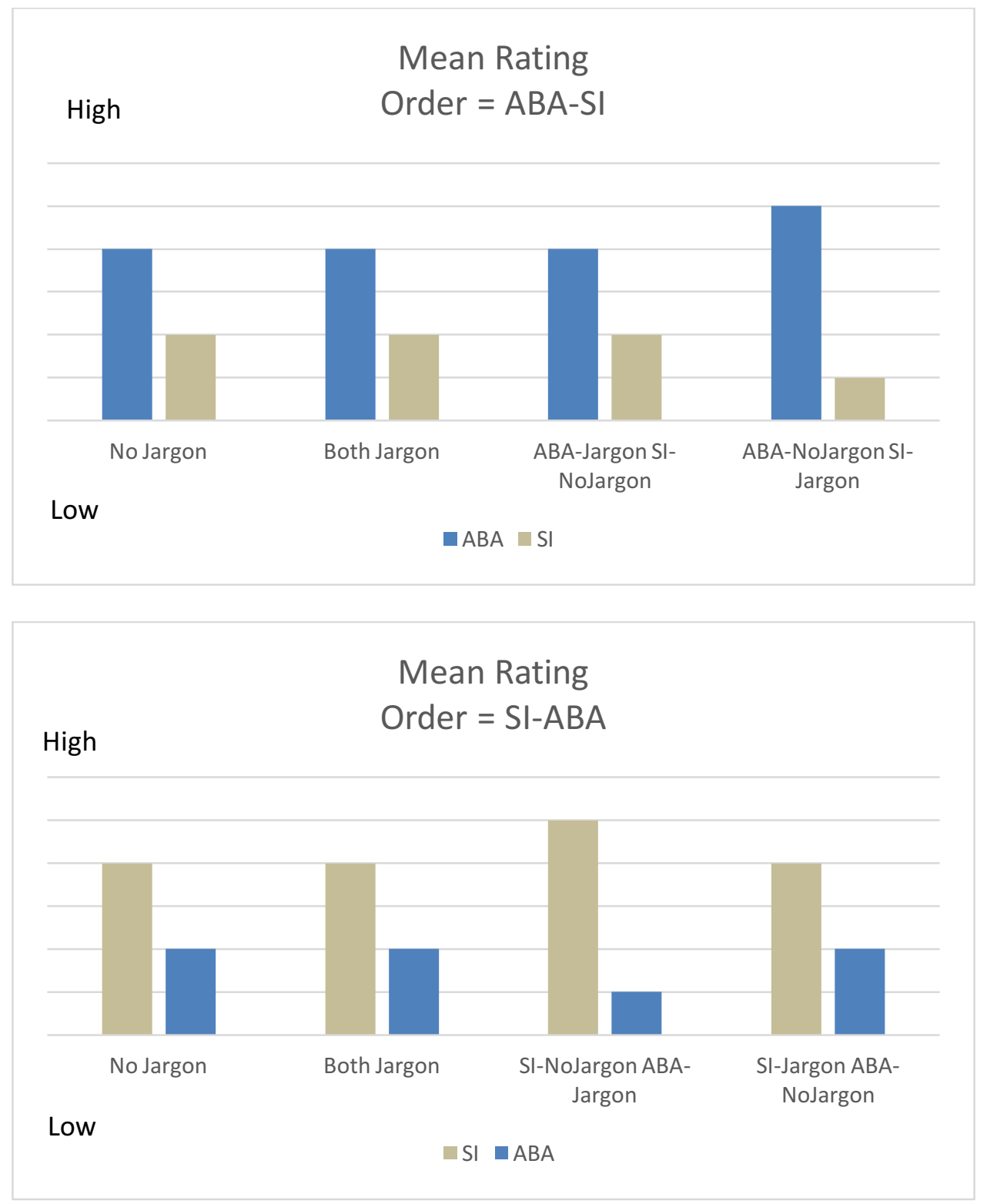

Figure 9. Predicted interaction for ratings of effectiveness, credibility, and likelihood of recommendation as a function of Order, Intervention, and Survey Version. The top panel shows the predicted mean ratings when ABA is presented first (blue bars); the bottom panel shows the predicted means when SI was presented first (grey bars). I predict the order effect will be exaggerated when a vignette with jargon follows a vignette without jargon.

I also hypothesized that participants would be more likely to select the first intervention they read about when presented with a forced-choice question regarding which intervention they would pick if they had a child with ASD or were being asked to recommend an intervention for a friend's child. In most research, an order effect would be considered a nuisance variable 
(Goodwin, 2008). However, pragmatically, finding that the order in which parents and others learn about an intervention matters could be a potentially valuable clinical insight for those hoping to encourage the use of evidence-based interventions. The clinical and pragmatic importance of order effects and interactions with order will be discussed in more detail in Chapter VI.

\section{Illness Perception Hypotheses}

Participants' perceptions of ASD were measured using an English translation of the Illness Perception Questionnaire, Revised for Autism (IPQ-RA; Al Anbar et al., 2010), which measures identity (associated symptoms), consequences, timeline (acute/chronic and cyclical), control/cure (personal and treatment control), cause, and emotional representations of the illness (see Chapter IV for a detailed description). I hypothesized that participants' ratings of the effectiveness of SI would be positively correlated with their perceptions of ASD as having an external cause. I also hypothesized that participants' ratings of the effectiveness of ABA would be negatively correlated with their perceptions of ASD as having an external cause. Further, I hypothesized that this same relationship would occur between participants' perceptions of ASD as having an external cause and their perceptions of both interventions' credibility as well as their likelihood of implementing and recommending the intervention. 


\section{CHAPTER IV: METHOD}

\section{Participants}

A total of 421 participants who were at least 18-years-old were recruited through Amazon's Mechanical Turk (MTURK) service. Participants who answered the attention check questions as described in the pilot study were paid $\$ 0.25$ for their participation. Demographic information was collected (e.g., gender, race, age, whether they have children with or without ASD; see Appendix D). Additionally, participants were required to be United States residents, have an at least $80 \%$ HIT approval rating, have completed at least $100 \mathrm{HITS}$, and complete the survey within 45 minutes. Based on previous research (Reiher, 2016) and the results of the pilot study, I expected around half of the sample would have some paid and/or unpaid experience with ASD.

A majority of participants were female $(n=294,70.0 \%)$. The average age of participants was $36.44(S D=11.07)$. Most participants were married $(n=189,45 \%)$ or single $(n=100$, $23.83 \%)$ and white $(n=324,77 \%)$. The majority of participants had some college $(n=118$, $28 \%)$ or had graduated college $(n=158,37.5 \%)$. Fifty percent of participants had at least one child $(n=209)$, and approximately nine percent of participants had a child with ASD $(n=21)$. Most parents of children with ASD had one child with ASD. The average age for oldest child with ASD was $11.22(S D=5.8)$ and the average years since ASD diagnosis was $6.5(S D=5.1)$.

Few participants reported having ASD themselves $(n=12,2.9 \%)$, but almost half had experience with $\operatorname{ASD}(N=193,45.8 \%)$. For participants who reported having an ASD diagnosis, the average years since diagnosis was $5.9(S D=7.3)$. Participants were defined as having ASD experience if they had an ASD diagnosis, had a child or another close family member with an 
ASD diagnosis, or spent any amount of time per week within the past three months with someone with ASD. See Chapter V for additional information gathered from the Autism Experiences Questionnaire.

\section{Measures}

\section{Illness Perception Questionnaire-Revised for Autism, English Version (IPQ-RAE)}

This assessment is an English translation of the French IPQ-RA created by Al Anbar, Dardennes, Prado-Netto, Kaye, and Contejean (2010). The IPQ-RA is an adaptation of the IPQR, devised by Moss-Morris et al. (2002). The IPQ-R assesses the five components of Leventhal et al.'s (1997) Self-Regulatory Model of illness representation. The five components are: identity, consequences, timeline (acute/chronic and cyclical), control/cure (personal and treatment control), and cause. It also measures emotional representations of illnesses. The IPQ-R and its adaptations have been used to measure people's perceptions of their own illness and those of their spouses (e.g., Hagger \& Orbell, 2005; Sterba \& Devllis, 2009). The IPQ-R also has been used to assess the illness perceptions of people with rheumatoid arthritis, type II diabetes, asthma, chronic and acute pain, multiple sclerosis, and myocardial infarctions, among others (Moss-Morris et al., 2002). The IPQ-R measures whether people experience certain symptoms, how they perceive their illness, and to what causes they attribute their illness. The subscales have been found to be reliable (consequences, $\alpha=.84$; timeline acute/chronic, $\alpha=.89$; timeline cyclical, $\alpha=.79$; personal control, $\alpha=.81$; treatment control, $\alpha=.80$; and emotional representations, $\alpha=.88$ ). The original identity subscale composed on non-disorder-specific health issues was also found to be reliable ( $\alpha=.75$; Moss-Morris et al., 2002). Moss-Morris et al. found that four factors composed the causes subscale: psychological attributions, $\alpha=.86$; risk factors, $\alpha=.77$; immunity, $\alpha=.67$; and accident or chance, $\alpha=.23$. However, the $\mathrm{Al}$ 
Anbar et al. (2010) study reporting finding only three factors that composed the causes subscale: personal attributions, $\alpha=.89$; external attributions, $\alpha=.82$; and hereditary attributions, $\alpha=$ .70. The external attributions factor, which will be used as a predictor variable in the current study, is comprised of the items from the Immunity factor along with the "past poor medical care" item that loaded on to the Risk-Factors factor in the Moss-Morris et al. (2002) study. Al Anbar et al. (2010) modified the symptom list to reflect symptoms commonly experiences by children who have ASD. They also altered the phrase "my illness" to "my child's disorder." The word disorder was chosen instead of illness because ASD is considered to be a disorder, and labeling it as an illness may be offensive to parents.

Another version of the IPQ-R has been used to assess healthy people's perceptions of illnesses. Figueiras and Alves (2007) created the Revised Illness Perception Questionnaire for healthy people (IPQ-RH). They assessed healthy adults' perceptions of one of three illnesses: AIDS, tuberculosis, or skin cancer. Participants were asked to what extent symptoms were associated with a given illness, their perceptions of the illness, and the causes of the illness. An adapted version of this measure, the Illness Perception Questionnaire for Healthy People-Revised for Autism, was used to measure participants' illness perceptions related to ASD. For the purposes of this study, it will simply be referred to as the IPQ. The external attributions subscale used in this study was found to be reliable, $\alpha=.77$.

\section{Vignettes}

Four vignettes were used, two endorsing ABA and two endorsing SI (see Appendix A). The ABA- and SI-endorsing vignettes were created with and without jargon. See pilot study for more information on the reading level and comprehensibility of the vignettes. 
Equivalence of ABA and SI vignettes. There was no significant difference between the overall ratings for the reading level of the $\mathrm{ABA}$ and SI vignettes $t(419)=.57, p=.57$. Participant ratings of the comprehensibility of the ABA and SI vignettes were not significantly different $t(420)=.76, p=.45$.

Differences between the jargon and no-jargon versions. Participants rated the ABA vignette without jargon as having an average readability score of $2.80(S D=1.58)$ and the ABA vignette with jargon as having an average readability score of $4.15(S D=1.63)$. This difference was significant, $t(419)=-8.59, p \leq .001$. Participants rated the SI vignette without jargon as having an average readability score of $2.83(S D=1.73)$ and the SI vignette with jargon as having an average readability score of $3.99(S D=1.73), t(418)=-7.30, p \leq .001$. For comprehensibility, the ABA vignette without jargon had an average comprehensibility rating of $5.85(S D=1.11)$ and the ABA vignette with jargon had an average comprehensibility rating of $5.44(S D=1.37)$. These ratings were significantly different, $t(419)=3.41, p=.001$. The SI vignette without jargon had an average comprehensibility score of $5.81(S D=1.09)$ and the SI vignette with jargon had an average comprehensibility score of $5.40(S D=1.30)$. These ratings were significantly different $t(419)=3.47, p=.001$.

As in the pilot study, participants rated the vignettes in ways that indicated they perceived differences in comprehensibility and reading level between the jargon and non-jargon versions of the vignettes, but such differences were not found between the ABA and SI versions.

\section{Intervention Perceptions Rating Scale}

Participants were asked to rate their perceptions of the interventions' credibility, effectiveness, and ease of implementation, as well as their likelihood of implementing and recommending the intervention on a seven-point Likert scale with one being unlikely to 
recommend, implement, etc. and seven being very likely to recommend, implement etc. They were also asked about their familiarity with each intervention and its evidence base. Participants were asked if they know someone who received ABA or SI therapy and if so, if it was effective for that person. Additionally, participants were asked to describe the differences between the interventions (as an attention and manipulation check) and then answer a forced-choice question about which intervention they would use or recommend if they or a close friend or family member had a child with ASD. Participants were asked to rate the importance of intervention characteristics such as efficiency, cost, reduces symptoms, ease of implementation, decreases undesired behaviors, or increases desired behaviors to their decision-making (see Appendix C).

\section{ASD Experiences Questionnaire}

Participants were asked how many friends, direct and extended family members, and clients with ASD they have. They also were asked about their training, paid, and unpaid experiences related to ASD and how much time per week they spend with people with ASD (see Appendix B).

\section{Procedure}

Data were collected via an online Qualtrics survey. After the informed consent screen, participants were told they would be asked to answer questions about ASD, read about ASD interventions, and answer questions about ASD interventions. Participants were also informed they could leave the study at any time with no risk of repercussions. They were asked to verify that they were at least 18 years old.

After verifying their age and consenting to participate, participants were presented with two vignettes endorsing ABA or SI with or without jargon. They were randomly assigned to one of the four conditions (described in Chapter III, Table E-1). The order of presentation of ABA 
and SI vignettes was counterbalanced. After each vignette, participants completed the Intervention Perceptions Rating Scale for the intervention. Once they read both vignettes and completed the Intervention Perceptions Ratings Scales, participants were asked about the differences between the interventions, which intervention they would select if they had to pick only one, and the reasons why they selected that intervention. Next, participants were asked to complete the IPQ and then the Experiences with ASD scale. Finally, participants were asked demographic questions including age, race/ethnicity, and education level (see Appendix D). Upon completion of the demographics, they were thanked for their time and provided with more information about the rationale of the study, including a debriefing statement informing them that $\mathrm{ABA}$ is an evidence-based intervention for $\mathrm{ASD}$, but $\mathrm{SI}$ is not. Then, participants were directed to the MTURK page to enter the code needed to receive compensation. 


\section{CHAPTER V: RESULTS}

\section{Descriptive Statistics}

\section{Intervention Perceptions Rating Scale}

Approximately $23 \%$ of the sample reported knowing someone who had received ABA. Of those who knew someone who had received ABA, approximately $85 \%$ reported that it was effective for the person they knew. Nineteen percent of participants reported knowing someone who had received SI. Of those who knew someone who had received SI, approximately $84 \%$ reported that it was effective for the person they knew.

The results of a 2 (Experience: Experience vs. No Experience) x 2 (Intervention Choice: ABA vs. SI) ANOVA with ABA familiarity as a dependent variable revealed main effects of Experience $[F(1,419)=49.02, p<.001]$ and Intervention Choice $[F(1,419)=6.46, p=.01]$. No significant two-way interaction was found $(\mathrm{F} \approx 1)$. Participants who chose ABA had higher ratings of familiarity with ABA, as were participants with ASD experience. A 2 (Experience: Experience vs. No Experience) x 2 (Intervention Choice: ABA vs. SI) ANOVA with SI familiarity as a dependent variable revealed main effects of Experience $[F(1,419)=46.07, p<$ $.001]$ and Intervention Choice $[F(1,419)=16.85, p=.01]$. No significant two-way interaction was found $(\mathrm{F} \approx 1)$. Participants who chose SI had higher ratings of familiarity with SI, as did participants with ASD experience.

After selecting one of the interventions, participants were also asked to rate the importance of seven factors as influencing their forced-choice decision (i.e., efficiency, cost, ease of implementation, works best, reduces symptoms, increases desired behaviors, and decreases undesired behaviors). There was a significant difference in ratings of the importance of 
ease of implementation for participants who had no experience with ASD $(M=6.57, S D=2.75)$ and participants who had experience $(M=5.66, S D=2.85)$, where a higher rating indicates $($ easier to implement?), $t(419)=3.32, p=.001$. No other significant differences in ratings were found. See Table E-2 for all means and standard deviations.

\section{ASD Experiences Questionnaire}

Approximately $22 \%$ of the sample reported having a direct family member with ASD, and $30 \%$ had an extended family member with ASD. Approximately $56 \%$ of participants reported knowing someone with ASD (e.g., friend, neighbor), and approximately $30 \%$ had worked with a client or student with ASD. Twenty-four percent of participants had some type of training experience related to ASD, approximately $17 \%$ had some type of paid experience, and approximately $11 \%$ had some type of unpaid experience with ASD (not including having a child with ASD or having ASD themselves). Fifty-six percent of participants currently (within the last three months) did not spend any time per week with individuals with ASD.

Based on responses to the Autism Experiences Questionnaire, participants were dichotomized into one of two groups: Experience and No Experience. Participants were considered to have experience if they (a) had an ASD diagnosis, (b) had a child or other immediate family member with ASD, or (c) currently spent any amount of time per week with people with ASD. All other participants were place in the No Experience category. Although participants in this category might have had some ASD-related training or incidental contact with people with ASD, the intent was to have people in the Experience category who might be in a position to evaluate ASD interventions and who might know something about the interventions already. Because ASD has a high prevalence rate (CDC, 2014), individuals currently in the No 
Experience category might be in a position to evaluate intervention in the future. For example, a person in the No Experience category might have a child someday who is diagnosed with ASD.

\section{Hypothesis Testing: Jargon and ASD Experience}

My first set of hypotheses was that the use of jargon (jargon vs. no jargon) would affect participants' ratings of the (a) efficacy and (b) credibility of ABA and SI, as well as their (c) likelihood of implementing the intervention, (d) perceived ease of implementation, and (e) whether they would recommend the interventions. I also hypothesized that the effects of jargon would be different depending on whether participants had previous experience with ASD. Note that none of these hypotheses consider the possibility of order effects, so only the ratings of the first vignette that participants read are considered in these analyses.

To test this set of predictions outlined in Chapter III, I ran a 2 (Experience: Experience vs. No Experience) x 2 (Jargon: No Jargon vs. Jargon) x 2 (Intervention: ABA vs. SI) MANOVA on the ratings of five variables of interest. I found a significant multivariate main effect for jargon [Wilks' Lambda $=.022, F(5,421)=2.67, p=.02, \eta \mathrm{p}^{2}=.03$ ]. Participants rated interventions as more effective $\left[F(1,421)=5.31, p=.02, \eta \mathrm{p}^{2}=.01\right]$, credible $[F(1,421)=7.66, p$ $\left.=.02 . \eta p^{2}=.02\right]$, and easier to implement $\left[F(1,421)=8.50, p=.004, \eta p^{2}=.02\right]$ when the intervention was described without jargon. They also rated themselves as being more likely to implement $\left[F(1,421)=8.31, p=.004, \eta p^{2}=.02\right]$ and recommend $\left[F(1,421)=4.78, p=.03, \eta p^{2}=\right.$ $.01]$ interventions described without jargon. There was also a significant main effect of intervention type [Wilks' Lambda $\left.=.962, F(5,421)=3.26, p=.007, \eta p^{2}=.04\right]$. All else being equal, participants reported they would be more likely to implement $[F(1,421)=10.87, p=.001$, $\left.\eta \mathrm{p}^{2}=.03\right]$ and recommend $\left[F(1,421)=4.40, p=.04, \eta \mathrm{p}^{2}=.01\right] \mathrm{ABA}$ as compared to SI. 
I predicted that the effects of jargon on the five different ratings would be different depending on whether participants had previous experience with ASD. There was no main effect of Experience [Wilks' Lambda $=.991, F(5,421)=.78, p=.56, \eta p^{2}=.009$ ]. Additionally, there were no significant interactions between Jargon and Experience [Wilks' Lambda $=.988, F(5$, $\left.421)=.95, p=.46, \eta p^{2}=.01\right]$.

a. Intervention Effectiveness. I predicted a three-way interaction among Experience, Jargon, and Intervention Type (see Figure 4 for predicted pattern of results).

There was no significant three-way interaction, $F(1,413)=0.05, p=.83, \eta p^{2}<$ .001 . Additionally, none of the two-way interactions were significant (all F's $\approx 1$ ). This hypothesis was not supported (see Figure 10 for actual pattern of results).

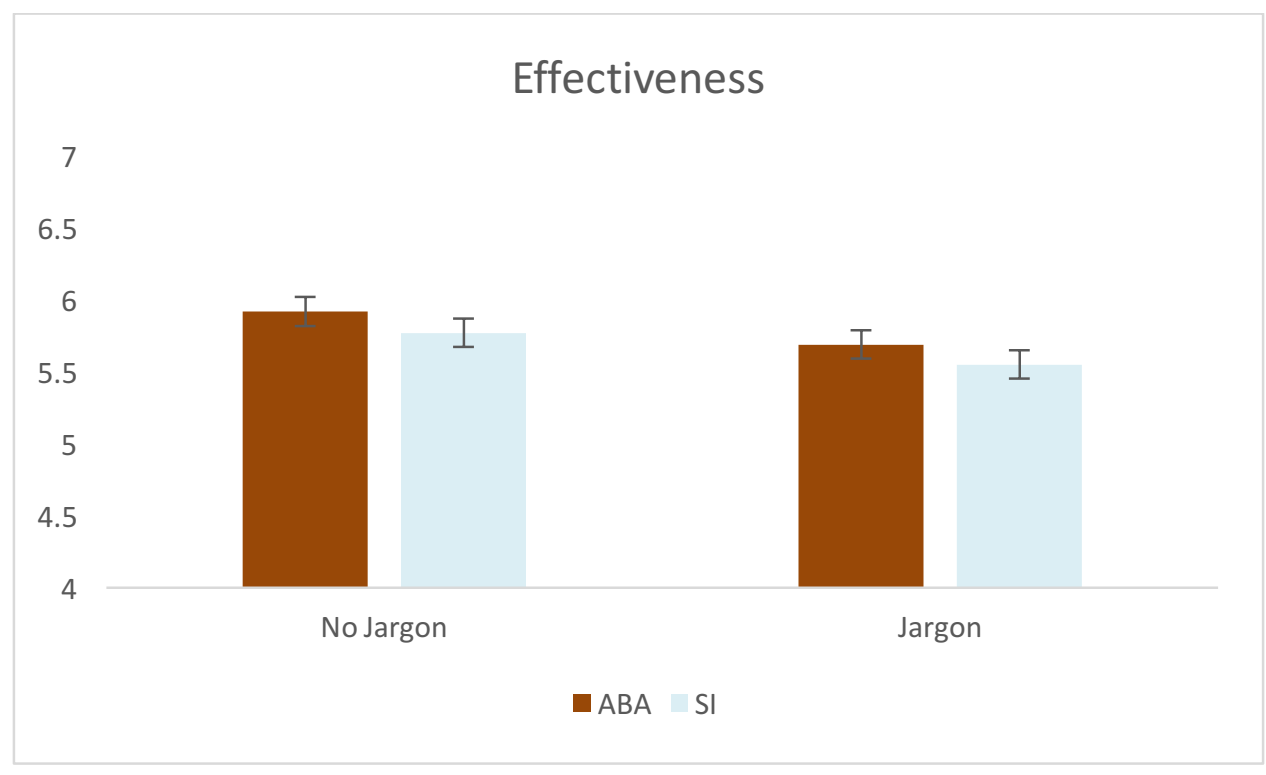

Figure 10. Participant ratings of the effectiveness of interventions. Only a main effect of Jargon was found; none of the predicted interactions with Experience or Intervention Type were found. Because experience had no effect on participant ratings, nor interacted with any of the other variables, it was omitted from the figure. Bars on each column indicate the standard error.

b. Credibility. I predicted a three-way interaction among Experience, Jargon, and Intervention Type (see Figure 5 for predicted pattern of results). There was no 
significant three-way interaction, $F(1,413)=.01, p=.93, \eta \mathrm{p}^{2}<.001$.

Additionally, none of the two-way interactions were significant (all F's $\approx 1$ ). This hypothesis was not supported (see Figure 11 for actual pattern of results).

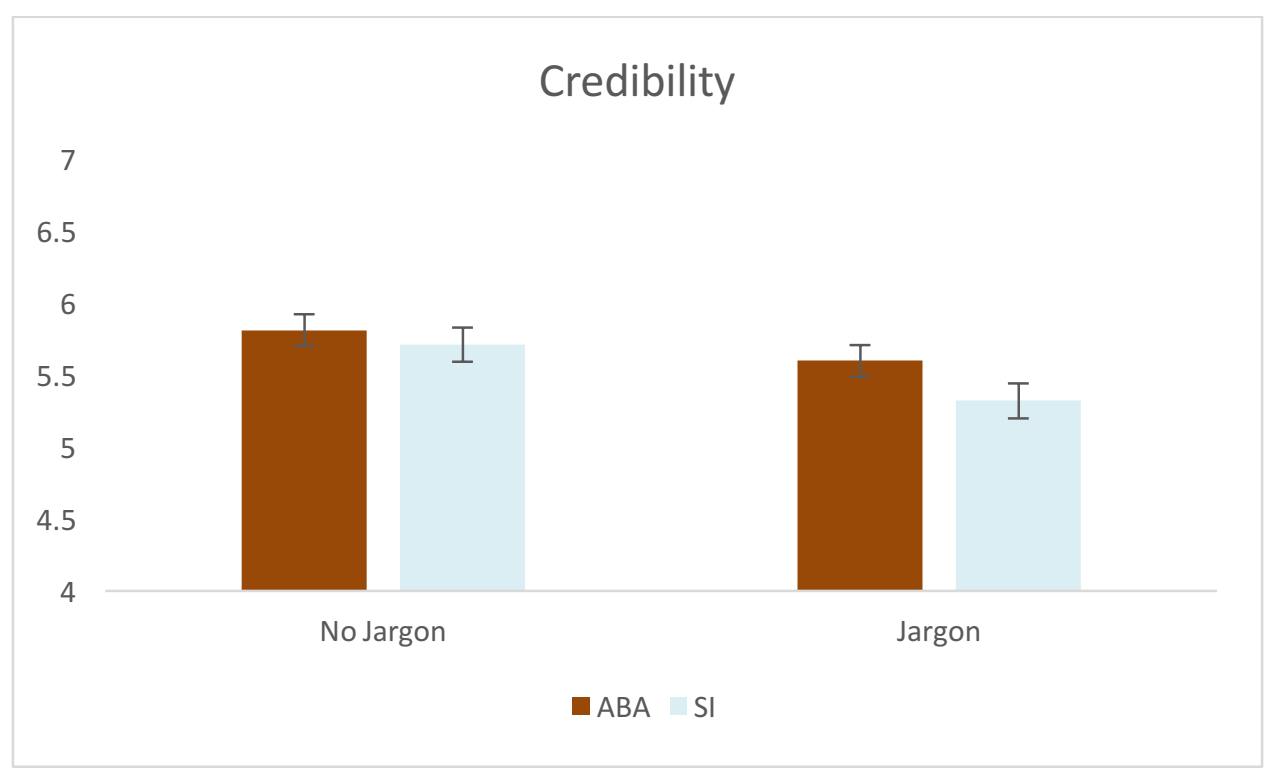

Figure 11. Participant ratings of the credibility of interventions. Only a main effect of Jargon was found; none of the predicted interactions with Experience or Intervention Type were found. Because experience had no effect on participant ratings, nor interacted with any of the other variables, it was omitted from the figure. Bars on each column indicate the standard error.

c. Likelihood of Implementation. I predicted a three-way interaction among Experience, Jargon, and Intervention Type (see Figure 6 for predicted pattern of results). There was no significant three-way interaction, $F(1,413)=.51, p=.48$, $\eta \mathrm{p}^{2}<.001$. Additionally, none of the two-way interactions were significant (all F's $\approx 1$ ). This hypothesis was not supported (see Figure 12 for actual pattern of results). 


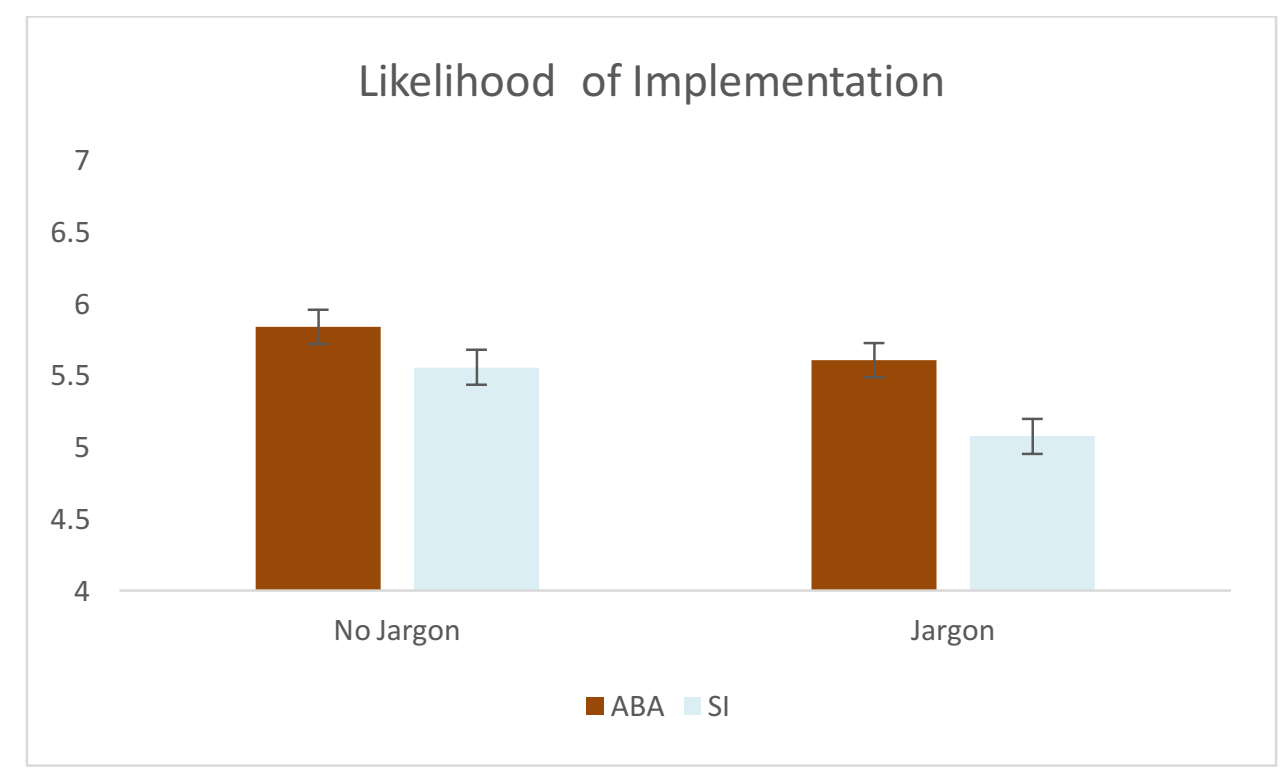

Figure 12. Participant ratings of their likelihood of implementing the interventions. Main effects of Jargon and Intervention Type were found; none of the predicted interactions with Experience or Intervention Type were found. Because experience had no effect on participant ratings, nor interacted with any of the other variables, it was omitted from the figure. Bars on each column indicate the standard error.

d. Ease of Implementation. I predicted a three-way interaction among Experience, Jargon, and Intervention Type (see Figure 7 for predicted pattern of results). There was no significant three-way interaction, $F(1,413)=.25, p=.62, \eta p^{2}<$ .001. Additionally, none of the two-way interactions were significant (all F's $\approx 1$ ). This hypothesis was not supported (see Figure 13 for actual pattern of results). 


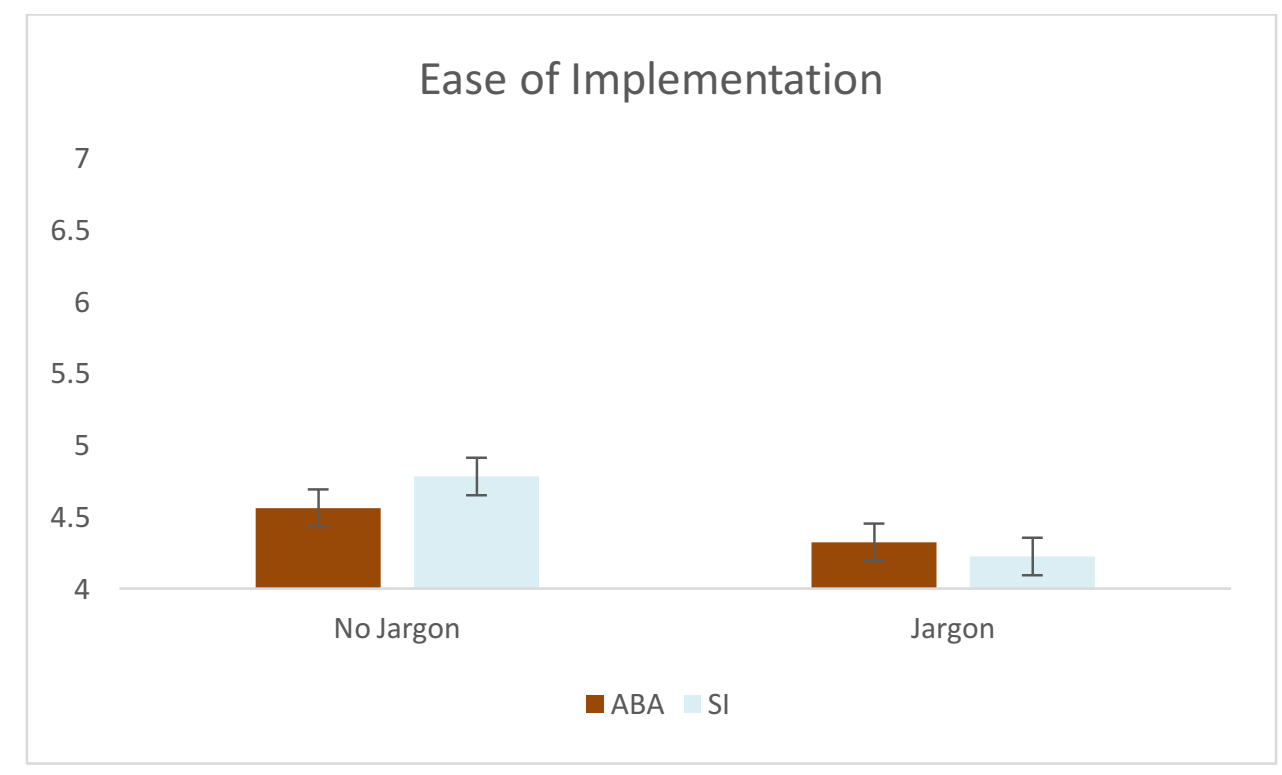

Figure 13. Participant ratings of the ease of implementing the interventions. Only a main effect of Jargon was found; none of the predicted interactions with Experience or Intervention Type were found. Because experience had no effect on participant ratings, nor interacted with any of the other variables, it was omitted from the figure. Bars on each column indicate the standard error.

e. Likelihood of recommendation. I predicted a three-way interaction among Experience, Jargon, and Intervention Type (see Figure 8 for predicted pattern of results). There was no significant three-way interaction, $F(1,413)=.08, p=.78$, $\eta \mathrm{p}^{2}<.001$. Additionally, none of the two-way interactions were significant (all F's $\approx 1$ ). This hypothesis was not supported (see Figure 14 for actual pattern of results). 


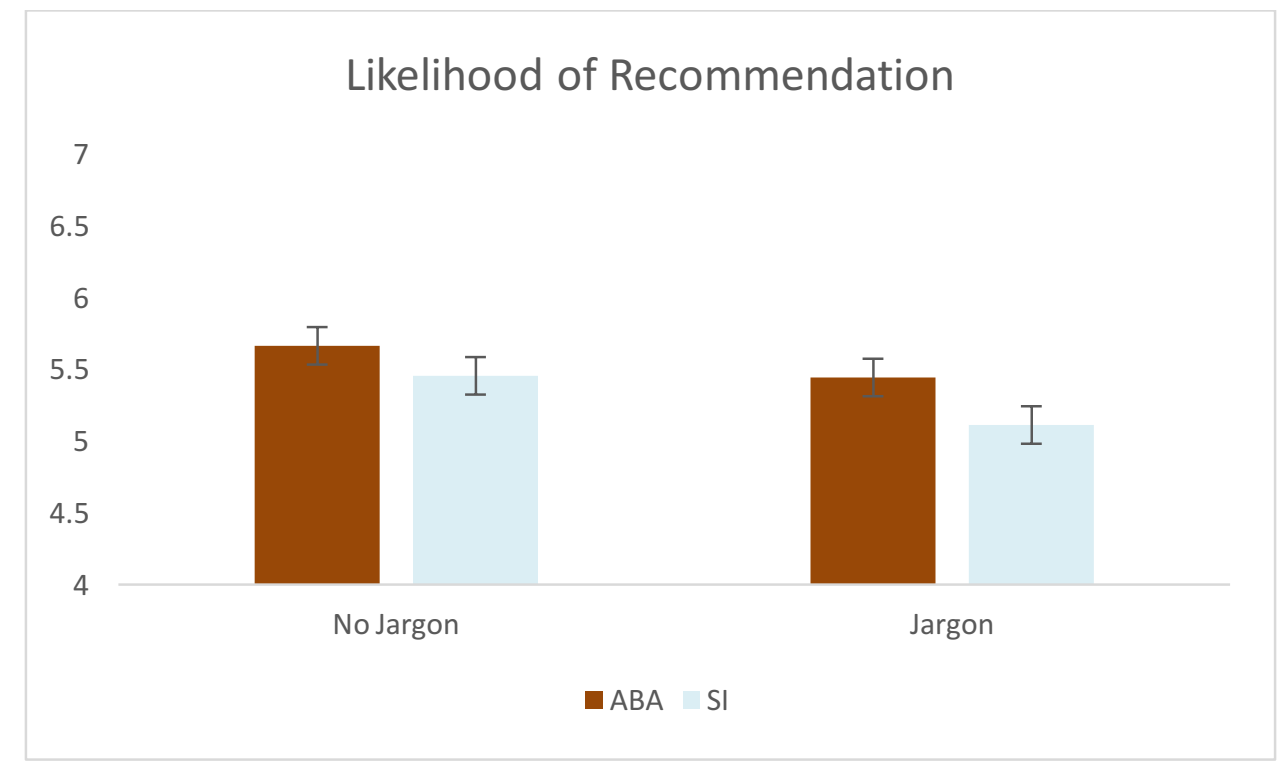

Figure 14. Participant ratings of their likelihood of recommending the interventions. Main effects of Jargon and Intervention Type were found; none of the predicted interactions with Experience or Intervention Type were found. Because experience had no effect on participant ratings, nor interacted with any of the other variables, it was omitted from the figure. Bars on each column indicate the standard error.

\section{Hypothesis Testing: Order Effects}

My second set of hypotheses involved order effects, as they were evident in the pilot study. I predicted that participants would rate the first intervention they read about more favorably. I also hypothesized this effect would be exaggerated for participants who read a nonjargon vignette followed by a jargon vignette. I ran a series of mixed ANOVAs with Intervention Type as a repeated-measures variable and Survey Version and Order as between-subjects variables. Survey Version was used to examine the effects of reading a jargon vignette in the context of having read a non-jargon vignette and vice versa and to consider order effects when both vignettes are described with or without jargon.

a. I hypothesized that participants would rate the first intervention they read about as more effective. A 2 (Intervention: ABA vs. SI) x 4 (Survey Version: No Jargon; Both Jargon; ABA-Jargon-SI-NoJargon; ABA-NoJargon; SI- 
Jargon) x 2 (Order: ABA first vs. SI first) mixed ANOVA was conducted on ratings of effectiveness. There was a significant within-subjects main effect of Intervention, $F(1,413)=13.88, p<.001, \eta \mathrm{p}^{2}=.03$. There were significant two-way interactions between Intervention and Survey Version $[F(1,413)=$ $\left.3.49, p=.02, \eta p^{2}=.03\right]$ and between Intervention and Order $[F(1,413)=$ $\left.42.39, p<.001, \eta p^{2}=.09\right]$. There was no significant three-way interaction among Intervention, Survey Version, and $\operatorname{Order}(\mathrm{F} \approx 1)$.

However, consistent with my hypothesis, ABA was rated as significantly more effective when read first in three of the four Survey Versions (see top panel of Figure 15). Simple effects of Order were evident when both ABA and SI were described without jargon [Wilks' Lambda = $\left..934, F(1,413)=29.05, p<.001, \eta p^{2}=.07\right]$, when both interventions were described using jargon [Wilks' Lambda $=.974, F(1,413)=11.13, p=.001, \eta p^{2}=.03$ ], and when ABA was described without jargon and SI was described with jargon [Wilks' Lambda $=.954, F(1,413)=$ $\left.20.00, p<.001, \eta p^{2}=.05\right]$. There was no significant difference when ABA was described with jargon and SI was described without $(F \approx 1)$. Also consistent with my hypothesis, when SI was read first and described without jargon and then ABA was described using jargon, participants rated it as significantly more effective [Wilks' Lambda $=.982, F(1,413)=7.45, p=.007, \eta p^{2}=$ .02]. No other significant differences for Order were found when SI was read first (all F's $\approx 1$; see bottom panel of Figure 15). This hypothesis was partially supported. 

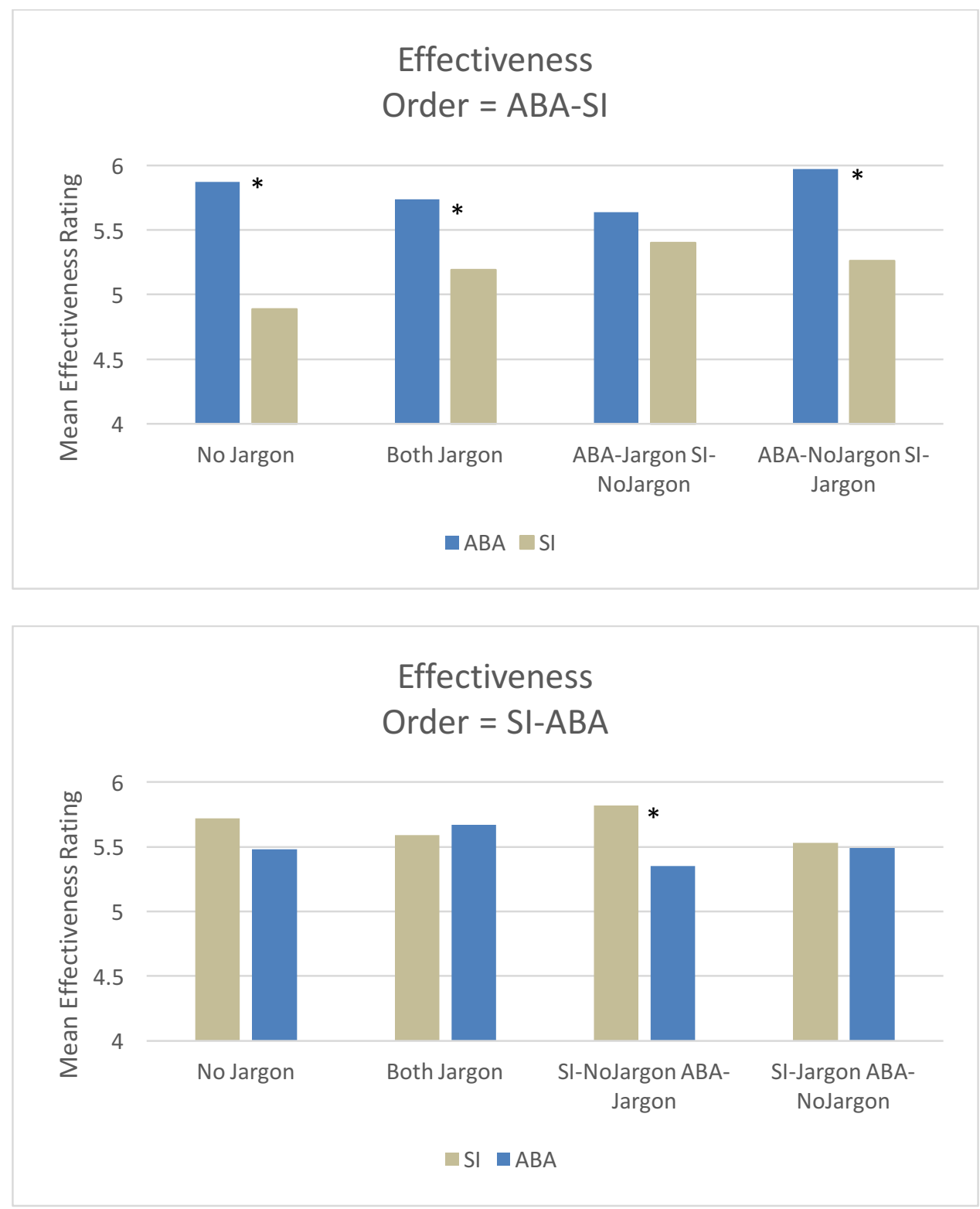

Figure 15. Mean ratings of whether an intervention would be perceived as effective as a function of Order, Intervention, and Survey Version. The top panel shows the mean ratings for whether an intervention is effective when ABA was presented first (blue bars); the bottom panel shows the means when SI was presented first (grey bars). Although the means for the full 2 (Jargon) x 4 (Survey Version) x 2 (Intervention) design are shown, only the two-way interactions between Intervention and Survey version and between Intervention and Order were significant. An asterisk (*) indicates a significant simple effects difference between means.

b. I hypothesized that participants would be more likely to rate the intervention they read about first as more credible. A 2 (Intervention: ABA vs. SI) x 4 (Survey Version: No Jargon; Both Jargon; ABA-Jargon-SI-NoJargon; ABA- 
NoJargon; SI-Jargon) x 2 (Order: ABA first vs. SI first) mixed ANOVA was conducted on ratings of credibility. There was a significant main effect of Intervention, $F(1,413)=26.37, p<.001, \eta \mathrm{p}^{2}=.06$. There were also significant interactions between Intervention and Survey Version $[F(1,413)=4.68, p=$ $\left..003, \eta p^{2}=.03\right]$ and between Intervention and Order $[F(1,413)=33.80, p<$ $\left..001, \eta \mathrm{p}^{2}=.08\right]$. These effects were qualified by a significant three-way interaction among Intervention, Survey Version, and Order, $F(3,413)=2.88$, $p=.04, \eta p^{2}=.02$. There were no other significant between-subjects main effects or interactions (all F's $\approx 1$ ).

Consistent with my prediction, ABA was rated as significantly more credible in three of the four Survey Versions (see top panel of Figure 16). Simple effects of Order were evident when ABA was read first and both it and SI were described without jargon [Wilks' Lambda= $\left..932, F(1,413)=30.19, p<.001, \eta p^{2}=.07\right]$, when both interventions were described using jargon [Wilks' Lambda $=.956, F(1,413)=18.87, p<.001, \eta \mathrm{p}^{2}=.04$ ], and when ABA was described without jargon and SI was described with jargon [Wilks' Lambda $=.957, F(1,413)=$ $\left.18.49, p<.001, \eta p^{2}=.04\right]$. There was no significant difference when ABA was described with jargon and SI was described without $(\mathrm{F} \approx 1)$. Also consistent with my hypothesis, when SI was read first and described without jargon and ABA was described using jargon, participants rated it as significantly more credible [Wilks' Lambda $=.990, F(1,413)=4.36, p=.04, \eta p^{2}=.04$ ]. Inconsistent with my hypothesis, and the opposite of what I predicted, when SI was read first and both interventions were described with jargon, SI was rated as significantly less credible [Wilks' Lambda $\left.=.984, F(1,413)=6.53, p=.01, \eta p^{2}=.02\right]$. No other significant differences were found 
when SI was read first (all F's $\approx 1$; see bottom panel of Figure 16). This hypothesis was partially supported.
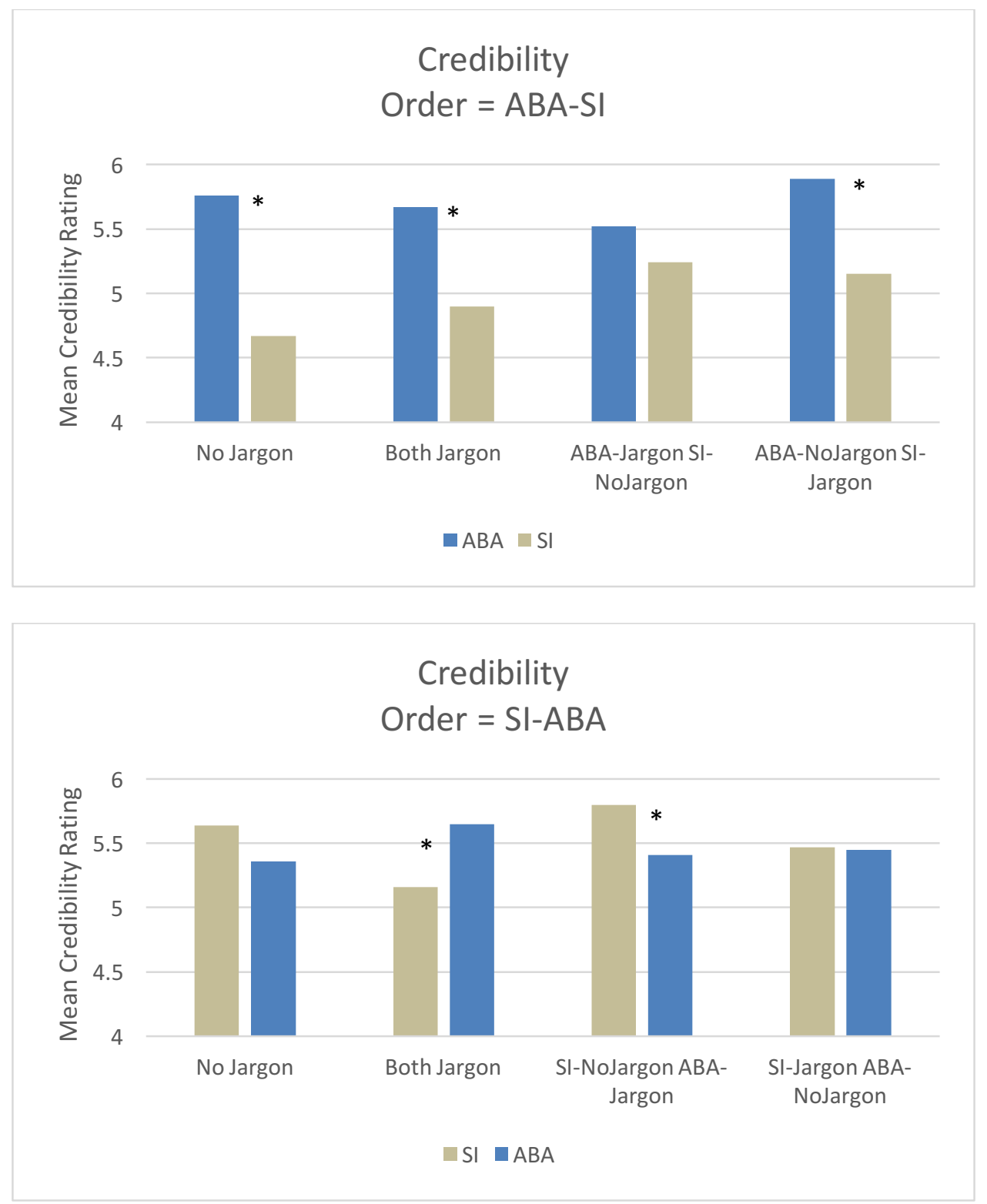

Figure 16. Mean ratings of whether an intervention would be perceived as credible as a function of Order, Intervention, and Survey Version. The top panel shows the mean ratings for whether an intervention is rated as credible when ABA was presented first; the bottom panel shows the means when SI was presented first. An asterisk (*) indicates a significant simple effects difference between means.

c. I hypothesized that participants would rate themselves as more likely to recommend the intervention they read about first. A mixed ANOVA with 
Intervention Type as a repeated measures variable and Survey Version and Order as between-subjects variables was conducted on ratings of likelihood of recommendation. There was a significant within-subjects main effect of Intervention, $F(1,413)=11.33, p=.001, \eta p^{2}=.03$. There were also significant interactions between Intervention and Survey Version $[F(1,413)=3.99, p=$ $\left..008, \eta p^{2}=.03\right]$ and between Intervention and Order $[F(1,413)=26.31, p<$ $\left..001, \eta \mathrm{p}^{2}=.06\right]$. There was also a marginally significant three-way interaction among Intervention, Survey Version, and Order $\left[F(3,413)=2.38, p=.07, \eta p^{2}\right.$ $=.02]$. There were no other significant between-subjects main effects or interactions (all $F \mathrm{~s} \approx 1)$.

Consistent with my hypothesis, participants rated themselves as being significantly more likely to recommend ABA in three of the four Survey Versions (see top panel of Figure 17). Simple effects of Order were evident when ABA was read first and both it and SI were described without jargon [Wilks' Lambda $\left.=.96, F(1,413)=17.09, p<.001, \eta p^{2}=.04\right]$, when both interventions were described using jargon [Wilks' Lambda $=.99, F(1,413)=5.04, p=.03, \eta p^{2}=$ .01] and when ABA was described without jargon and SI was described with jargon [Wilks' Lambda $\left.=.96, F(1,413)=17.43, p<.001, \eta p^{2}=.04\right]$. There was no significant difference when ABA was described with jargon and SI was described without $(\mathrm{F} \approx 1)$. Also consistent with my hypothesis, when SI was read first and described without jargon and ABA was described using jargon, participants rated themselves as being significantly more likely to recommend it [Wilks' Lambda $\left.=.975, F(1,413)=10.81, p=.001, \eta p^{2}=.03\right]$. No other significant differences were found when SI was read first (all F's $\approx 1$; see bottom panel of Figure 17). This hypothesis was partially supported. 

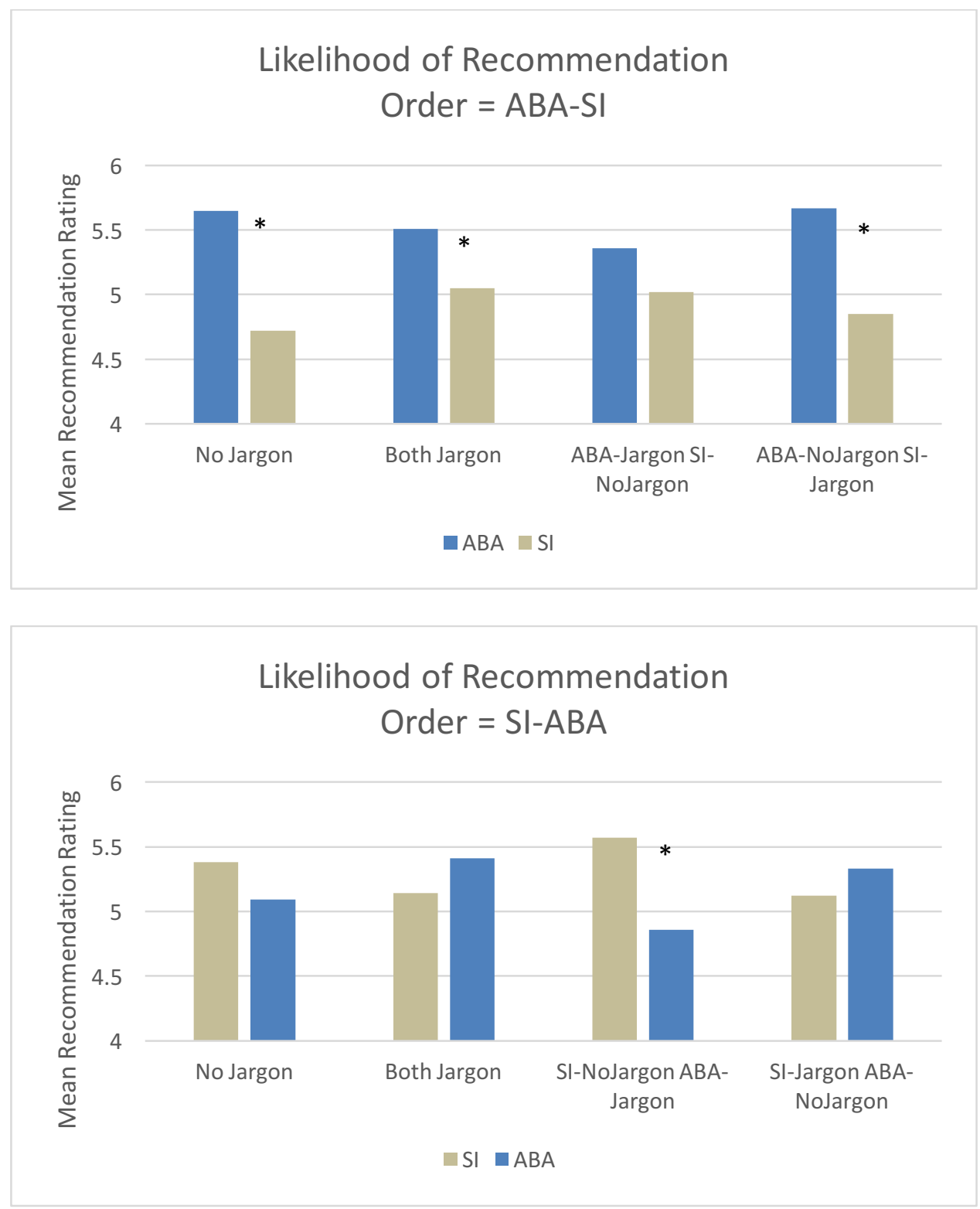

Figure 17. Mean ratings of whether an intervention would be recommended as a function of Order, Intervention, and Survey Version. The top panel shows the mean ratings when ABA was presented first; the bottom panel shows the means when SI was presented first. An asterisk (*) indicates a significant simple effects difference between means.

d. I hypothesized that participants would be more likely to select the first intervention they read about when presented with a forced-choice question regarding which intervention they would pick if they had a child with ASD or were being asked to recommend an intervention for a friend's child. To test 
this hypothesis, I conducted a chi-square test of association to determine if the proportion of people who select an intervention depends on the order of presentation. Participants were significantly more likely to choose the intervention they read about first, $X^{2}(1, N=420)=33.49, p \leq .001$. When ABA was read about first, approximation $63 \%(n=153)$ of participants chose it. Approximately $66 \%(n=116)$ of participants selected SI when they read about it first. This hypothesis was supported.

\section{Hypothesis Testing: Correlations with External Cause}

My third hypothesis was that participants' ratings of the interventions would be correlated with their perceptions of ASD as a disorder, specifically the extent to which it has an external cause.

a. I hypothesized that participants' ratings of the effectiveness of SI would be positively correlated with their perceptions of ASD as having an external cause. To test this hypothesis, I correlated participants' ratings of the effectiveness of SI with perceptions of the external factors as causing ASD (a composite score of items three, six, seven, and eighteen on the causes subscale of the IPQ). This hypothesis was not supported $(r=-.05, p=.29)$.

b. I hypothesized that participants' ratings of the effectiveness of ABA would be negatively correlated with their perceptions of ASD as having an external cause. To test this hypothesis, I correlated participants' ratings of the effectiveness of ABA with perceptions of external factors as causing ASD. This hypothesis was not supported $(r=-.08, p=.12)$. 
c. I hypothesized that participants' ratings of the credibility of SI would be positively correlated with their perceptions of ASD having an external cause. To test this hypothesis, I correlated participants' ratings of the credibility of SI with perceptions of external factors as causing ASD. This hypothesis was not $\operatorname{supported}(r=-.05, p=.35)$.

d. I hypothesized that participants' ratings of the credibility of ABA would be negatively correlated with their perceptions of ASD having an external cause. To test this hypothesis, I correlated participants' ratings of the credibility of ABA with perceptions of external factors as causing ASD. This hypothesis was not supported $(r=-.05, p=.30)$.

e. I hypothesized that ratings of likelihood to recommend SI would be positively correlated with perceptions of ASD having an external cause. To test this hypothesis, I correlated participants' ratings of their likelihood of recommending SI with perceptions of external factors as causing ASD. This hypothesis was not supported $(r=-.08, p=.12)$.

f. I hypothesized that ratings of likelihood to recommend ABA would be negatively correlated with perceptions of ASD having an external cause. To test this hypothesis, I correlated participants' ratings of their likelihood of recommending ABA with perceptions of external factors as causing ASD. This hypothesis was not supported $(r=-.03, p=.57)$.

\section{Exploratory Analyses}

To better understand whether experience with ASD interacts with the other variables, a 2 (Experience: Experience vs. Experience) x 2 (Order: ABA First vs. SI First) x 4 (Survey 
Version: No Jargon; Both Jargon; ABA-Jargon-SI-NoJargon; ABA-NoJargon; SI-Jargon)

MANOVA was conducted on the ratings of five variables of interest. Difference scores were computed for this analysis (i.e., rating ABA $_{-}$rating ${ }_{\mathrm{SI}}$ ). Scores above zero indicate a preference for ABA over SI and scores below zero indicating a preference for SI over ABA (scores near zero represent that neither intervention is preferred). Because main effects of Order and Survey Version were described in the analyses for Hypothesis 2, only the effects involving Experience will be described here.

There was an interaction between Survey Version and Experience [Wilks' Lambda $=.99$, $F(5,401)=1.73, p=.04]$. This effect was evident for participants' ratings of intervention credibility $[F(3,413)=2.64, p=.05]$ and their likelihood of implementation $[F(3,413)=3.52, p$ $=.02]$. There was also a marginally significant interaction between Survey Version and Experience for participants' likelihood of recommendation $[F(3,413)=2.52, p=.06]$. There were no other significant interactions between Survey Version and Experience (all $F^{\prime} \mathrm{s} \approx 1$ ).

Simple effects of Experience were evident when ABA was described without jargon and SI was described with jargon such that participants with no experience rated ABA as more effective $[F(1,405)=5.96, p=.02]$, credible $[F(1,405)=9.38, p=.002]$, and easy to implement than SI $[F(1,405)=4.71, p=.03]$. When ABA was described without jargon and SI was described with jargon, participants with no experience also reported being more likely to implement $[F(1,405)=8.41, p=.004]$ and recommend $[F(1,405)=8.37, p=.004]$ ABA than SI. See Figures 18-22 for all difference scores. 


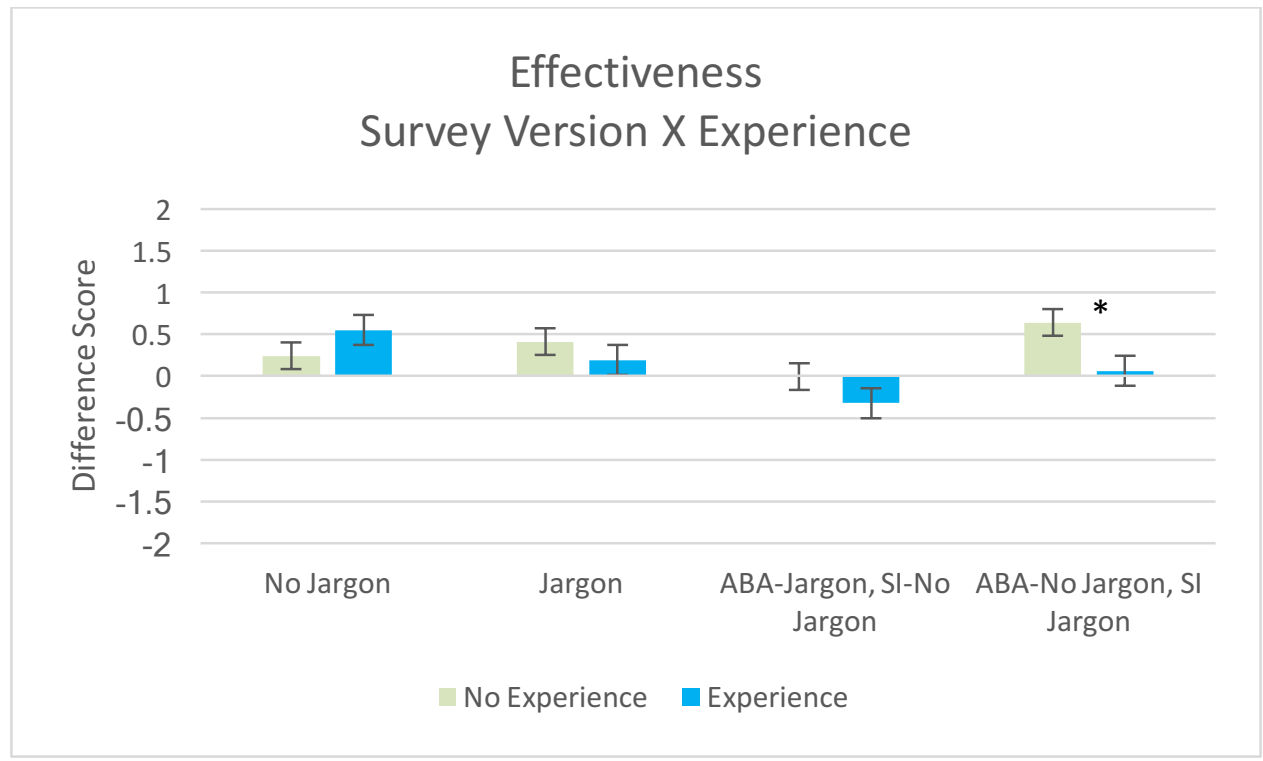

Figure 18. Difference scores indicating higher effectiveness rating for ABA (positive numbers) and SI (negative numbers) based on survey version received and participants' previous ASD Experience. An asterisk (*) indicates a significant simple effects difference between means.

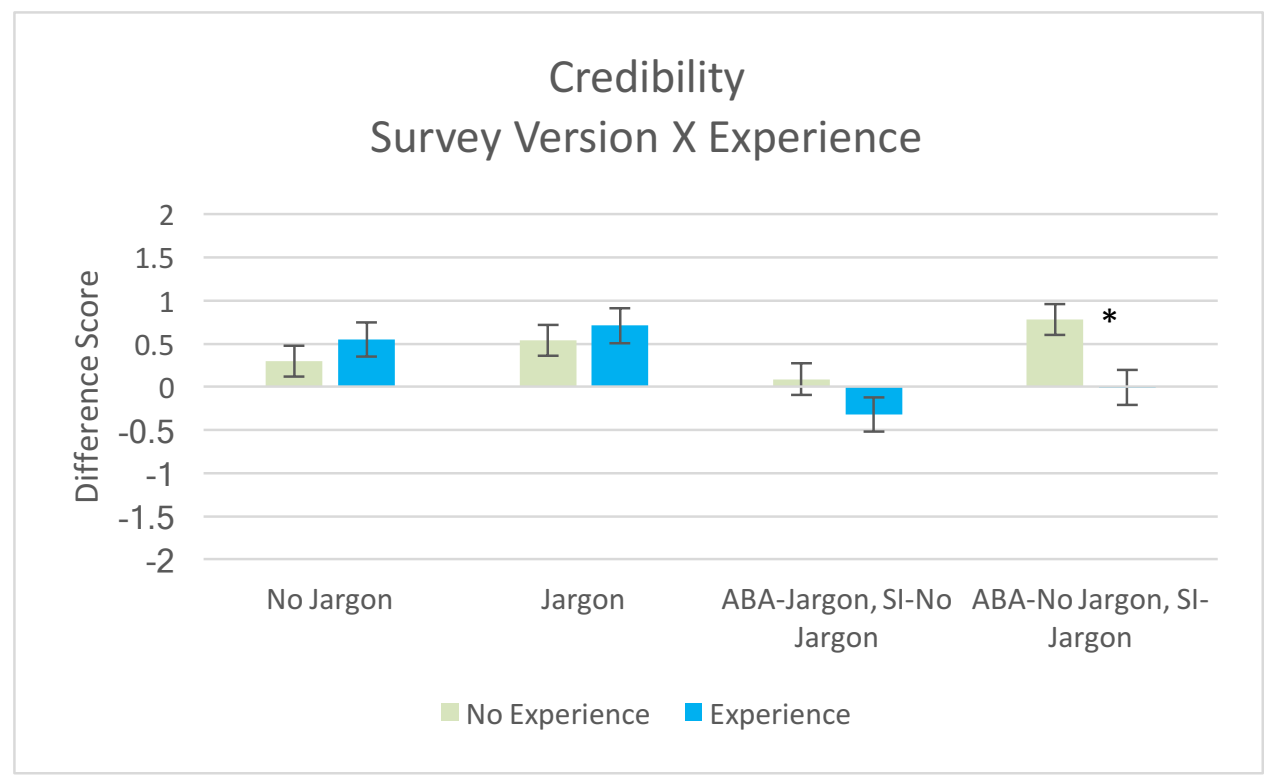

Figure 19. Difference scores indicating higher credibility rating for ABA (positive numbers) and SI (negative numbers) based on survey version received and participants' previous ASD Experience. An asterisk (*) indicates a significant simple effects difference between means. 


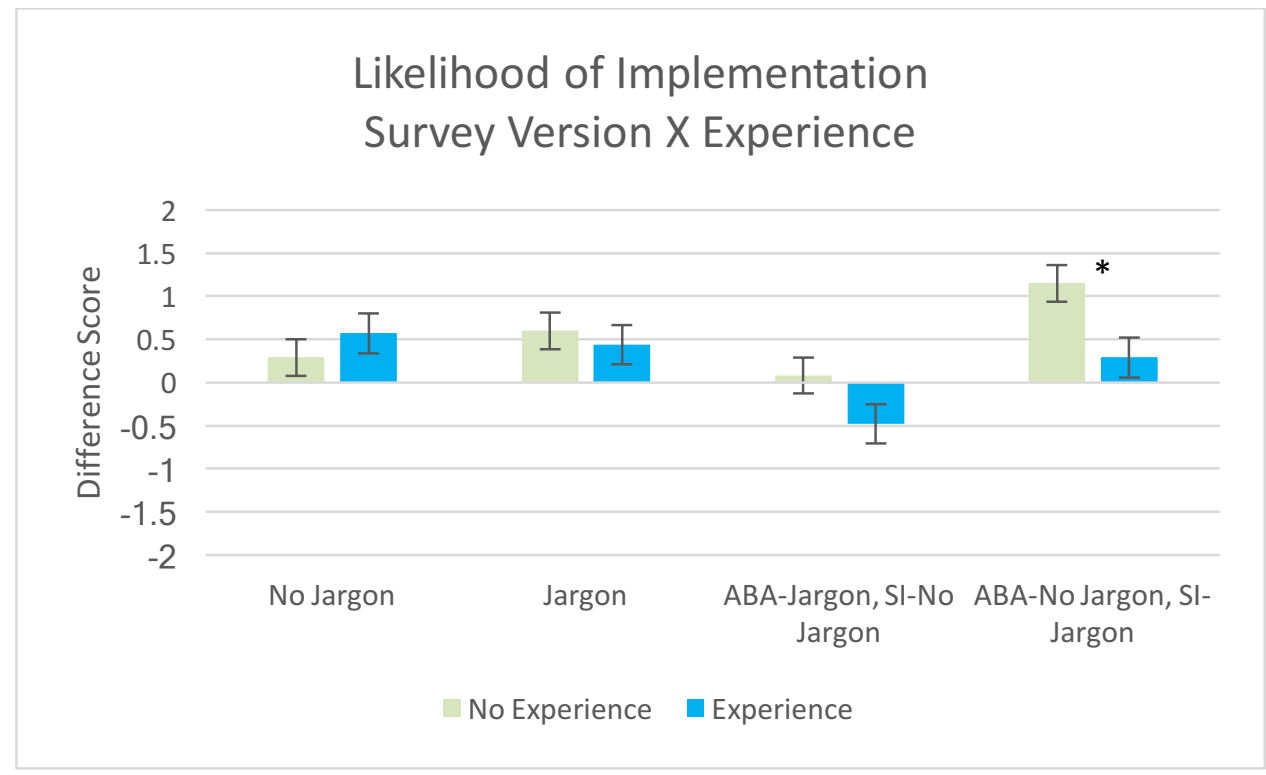

Figure 20. Difference scores indicating higher likelihood of implementation rating for ABA (positive numbers) and SI (negative numbers) based on survey version received and participants' previous ASD Experience. An asterisk (*) indicates a significant simple effects difference between means. The difference between the two experience groups for the survey version including $\mathrm{ABA}$ with jargon and SI without jargon was marginally significant $(p=.08)$.

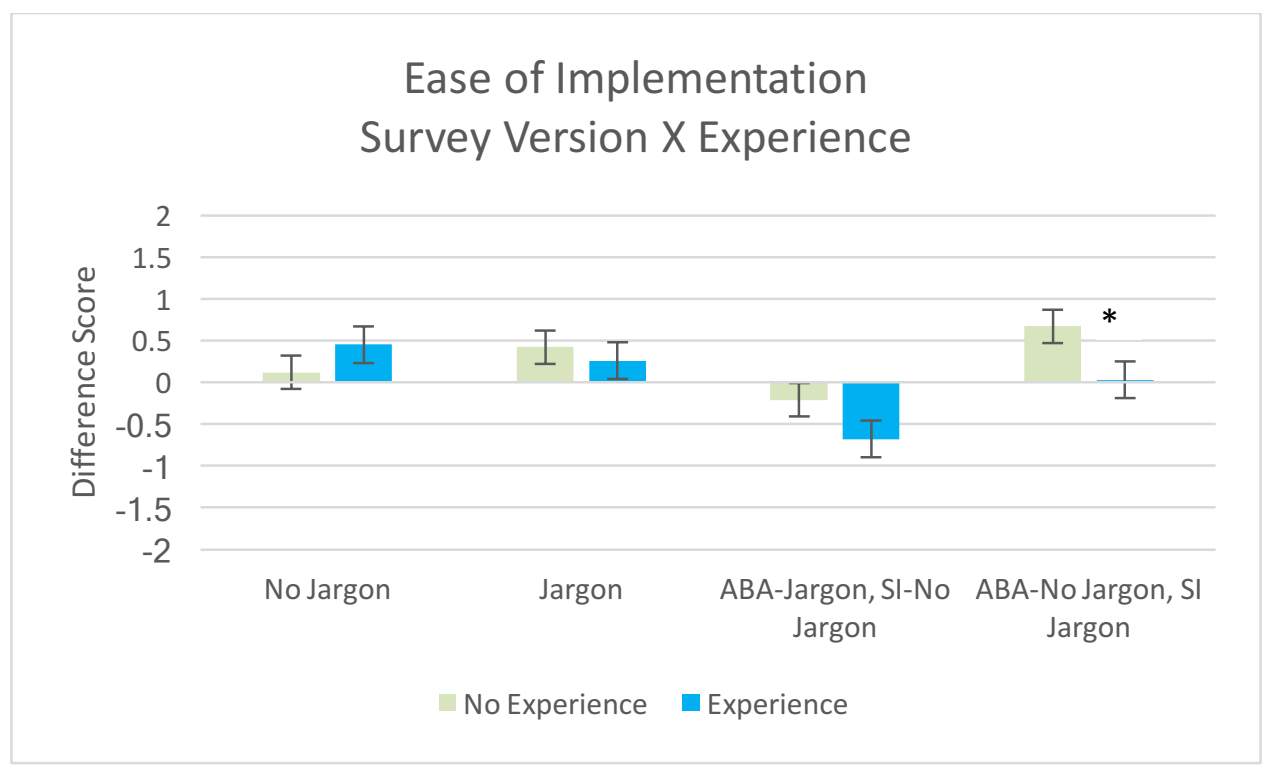

Figure 21. Difference scores indicating higher ease of implementation rating for ABA (positive numbers) and SI (negative numbers) based on survey version received and participants' previous ASD Experience. An asterisk (*) indicates a significant simple effects difference between means. 


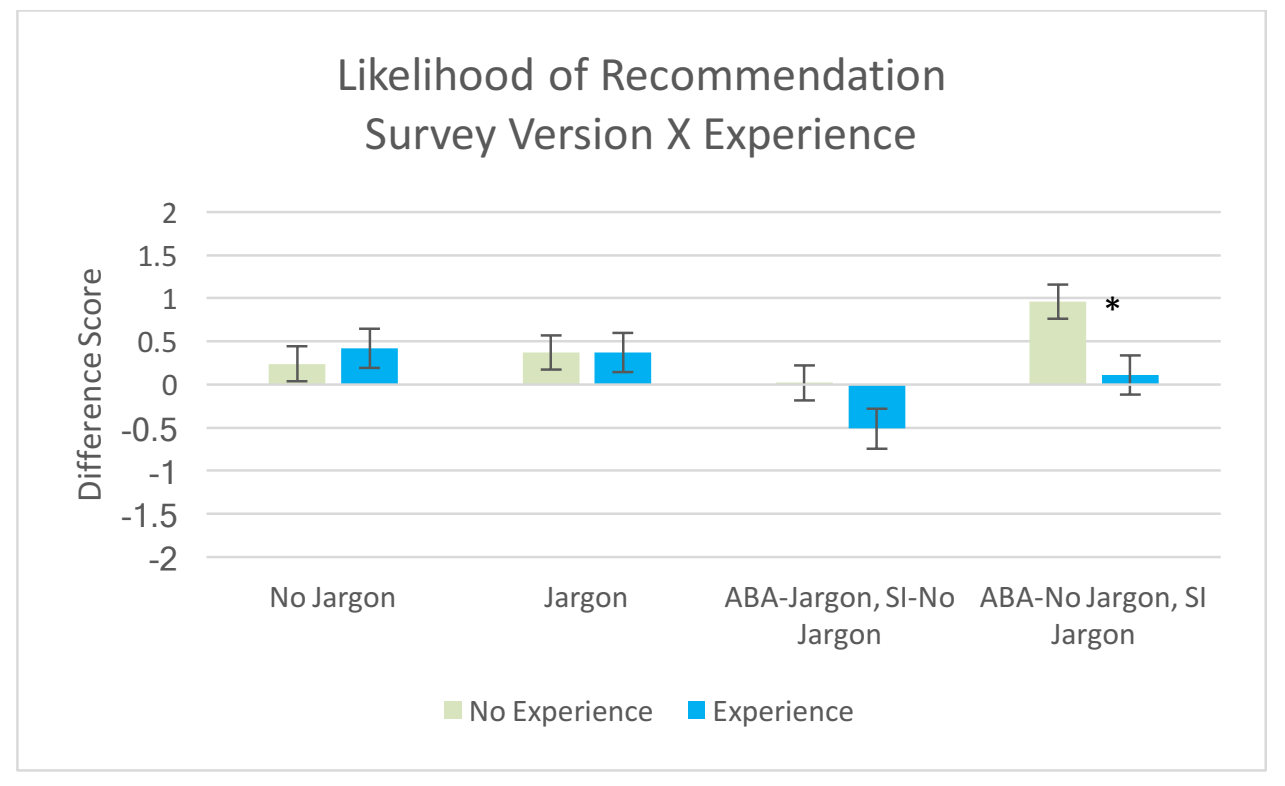

Figure 22. Difference scores indicating higher likelihood of recommendation rating for ABA (positive numbers) and SI (negative numbers) based on survey version received and participants' previous ASD Experience. An asterisk (*) indicates significant simple effects difference between means. The difference between the two experience groups for the survey version including ABA with jargon and SI without jargon was marginally significant $(p=.09)$. 


\section{CHAPTER VI: CONCLUSIONS}

\section{General Discussion}

The reported incidence rate of ASD has increased over the past 15 years (CDC, 2014). This increase has been accompanied by the emergence of many interventions designed to address ASD, either by reducing associated symptoms or attempting to "cure" the disorder (Green et al., 2006). Previous researchers have examined factors that influence how people make intervention decisions for children with ASD (e.g., Al Anbar et al., 2010; Green, 2007; Hebert, 2014). Previously identified predictors of intervention selection include people's perceptions of ASD as a disorder. Additionally, the language used to describe interventions has been found to influence people's decisions about those interventions in a variety of settings, including schools, medicine, and advertising (e.g., Elliot,1988; Gong et al., 2013; Levin \& Gaeth, 1988).

In the current study, I examined the relationship between people's experience with ASD and their ratings of Applied Behavior Analysis (ABA) and Sensory Integration (SI) in terms of effectiveness, credibility, likelihood and ease of implementation, and likelihood of recommendation. Based on the results of the Pilot study, I also examined the effects of order of presentation on participants' ratings of ABA and SI, as well as which intervention they selected when presented with a forced-choice question asking which intervention they would use or recommend a friend use with a child with ASD. Additionally, I examined the relationships between participants' views of ASD as having an external cause and their ratings of ABA and SI's effectiveness, credibility, likelihood and ease of implementation, and likelihood of recommendation. I also conducted an exploratory analysis to examine whether participants' experience with ASD interacted with survey version to influence their ratings of ABA and SI. 
My first set of hypotheses examined participants' experience with ASD and the language used to describe the intervention and whether these variables would interact to influence ratings of the effectiveness, credibility, and ease of implementation, as well as their likelihood of implementing and recommending the two interventions. Participants rated interventions described without jargon more favorably on all dependent variables. Moreover, they rated themselves as more likely to recommend and implement ABA as compared to SI. However, no main effect of experience or nor any predicted interactions with experience and jargon were found. This hypothesis was not supported.

It is possible these hypotheses were not supported because the type of experience matters more than simply having experience. That is, although a special education teacher and an ABA therapist might have spent a similar number of hours training and working with people with ASD, qualitative differences in their experiences might affect their perceptions of interventions more than the time spent. This idea is supported by the finding that participants in the Experience group were more familiar with both $\mathrm{ABA}$ and SI, but did not rate them significantly differently than the No Experience participants. Also, dichotomizing people into No Experience vs. Experience groups might not have captured the meaningful variations of people's experience levels. In the current study, participants were classified as Experienced if they had an ASD diagnosis, had a child or other immediate family member with ASD, or if they spent any amount of time per week with a person with ASD. All other participants were grouped in the No Experience category. However, many of these people did have some passing experience with ASD (e.g., had learned about ASD in classes, had friends with ASD, knew friends' children with ASD). Group differences might have been seen if participants without any experience at all were compared to participants with the highest amount of experience, for example. Additionally, 
given that the task involved both implicit and explicit comparisons between two different interventions, Order was found to be important in the pilot study. As such, Experience did matter in the context of reading both vignettes. An exploratory analysis that combined all the manipulated variables along with Experience is discussed in detail below.

My second set of hypotheses concerned Order and context. I predicted that participants would rate the first intervention they read about more favorably and that this effect would be exaggerated for participants who read a non-jargon vignette followed by a jargon vignette. Specifically, I hypothesized that participants would rate the first intervention they read about as more effective. This was true for ABA in every condition except when ABA was described first with jargon and SI was described without jargon. However, the only condition under which participants rated SI as more effective occurred when it was read first without jargon and then ABA was described with jargon. The same pattern was found for participants' ratings of ABA's credibility when it was read first. Participants also perceived SI as more credible when it was read first and either both interventions were described with jargon or SI was described without jargon and ABA was described with jargon. Participants' ratings of their likelihood of recommending $\mathrm{ABA}$ and SI followed the same pattern as they did for effectiveness. Additionally, consistent with my hypothesis, participants were more likely to select the first intervention they read about when given a forced-choice question about which intervention they would choose if they had to select only one for their own or a friend's child.

These hypotheses were partially supported. Participants did generally prefer ABA when it was read about first and preferred SI when it was read about first in some conditions. Importantly, participants only rated ABA lower than SI when it was read first and described with jargon and SI was not. Similarly, SI was preferred only when it was read about first, it was 
described without jargon, and ABA was described with jargon (or, in the case of credibility, both described with jargon). This pattern of findings is relevant for those who work with people with ASD because it indicates that a bias toward or neutral ratings of ABA can be overridden by using jargon to describe ABA. Based on these findings, practitioners should aim to tell people who make decisions about ASD interventions about ABA as soon as possible using non-technical language. Although these hypotheses were partially supported, SI was generally not preferred across the board when read about first as predicted. This finding could be a result of a general pro-ABA bias as found in Hypothesis 1.

My third set of hypotheses focused on perceptions of ASD as a disorder, specifically with respect to its cause. I predicted that people who viewed ASD as having more of an external cause (e.g., past poor medical care) would rate SI as more effective and credible and rate themselves as more likely to implement it than those who viewed ASD as having an internal cause (e.g., genetics). I also hypothesized that the opposite pattern would be true for participants' ratings of ABA. Instead, there were nonsignificant negative correlations between ABA and SI and effectiveness, credibility, and likelihood of recommendation. These hypotheses were not supported. It might not have been supported because some of the dependent variables were correlated with each other. Additionally, the external cause subscale measures the extent to which people believe ASD is caused by something in the person's environment. Although the IPQ was meant to measure people's general perceptions of ASD's causes, it was completed after participants read the vignettes. In the vignettes, both interventions were described as working via changing something in the child's environment, even though the SI description also included a component of changing the brain. It is possible that if SI were described with a focus on this 
internal component, there might have been more of a distinction between participants' ratings. Similarly, the order of tasks may have done something to subtly prime perceptions about ASD. I also conducted an exploratory analysis to examine the effects of Experience in conjunction with Order and Survey Version. Because the main effects and interactions involving Order and Survey version were described in my previous analyses, I focused on those involving Experience. There were significant interactions between Survey Version and Experience on participants' ratings of interventions' credibility and their likelihood of implementing the intervention, as well as a marginally significant effect on their likelihood of recommending the interventions. Analyses of simple effects revealed that when participants without ASD experience read about ABA with no jargon and SI with jargon, they rated ABA as significantly more effective, credible, and easy to implement than did participants with ASD experience. They also rated themselves as more likely to implement and recommend ABA under those conditions. The results of Hypotheses 1 and 2 suggest that jargon is generally rated unfavorably and that it is more so in the context of a description of an intervention without jargon. The Exploratory Analysis indicates that people who are unfamiliar with ASD are especially susceptible to the effects of jargon. To extend the recommendation based on the results of Hypothesis 2, practitioners should seek to tell ASD intervention decision-makers about ABA first without jargon, especially when those people have little-to-no previous exposure to ASD.

\section{Strengths and Limitations of the Current Study}

One strength of the current study was that it examined people's perceptions of two of the most used interventions for ASD (Green, 2006). The decision to focus on these interventions (out of the wide range of possible choices available) was supported by the finding that participants who had experience with ASD were more familiar with both ABA and SI than participants with 
no experience. Additionally, similar percentages of participants reported knowing someone who had received ABA (23\%) and SI (19\%). Examining these two interventions is beneficial because the results are likely to be generalizable to more people who make decisions regarding ASD interventions.

Another strength of this study was examining the role of experience in people's perceptions of and decisions about ASD interventions. People making decisions about interventions do so from a variety of backgrounds and education levels, and may include newly trained therapists, parents of a young child diagnosed with ASD, or parents of an adolescent who was only recently was diagnosed with ASD. These people have different previous experiences, levels of comfort, and possibly different goals. They may also be subject to advice from family members and friends with varying levels of experience and knowledge, and from media sources with varying degrees of credibility. It is important for practitioners to know if they need to talk to people about interventions differently based on their backgrounds so those people can make the best possible decisions about ASD interventions.

Although order effects are generally considered a nuisance factor or a weakness of an experimental design, the inclusion of Order as a variable of interest was a strength of this study. Practitioners who are less familiar with specific interventions might present decision-makers with a variety of options. It is helpful to know that it matters which of those interventions are presented first. The 100 Day Kit published by Autism Speaks (2018) is designed to provide parents of newly diagnosed children under the age of four with information about ASD and ASD interventions. In the kit, ABA and related evidence-based interventions including pivotal response teaching and verbal behavior are listed first. According to the results of this study, that 
placement is meaningful and makes it more likely that parents of newly diagnosed young children will select an evidence-based intervention.

Finally, this study replicated Becirevic et al.'s (2016) findings that people preferred interventions when described without jargon and adds to a body of literature indicating that the language used to describe interventions affects people's perceptions of the intervention (e.g., Levin \& Gaeth, 1988; Yamagishi, 2002). However, results of this study also indicated that Weisberg et al.'s (2008) "seductive allure of neuroscience" did not hold true for participants who read about SI when it was described with neuroscience-type jargon (e.g., "restore neurological processing"). Instead, participants disliked all jargon, especially when compared to a description without jargon. As Gong et al. (2013) found in their meta-analysis on the role of framing on health-related decision-making, the "seductive allure of neuroscience" effect could be dependent on other factors including presentation of the information and the participants' backgrounds. It is possible that neuroscientific jargon is favored when deciding whether an explanation is good or bad, but not when people must make decisions using information from that explanation. In the 100 Days Kit, evidence-based (ABA, pivotal response teaching, and verbal behavior) and nonevidenced-based interventions (e.g. Early Start Denver Model, Relationship Development Intervention, etc.) are all described using jargon (Autism Speaks, 2018). The guide does define the terms, but further research would be needed to determine if the explanations override the negative connotations of the jargon.

One limitation with respect to the Order effect is the lack of a coherent explanation. Order effects are pervasive in psychological research, and have been found it diverse areas such as the order of candidates when voting (Ho \& Imai, 2008), order of response choices in Gallup polls (Holbrook, Krosnick, Moore, \& Tourangeau, 2007) and even judgments about the quality 
of stockings (Nisbett \& Wilson, 1977). Recent theorizing has included invoking ideas of quantum models of cognition (e.g., Wang, Busemeyer, Atmanspacher, \& Pothos, 2013). Although the basic science investigations of order effects continue, it is still pragmatically important to have empirically demonstrated that order of presentation matters when evaluating and selecting interventions.

Another limitation of the current study is that I was not able to make precise distinctions among participants' level of experience beyond experience vs. no experience. It might be that not only do people who do not spend any time with people with ASD rate interventions differently than participants with 40 hours per week, people with 10 or 100 hours per week may differ as well. Because those who make decisions about ASD interventions range from pediatricians who serve many children without ASD to professionals who specialize in ASD, it is important to know if these differences are meaningful.

A related limitation is the lack of information regarding the role type of experience plays when rating ASD interventions. Not only do ASD intervention decision-makers differ on their amount of experience, they vary widely in terms of their training, unpaid, and paid experiences. Participants' training experiences included ABA therapy, college courses, and correctional counselor training. Unpaid experiences included internships, observations, and friendships with people with ASD. Paid experiences included therapists, general and special education teachers, and babysitters. These participants might have spent similar amounts of time with people with ASD, but their experiences, exposure to interventions, and perceptions of ASD as a disorder might be qualitatively different, as might be their perceptions of interventions. For example, it is difficult to know if the experiences of a therapist who spends 30 hours per week with children 
with ASD are similar to those of a sibling of a child with ASD who spends approximately the same amount of time per week with their sibling.

Parents of children with ASD and people with ASD themselves are another group whose experiences might be qualitatively different than others. Although I asked about own and children's ASD in the current study, there were not enough participants in either group to examine them apart from other participants with experience. This is an important limitation because although others might recommend or implement various interventions, parents are likely to make the final decisions about which interventions get implemented. Additionally, adults with ASD may have made or currently make their own decisions about interventions for themselves. Even when they are not their own guardians, best practices from most organizations dictate that children who are able to communicate their preferences and adults who still have legal guardians should also be consulted regarding their interventions. Another consideration is that the recommendations of parents and people with ASD might be weighted more heavily, so it might be most important for people trying to promulgate evidence-based interventions to target those groups.

\section{Directions for Future Research}

Future research should focus on finding the meaningful distinctions in participants' types and amounts of experience with ASD. Researchers should examine whether there are certain cutoff amounts of experience at which people's perceptions differ. Additionally, future research should examine the role of the type of experience, perhaps by limiting a study to participants with restricted types of experiences. One difficulty future researchers might face is finding people who only have one type of experience. In the current study, participants who had experience often had more than one type of experience or training. Parents might also need to be 
examined in separate groups such as parents of recently diagnosed young children, parents of children who had been diagnosed for a few years, and parents of adult children with ASD. The severity of children's ASD might also affect parents' perceptions of interventions. All these factors are areas that would benefit from future research.

Another area for future research is determining if order of completing the IPQ affects the relationship between participants' views of ASD as having an external cause and their ratings of interventions. As previously mentioned, participants might have been primed by the vignettes to think of both ABA and SI as working by changing things in a child's environment. It would be interesting to know if information presented directly before measuring people's perceptions of ASD as a disorder changes those perceptions and if so, how that indirectly affects people's ratings of interventions. Researchers could also attempt to replicate the findings of Al Anbar et al. (2010) regarding the relationship between people's perceptions of the consequences, timeline, control, and negative emotionality related to ASD and their endorsement of various interventions. Additionally, researchers could investigate whether reading the vignettes first affects participants' IPQ ratings.

Although it was beyond the scope of the current study, future research should examine the role of source in people's decision-making regarding ASD interventions. Previous research makes it clear that people use a variety of sources when making health decisions including alternative medical practitioners, the internet, and special interest groups such as Autism Speaks (e.g., Crawley et al., 2014; Criss et al., 2015). Although there is evidence-based information regarding ASD interventions available online through organizations like the Association for Science in Autism Treatment, people can also find what looks like strong support for nonevidence-based interventions through organizations like the Autism Treatment Center of 
American. Similarly, some practitioners know which interventions are evidence-based, and others recommend evidence-based and non-evidence-based interventions equally. People also evaluate information from those sources differently based on factors like consensus, source expertise, and similarity of source to themselves (Bohner et al., 2008; Hartman \& Weber, 2009). Participants in the current study had a wide variety of experiences with ASD, and all of them could be in a position to recommend or implement ASD interventions. Future researchers should determine which of these source factors are relevant to ASD intervention decision-making.

\section{Conclusions}

The prevalence of ASD has increased over the past several years. At the same time, people making decisions about ASD interventions are exposed to information about many evidence-based and non-evidence-based interventions. As such, it is important to know what factors affect their ratings of ASD interventions' effectiveness, credibility, and ease of implementation, as well as likelihood to implement or recommend those interventions. ABA and SI were examined in the current study because they are two of the most used interventions for ASD (Green, 2006). The results of the current study indicate that people rate both ABA and SI lower on these factors when they are described with jargon, particularly when the description is paired with an intervention described without jargon. Encouragingly, when order is not considered, people rate themselves as more likely to implement and recommend the evidencebased intervention, ABA. However, when order is considered, people are more likely to choose the intervention they read about first and rate it as higher. These findings indicate the importance of using easily comprehensible language when describing interventions and ensuring decisionmakers have early exposure to evidence-based interventions. 


\section{REFERENCES}

Al Anbar, N. N., Dardennes, R. M., Prado-Netto, A., Kaye, K., \& Contejean, Y. (2010).

Treatment choices in Autism Spectrum Disorder: The role of parental illness perceptions. Research in Developmental Disabilities, 31, 817-828. DOI:10.1016/j.ridd.2010.02.007.

American Psychiatric Association. (2013). Diagnostic and statistical manual of mental disorders (5th ed.). Arlington, VA: American Psychiatric Association.

Becirevic, A., Critchfield, T. S., \& Reed, D. D. (2016). On the social acceptability of behavioranalytic terms: Crowdsourced comparisons of lay and technical language. The Behavior Analyst, 39, 305-317. DOI 10.1007/s40614-016-0067-4.

Berquist, K. L., \& Charlop, M. H. (2014). Teaching parents of children with autism to evaluate interventions. Journal of Developmental and Physical Disabilities, 26, 451-472. DOI: 10.1007/s10882-014-9374-4.

Bohner, G., Dykema-Engblade, A., Tindale, R. S., \& Meisenhelder, H. (2008). Framing of majority and minority source information in persuasion. Social Psychology, 39, 108-116. DOI 10.1027/1864-9335.39.2.108.

Bruine de Bruin, W. \& Bostrom, A. (2013). Assessing what to address in science communication. PNAS, 110, 14062-14068. www.pnas.org/cgi/doi/10.1073/pnas.1212729110.

Criss, S., Baidal, J. A.W., Goldman, R. E., Perkins, M., Cunningham, C., \& Taveras, E. M. (2015).The role of health information sources in decision-making among Hispanic mothers during their children's first 1000 days of life. Maternal \& Child Health Journal, 19, 2526-2543. DOI 10.1007/s10995-015-1774-2.

Critchfield, T. S., Doepke, K. J., Epting, L. K., Becirevic, A., Reed, D. D., Fienup, D. M., Kremsreiter, J. L., \& Ecott, C. L. (2017). Normative emotional responses to behavior analysis jargon or how not to use words to win friends and influence people. Behavior Analysis in Practice, 10, 97-106. DOI: 10.1007/s40617-016-0161-9.

Elliot, S.N. (1988). Acceptability of behavioral treatments: Review of variables that influence Treatment selection. Professional Psychology: Research and Practice, 19, 68-80. https://doi.org/10.1037/0735-7028.19.1.68.

Fairbanks, L. D., \& Stinnett, T. A. (1997). Effects of professional group membership, intervention type, and diagnostic label on treatment acceptability. Psychology in the Schools, 34, 329-355. https://doi.org/10.1002/(SICI)15206807(199710)34:4\%3C329::AID-PITS4\%3E3.0.CO;2-G. 
Frawley, J. Adams, J., Broom, A., Steel, A., Gallois, C., \& Sibbritt, D. (2014). Majority of women are influenced by nonprofessional information sources when deciding to consult a complementary and alternative medicine practitioner during pregnancy. The Journal of Complementary and Alternative Medicine, 7, 571-577. DOI: 10.1089/acm.2014.0028.

Figueiras, M. J. (2007). Lay perceptions of serious illness: An adapted version of the Revised Illness Perception Questionnaire (IPQ-R) for healthy people. Psychology \& Health, 22, 143-158. DOI:10.1080/14768320600774462.

Fischhoff, B., \& Davis, A. L. (2014). Communicating scientific uncertainty. PNAS, 11, 1366413671. www.pnas.org/cgi/doi/10.1073/pnas.1317504111.

Galli, C., Kreider, R., \& Ross, B. (2016). Wacky church under fire over "miracle cure" for autism. $A B C$ News. Retrieved from http://abcnews.go.com/US/wacky-church-firemiracle-cure-autism/story?id=43054429.

Grant, N., Rodger, S., \& Hoffman, T. (2015). Evaluation of autism-related health information on the web. Journal of Applied Research in Intellectual Disabilities, 28, 276-282. https://doi.org/10.1111/jar.12127.

Gee, B. M., Devine, N., Werth, A., \& Phan, V. (2013). Paediatric occupational therapists' use of sound-based interventions: A survey study. Occupational Therapy International, 20, 155162. https://doi.org/10.1002/oti.1354.

Gong, J., Zhang, Y., Yang, Z., Huang, Y., Feng, J., \& Zhang, W. (2013). The framing effect in medical decision-making: A review of the literature. Psychology, Health \& Medicine, 18, 645-653. http://dx.doi.org/10.1080/13548506.2013.766352.

Goodwin, C. J. (2008). Research in psychology: Methods and design. Hoboken, NJ: John Wiley \& Sons, Inc.

Green, V. A., Pituch, K. A., Itchon, J., Choi, A., O’Reilly, M., \& Sigafoos, J. (2006). Internet survey of treatments used by parents of children with autism. Research in Developmental Disabilities, 27, 71-84. DOI:10.1016/j.ridd.2004.12.002.

Green, V. A., (2007). Parental experience with treatments for autism. Journal of Developmental \& Physical Disabilities, 19, 70-84. DOI 10.1007/s10882-007-9035-y.

Guldberg, K. (2017). Evidence-based practice in autism educational research: Can we bridge the research and practice gap? Oxford Review of Education, 43, 149-161.

DOI:10.1080/03054985.2016.1248818.

Hagger, M. S., \& Orbell, S. (2005). A confirmatory factor analysis of the revised illness perception questionnaire (IPQ-R) in a cervical screening context. Psychology and Health, 20, 161-173. DOI: 10.1080/0887044042000334724. 
Hallenstein, E. B. (1978). Ethical problems of psychological jargon. Professional Psychology, 9, $111-116$.

Hartman, T. K. \& Weber, C. R. (2009). Who said what? The effect of source cues in issue frames. Political Behavior, 31, 537-558. DOI 10.1007/s11109-009-9088-y.

Hebert, E. B. (2014). Factors affecting parental-decision making regarding interventions for their child with autism. Focus on Autism and Other Developmental Disabilities, 29, 451472. DOI: $10.1177 / 1088357614522291$.

Ho, D. E., \& Imai, K. (2008). Estimating causal effects of ballot order from a randomized natural experiment: The California alphabet lottery, 1978-2002. Public Opinion Quarterly, 72, 216-240. DOI:10.1093/poq/nfn018.

Holbrook, A. L., Krosnick, J. A., Moore, D., \& Tourangeau, R. (2007). Response order effects in dichotomous categorical questions presented orally: The impact of question and respondent attributes. Public Opinion Quarterly, 71, 325-348. DOI: 10.1093/poq/nfm024

Hupp, S. D., Stary, A. K., Bradshaw, K. N., \& Owens, S. A. (2012). Debunk, debunk, debunk: Some evidence for why dissemination is only half the battle. The Behavior Therapist, 35, 76-78. ISSN 0278-8403.

Hupp, S. D. A., McKenney, E., Schmittel, M., McCobin, A., \& Owens, S. A. (2013). Disseminate, debunk, differentiate: Teaching about evidence-based treatments in a child psychology course. The Behavior Therapist, 36, 14-16. ISSN 0278-8403.

Jacobson, J. W., Mulick, J. A., Foxx, R. M., \& Kryszak, E. (2016). History of fad, pseudoscientific, and dubious treatments in intellectual disabilities. In R.M. Foxx \& J.A. Mulick, (Eds.), Controversial therapies for autism and intellectual disabilities (pp. 4570). New York, NY: Routledge.

Kadar, M., McDonald, R., \& Lentin, P. (2012). Evidence-based practice in occupational therapy services for children with autism spectrum disorders in Victoria, Australia. Australian Occupational Therapy Journal, 59, 284-293. DOI: 10.nil/j.1440-1630.2012.01015.x.

Kienhues, D., Bromme, R., \& Stahl, E. (2008). Changing epistemological beliefs: The unexpected impact of a short-term intervention. The British Psychological Society, 78, 545-565. DOI:10.1348/000709907X268589.

Klahr, D., \& Li, J. (2005). Cognitive research and elementary science instruction: From the laboratory, to the classroom, and back. Journal of Science Education and Technology, 14, 217-238. DOI: 10.1007/s10956-005-4423-5.

Levin, I.P., \& Gaeth, G.J. (1988). How consumers are affected by the framing of attribute information before and after consuming the product. Journal of Consumer Research, 15, 374-378. DOI:10.1086/209174. 
Lipstein, E. A., Lovell, D. J., Denson, L. A., Kim, S. C., Spencer, C., \& Britto, M. T. (2016). Parents' information needs and influential factors when making decisions about TNF- $\alpha$ inhibitors. Pediatric Rheumatology, 14, 1-9. DOI 10.1186/s12969-016-0113-5.

McDonald, M. E., Pace, D., Blue, E., \& Schwartz, D. (2012). Critical issues in causation and treatment of autism: Why fads continue to flourish. Child \& Family Behavior Therapy, 34, 290-304. DOI: 10.1080/07317107.2012.732849.

Moss-Morris, R., Weinman, J., Petrie, K. J., Horne, R., Cameron, L. D., \& Buick, D. (2002). The revised illness perception questionnaire (IPQ-P-R). Psychology and Health, 17, 1-16. DOI: 10.1080/08870440290001494.

National Autism Center. (2015). Findings and conclusions: National standards project, phase 2. Randolph, MA: Author.

Nisbett, R. E., \& Wilson, T. D. (1977). Telling more than we can know: Verbal reports on mental processes.” Psychological Review; Psychological Review 84, 231-259. DOI: $10.1037 / 0033-295 X .84 .3 .231$.

Peterson, G. B., Larsson, E. V., \& Riedesel, K. L. (2003). A conceptual toolkit for intensive early behavioral intervention teachers. Journal of Behavioral Education, 12, 131-146. DOI: 1053-0819/03/0600-0131/0.

Reiher, J. (2016). The effects of cultural cognition and parent perceptions of autism spectrum disorder on perceptions of intervention efficacy. (Unpublished master's thesis). Illinois State University, Normal.

Riggot, J. (2005)Pseudoscience in autism treatment: Are the new and entertainment media helping or hurting? The Scientific Review of Mental Health Practice, 4, 55-58.

Sterba, K. R. \& DeVellis, R. F. (2009). Developing a spouse version of the Illness Perception Questionnaire-Revised (IPQ-R) for husbands of women with rheumatoid arthritis. Psychology \& Health, 24, 473-487. DOI: 10.1080/0887044070186778.

Taylor, B. (2006). Vaccines and the changing epidemiology of autism. Child: Care, Health \& Development, 32, 511-519. DOI: 10.1111/j.1365-2214.2006.00655.x

Tversky, A., \& Kahneman, D. (1981). The framing of decisions and the psychology of choice. Science, 211, 453-458. https://doi.org/10.1126/science.7455683.

van 't Riet, J., Ruiter, R. A. C., Werrij, M. Q., Candel, M. J. J .M., \& De Vries, H. (2010). Distinct pathways to persuasion: The role of affect in message-framing effects. European Journal of Social Psychology, 40, 1261-1276. DOI: 10.1002/ejsp.722.

von Winterfeldt, D. (2013). Bridging the gap between science and decision making. PNAS, 110,14055-14061. www.pnas.org/cgi/doi/10.1073/pnas.1213532110. 
Wang, Z., Busemeyer, J. R., Atmanspacher, H., \& Pothos, E. M. (2013). The potential of using quantum theory to build models of cognition. Topics in Cognitive Science, 5, 672-688. DOI:/10.1111/tops. 12043 .

Weisberg, D. S., Keil, F. C., Goodstein, J., Rawson, R., \& Gray, J. R. (2008). The seductive allure of neuroscience explanations. Journal of Cognitive Neuroscience, 20, 470-477. https://doi.org/10.1162/jocn.2008.20040.

Wood, J. C., Heiskell, K. D., Delay, D. M., Jongeling, J. S., \& Perry, D. (2009). Teachers' preferences for ethnically diverse learners with Attention-Deficit Hyperactivity Disorder. Adolescence, 44, 273-288.

Yamagishi, K. (2002). Effects of valence and framing in decision-making: Assessing decisionmakers' perceived domains of choice. Japanese Psychological Research, 44, 209-227. https://doi.org/10.1111/1468-5884.t01-1-00023. 


\section{APPENDIX A: VIGNETTES}

\section{ABA-No Jargon}

I work with children with Autism Spectrum Disorders (ASD). I provide Applied Behavior Analysis therapy (ABA). In this type of therapy, I teach children which behaviors are appropriate and which behaviors are inappropriate using different kinds of rewards. I help parents to use rewards and different teaching methods to help set their children up for success. Additionally, I give children lots of help when they first start working on something so they can be successful right away. I also teach children to ask for what they want and need. Before they receive ABA therapy, the children I work with often have tantrums because they cannot express their wants and needs. After receiving ABA therapy, the children I work with have fewer tantrums because they can tell the people in their lives what they want and need. For example, one child I work with loves playing with a stuffed animal in my office. The first day he walked into my office, the child immediately began to yell and cry when he saw the stuffed animal. After he calmed down, the child pulled me toward the stuffed animal. Because I knew the child wanted the stuffed animal, I used it to teach him how to ask for things he wants. Now, after several weeks of ABA therapy, including teaching him to ask for the things he wants, the child walks into my office and says "animal" to get the stuffed animal on most days.

\section{SI-No Jargon}

I work with children with Autism Spectrum Disorders (ASD). I provide Sensory Integration therapy (SI). I set up an environment that challenges a child to effectively use all their senses to help their brains take in information. I do this by having children swing to help with their sense of balance and roll to increase their awareness of where their bodies are in space. The children I work with also sometimes receive deep pressure and wear weighted vests because pressure and 
weight are calming for them. I do these things to help children's brains function better and to make it easier for them to take in sensory information. I create a unique sensory diet for each child. Before they receive SI therapy, the children I work with often have tantrums because they cannot express their wants and needs. After receiving SI therapy, the children I work with have fewer tantrums because they can tell the people in their lives what they want and need. For example, one child I work with loves eating chocolate. The first day he walked into my office, the child immediately began to cry and stomp his feet when he saw my candy jar. After he calmed down, the child pulled me toward the candy jar. Now, after several weeks of SI therapy including wearing a weighted vest, the child walks into my office and says "chocolate" to get a piece of candy.

ABA-Jargon

I work with child clients with Autism Spectrum Disorders (ASD). I provide Applied Behavior Analysis therapy (ABA), which includes interventions such as reinforcement, antecedent modification, errorless prompting, and functional communication training. ABA is a systematic application of scientific principles derived from behavior analysis and uses those behavioral principles to change socially significant behavior to a meaningful degree. Before they undergo ABA therapy, the clients I work with often engage in maladaptive behaviors of varying intensities because they have limited communication repertoires with which to express their preferences and needs. After undergoing ABA therapy, the maladaptive behaviors of the clients I work with decrease, and their prosocial, functional behaviors increase because their communicative repertoires have expanded to the point where they can express their preferences and needs. For example, one client I work with loves playing with a stuffed animal in my office. The first day he walked into my office, the client immediately began to yell and cry when he saw 
the stuffed animal. After he calmed down, the client pulled me toward the stuffed animal. A paired choice preference assessment was conducted, and the stuffed animal was determined to be a reinforcer that was used in a manding program. Now, after several weeks of ABA therapy including functional communication training to increase the client's communicative repertoire, data indicates that the client walks into my office and verbalizes "animal" to obtain the stuffed animal across $90 \%$ of opportunities.

\section{SI-Jargon}

I work with child clients with Autism Spectrum Disorders (ASD). I provide Sensory Integration therapy (SI), which focuses on ameliorating children's inefficient processing of sensory information. It includes interventions designed to repair children's proprioceptive, vestibular, and tactile systems, including having children wear weighted pressure vests designed to provide tactile input. This is done to restore children's neurological processing and increase their ability to integrate sensory information. Sensory interventions are created to meet children's idiosyncratic needs. Before they receive SI therapy, the children I work with often demonstrate verbal and physical aggression because they cannot communicate their preferences and needs. After receiving SI therapy, the children I work with engaged in less verbal and physical aggression because they can tell the people in their lives what they want and need. For example, one child I work with loves eating chocolate. The first day he walked into my office, the child immediately began to cry and stomp his feet when he saw my candy jar. After he calmed down, the child pulled me toward the candy jar. After administering the Sensory Integration and Praxis Tests, it was determined that the child had difficulty with tactile discrimination. Now, after several weeks of SI therapy including wearing a weighted pressure vest designed to provide tactile input, the child walks into my office and says "chocolate" to get a piece of candy, 
indicating that the child's neural pathways have restructured to allow better processing of tactile information. 


\section{APPENDIX B: EXPERIENCES WITH AUTISM SPECTRUM DISORDER (ASD)}

Autism Spectrum Disorder (ASD) is a term used to refer to individuals with diagnoses of what has typically been referred to as autism, pervasive developmental disorder not otherwise specified, childhood disintegrative disorder, Rhett's, or Asperger's Syndrome.

\section{Personal Experience:}

1. How many people with ASD do you know? If uncertain, please estimate. *

a. Direct family members:

b. Extended family members:

c. Friends/classmates/coworkers/neighbors etc.:

d. Clients/students/mentees/children you babysit/nanny:

* If a person fits in more than one category, please just select what you consider to be the best choice.

2. Child and own ASD diagnosis:

a. Do you have children with ASD? If yes, how many? Yes/ No/ Prefer not to answer

b. How long has your child had an ASD diagnosis?

c. How old is your child with ASD?

d. Do you have ASD? Yes/ No/ Prefer to not answer

e. How long have you had your ASD diagnosis?

\section{Training Experience with ASD:}

3. List any training (e.g., coursework, webinars, seminars, job training, etc.) directly related to ASD. Approximate how many hours of training have you received. These experiences would include time in classes and one-on-one instruction and supervision that prepared you to work directly with people with ASD. Direct experience with clients, students, etc. will be covered in items below.

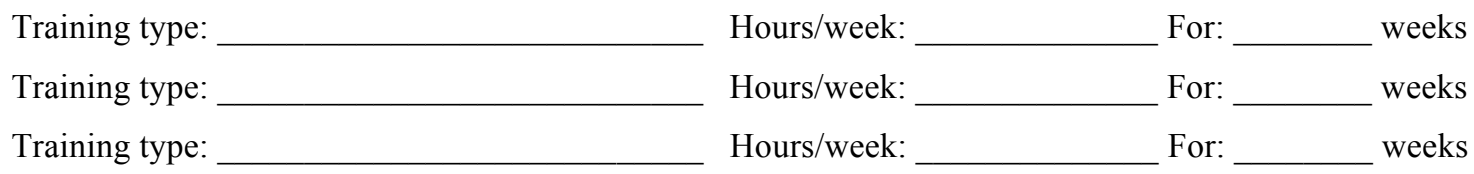

Paid and Unpaid Experience with ASD:

4. List any paid experiences you have had with individuals with ASD (e.g., teacher, therapist, babysitter, nanny, tutor, assessment, paid internship, paid research assistantship, etc.) and the approximate amount of time.

Paid experience type: Hours/week: For: weeks or months (circle)

Paid experience type: Hours/week: For: weeks or months (circle)

Paid experience type: Hours/week: For: weeks or months (circle) 
5. List any unpaid experiences you have had with individuals with ASD (e.g., unpaid internship, camp counselor, college independent study, research, practicum experience, volunteering at a school or an ASD organization, etc.) Having a child with ASD is not recorded in this section.

Unpaid experience type: (circle)

Unpaid experience type: (circle)

Unpaid experience type: (circle)

\section{Time spent with Individuals with ASD:}

6. Present: Thinking about the last 3 months, on average, how much time per week do you currently spend with people with ASD, including family members, friends, clients, etc.? Estimation is fine. /week

7. Recent Past: Thinking about the last year, on average, how much time per week did you spend with people with ASD, including family members, friends, clients, etc.? Estimation is fine.

/week

8. Past: Thinking about 1 year ago or longer, on average, how much time per week did you spend with people with ASD, including family members, friends, clients, etc.? Estimation is fine.

/week 


\section{APPENDIX C: INTERVENTION PERCEPTIONS RATING SCALES}

ABA

Please answer the following questions about ABA:

1. Applied Behavior Analysis (ABA) therapy is an effective intervention for Autism Spectrum Disorder (ASD).

$\begin{array}{ccccccc}1 & 2 & 3 & 4 & 5 & 6 & 7 \\ \begin{array}{c}\text { Strongly } \\ \text { Disagree }\end{array} & & & & & & \text { Strongly } \\ \text { Agree }\end{array}$

2. I found the information about ABA therapy to be credible.

$\begin{array}{ccccccc}1 & 2 & 3 & 4 & 5 & 6 & 7 \\ \begin{array}{c}\text { Strongly } \\ \text { Disagree }\end{array} & & & & & & \text { Strongly } \\ \text { Agree }\end{array}$

3. I would implement ABA therapy with a child with ASD in the future.

$\begin{array}{ccccccc}1 & 2 & 3 & 4 & 5 & 6 & 7 \\ \begin{array}{c}\text { Strongly } \\ \text { Disagree }\end{array} & & & & & & \begin{array}{c}\text { Strongly } \\ \text { Agree }\end{array}\end{array}$

4. It would be easy to implement ABA therapy for a child with ASD.

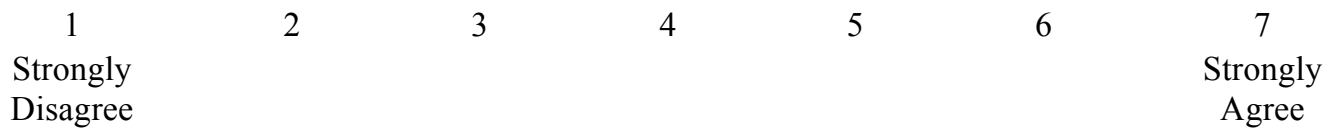

5. I would recommend that ABA therapy be used with a child with ASD in the future.

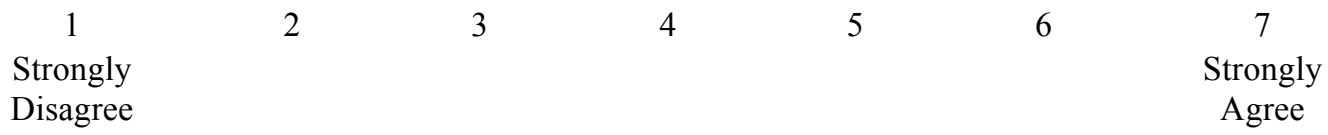

6. The information in the vignette about ABA therapy was comprehensible.

$\begin{array}{ccccccc}1 & 2 & 3 & 4 & 5 & 6 & 7 \\ \text { Strongly } & & & & & & \text { Strongly } \\ \text { Disagree } & & & & & & \\ \text { Agree }\end{array}$

7. Before reading this vignette, how familiar were you with ABA therapy?

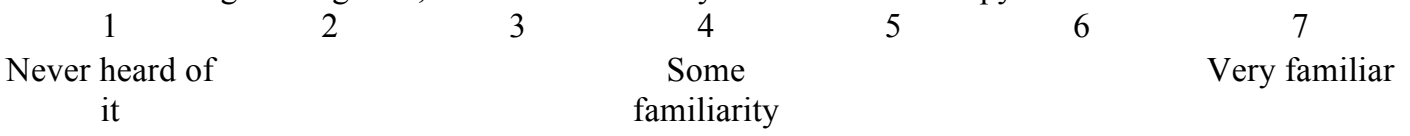

8. Please rate the reading level of this vignette:

$\begin{array}{ccccccc}1 & 2 & 3 & 4 & 5 & 6 & 7 \\ \begin{array}{c}\text { Easy reading } \\ \text { level }\end{array} & \begin{array}{c}\text { Medium } \\ \text { reading level }\end{array} & & \begin{array}{c}\text { Difficult } \\ \text { reading level }\end{array}\end{array}$

9. Before reading this vignette, how familiar were you with the evidence base for ABA Therapy?

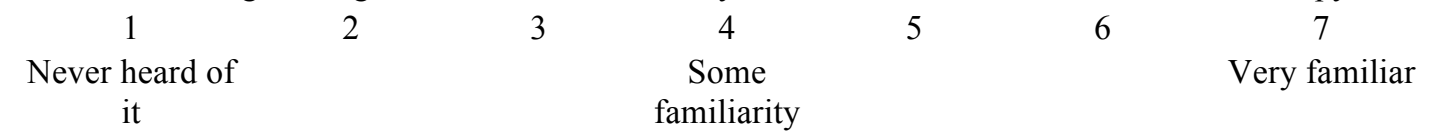

10. Do you know anyone who has received ABA therapy? Yes/No 
11. If yes, please rate the effectiveness of $A B A$ therapy for that person. If you know multiple people, please rate how effective it was for most people you know.

Not Effective

2

3

4

Don't

Know
5

7

Very Effective 


\section{SI}

Please answer the following questions about SI:

1. Sensory Integration (SI) therapy is an effective intervention for Autism Spectrum Disorder (ASD).

$\begin{array}{ccccccc}1 & 2 & 3 & 4 & 5 & 6 & 7 \\ \text { Strongly } & & & & & \text { Strongly } \\ \text { Disagree } & & & & \text { Agree }\end{array}$

2. I found the information about SI therapy to be credible.

$\begin{array}{ccccccc}1 & 2 & 3 & 4 & 5 & 6 & 7 \\ \text { Strongly } & & & & & \text { Strongly } \\ \text { Disagree } & & & & \text { Agree }\end{array}$

3. I would implement SI therapy with a child with ASD in the future.

$\begin{array}{ccccccc}1 & 2 & 3 & 4 & 5 & 6 & 7 \\ \text { Strongly } & & & & & \text { Strongly } \\ \text { Disagree } & & & & & \text { Agree }\end{array}$

4. It would be easy to implement SI therapy for a child with ASD.

$\begin{array}{ccccccc}1 & 2 & 3 & 4 & 5 & 6 & 7 \\ \begin{array}{l}\text { Strongly } \\ \text { Disagree }\end{array} & & & & & \text { Strongly } \\ \text { Agree }\end{array}$

5. I would recommend that SI therapy be used with a child with ASD in the future.

$\begin{array}{ccccccc}1 & 2 & 3 & 4 & 5 & 6 & 7 \\ \text { Strongly } & & & & & \text { Strongly } \\ \text { Disagree } & & & & & \text { Agree }\end{array}$

6. The information in the vignette about SI therapy was comprehensible.

$\begin{array}{ccccccc}1 & 2 & 3 & 5 & 6 & 7 \\ \text { Strongly } & & & & & \text { Strongly } \\ \text { Disagree } & & & & \text { Agree }\end{array}$

7. Before reading this vignette, how familiar were you with SI therapy?

\begin{tabular}{cccccc}
1 & 2 & 3 & 4 & 6 & 7 \\
$\begin{array}{c}\text { Never heard of } \\
\text { it }\end{array}$ & \multicolumn{1}{c}{$\begin{array}{c}\text { Some } \\
\text { familiarity }\end{array}$} & & Very familiar
\end{tabular}

8. Please rate the reading level of this vignette:

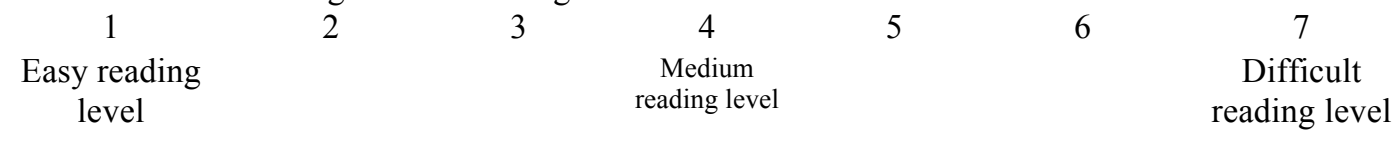

9. Before reading this vignette, how familiar were you with the evidence base for SI Therapy?

\begin{tabular}{cccccc}
1 & 2 & 3 & 4 & 6 & 7 \\
$\begin{array}{c}\text { Never heard of } \\
\text { it }\end{array}$ & \multicolumn{1}{c}{$\begin{array}{c}\text { Some } \\
\text { familiarity }\end{array}$} & 5 & Very familiar
\end{tabular}

10. Do you know anyone who has received SI therapy? Yes/No 
11. If yes, please rate the effectiveness of SI therapy for that person. If you know multiple people, please rate how effective it was for most people you know.

Not Effective
2

4

Don't

Know
5

6

Very Effective 


\section{Opinions about the Vignettes}

Briefly describe what you believe to be the key differences between the vignette about Applied Behavior Analysis (ABA) and the vignette about Sensory Integration therapy (SI).

Please refer back to the vignettes if you need to.

If you had a child with Autism Spectrum Disorder (ASD), or if you were advising a close friend or family member who had a child with ASD, which of the two interventions described in the vignettes would you choose? (Circle one.)
Applied Behavior Analysis
$\underline{\mathrm{OR}}$
Sensory Integration

From not at all important to very important, how important were the following when choosing an intervention (on a sliding scale of 0-10):

- Efficiency

- Cost

- Easy to do

- Works best

- Reduces symptoms

- Increases desired behaviors

- Decreases undesired behaviors

Other reasons why you selected the intervention:

Do you have any other comments or opinions about the vignettes you just read? 


\section{APPENDIX D: DEMOGRAPHICS}

Age:

Sex:

Years of Education:

Race/Ethnicity:

Marital Status:

Do you have children? If yes, how many? 


\section{APPENDIX E: TABLES}

Table E-1

Summary of Experimental Conditions

\begin{tabular}{ccccc} 
Survey Number & Condition & Order & Vignette 1 & Vignette 2 \\
\hline 1 & 1 & AS & ABA no jargon & SI no jargon \\
2 & 2 & SA & SI no jargon & ABA no jargon \\
4 & AS & ABA jargon & SI no jargon \\
5 & 3 & SA & SI no jargon & ABA jargon \\
6 & AS & ABA no jargon & SI jargon \\
7 & 4 & SA & SI jargon & ABA no jargon \\
8 & AS & ABA jargon & SI jargon \\
& & SA & SI jargon & ABA jargon \\
\hline
\end{tabular}


Table E-2

Intervention Selection Criteria Means and Standard Deviations

\begin{tabular}{|c|c|c|c|c|}
\hline \multirow[t]{2}{*}{ Selection Criteria } & \multirow{2}{*}{$\frac{\frac{\text { Participants with }}{\text { ASD Experience }}}{\frac{(N=193)}{\text { Mean }}}$} & \multicolumn{3}{|c|}{$\frac{\text { Participants without }}{\frac{\text { ASD Experience }}{(N=228)}}$} \\
\hline & & $S D$ & Mean & $S D$ \\
\hline Efficiency & 7.69 & 2.34 & 7.53 & 2.44 \\
\hline Cost & 4.39 & 3.23 & 4.93 & 3.35 \\
\hline Ease of & 5.66 & 2.85 & 6.57 & 2.75 \\
\hline \multicolumn{5}{|l|}{ Implementation* } \\
\hline Works Best & 8.74 & 1.88 & 8.65 & 1.91 \\
\hline $\begin{array}{l}\text { Reduction of } \\
\text { Symptoms }\end{array}$ & 8.38 & 2.18 & 8.57 & 1.77 \\
\hline $\begin{array}{l}\text { Increases Desired } \\
\text { Behaviors }\end{array}$ & 8.28 & 2.08 & 8.61 & 1.74 \\
\hline $\begin{array}{l}\text { Decreases Undesired } \\
\text { Behaviors }\end{array}$ & 8.07 & 2.39 & 8.22 & 2.36 \\
\hline
\end{tabular}

